\title{
Facilitators and Barriers to Adherence to a Gluten-Free Diet among Adults with Celiac Disease: A Systematic Review
}

\author{
Nicholas Abu-Janb
}

Thesis submitted to the University of Ottawa in partial Fulfillment of the requirements for the MSc. Health Systems

\author{
Supervisor: Dr. Mirou Jaana \\ Telfer School of Management \\ University of Ottawa
}

(C) Nicholas Abu-Janb, Ottawa, Canada, 2018 


\section{Table of Contents}

1. LIST OF ABBREVIATIONS.............................................................................. IV

2. LIST OF FIGURES .............................................................................................. IV

3. LIST OF TABLES …………………………….............................................. IV

4. ABSTRACT ……......................................................................................................

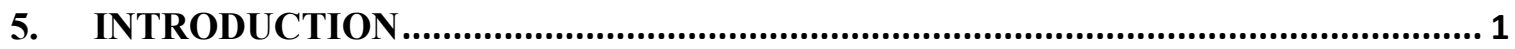

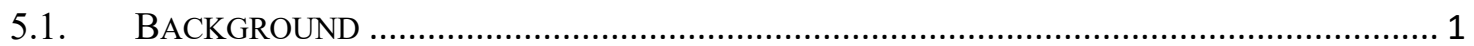

5.2. STATEMENT OF PROBLEM/RATIONALE ……………………………………..... 3

5.3. RESEARCH QUESTION/OBJECTIVE …………………........................................ 4

6. LITERATURE REVIEW ……………………...................................................... 5

6.1. CELIAC DISEASE IN CANADA........................................................................... 5

6.2. IMPORTANCE OF MAINTAINING A GLUTEN-FREE DIET …………………………....... 6

6.3. LOW ADHERENCE AMONG CELIAC POPULATION ………………………………..... 8

6.4. FACILITATORS AND BARRIERS: ADULTS VERSUS CHILDREN ………………….......... 9

6.5. ADHERENCE TO DIETARY RESTRICTIONS FOR OTHER CONDITIONS ………………...... 11

6.6. EXISTING EVIDENCE ON FACTORS AFFECTING DIETARY ADHERENCE AMONG ADULTS15

6.7. Bio-ECOLOGICAL THEORY OF DEVELOPMENT/SOCIAL ECOLOGICAL MODEL ............. 16

7. METHODOLOGY …………………………………............................................... 19

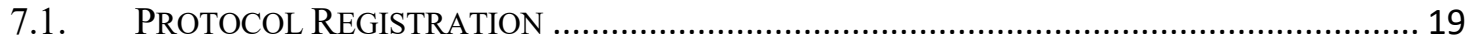

7.2. THE RELEVANCE OF A SYSTEMATIC REVIEW ………………………………….... 19

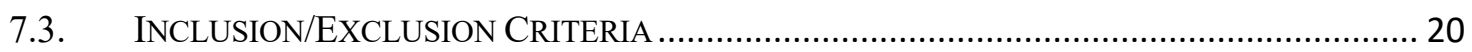

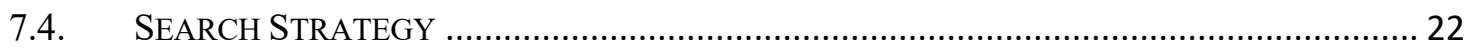

7.4.1. Stage 1-Key Terms ………………………………………………… 22

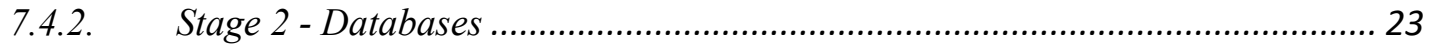

7.4.3. Stage 3-Additional search terms …………………………………….... 23

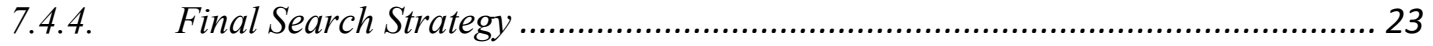

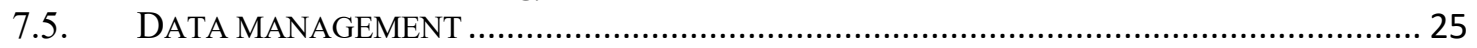

7.5.1. Data Extraction/Coding......................................................................... 25

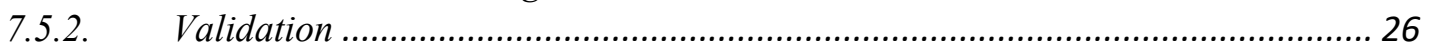

7.6. RISK OF BIAS/ASSESSMENT OF METHODOLOGICAL QUALITY …………………….... 26

7.6.1. Critical Appraisal ................................................................................. 26

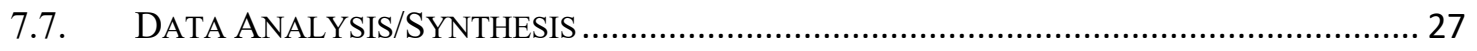

8. RESULTS............................................................................................................ 27

8.1. GENERAL OVERVIEW OF EMPIRICAL STUDIES ……………………………….... 27

8.2. CATEGORIZATION OF FACILITATORS AND BARRIERS................................................. 35

8.3. FACILITATORS TO GFD ADHERENCE IN ADULTS WITH CD .........................................36

8.4. BARRIERS TO GFD ADHERENCE IN ADULTS WITH CD ........................................... 50

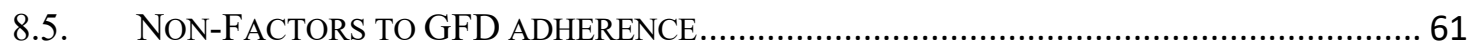

8.6. SYNTHESIS OF FACILITATORS AND BARRIERS......................................................... 63

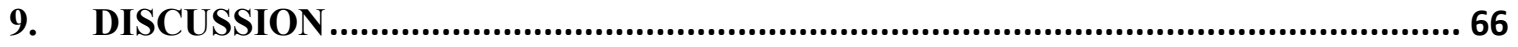

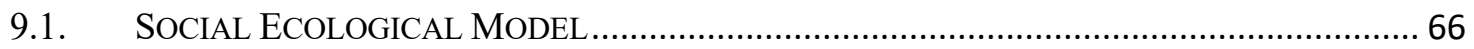

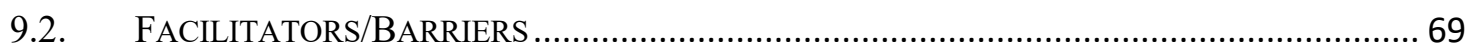

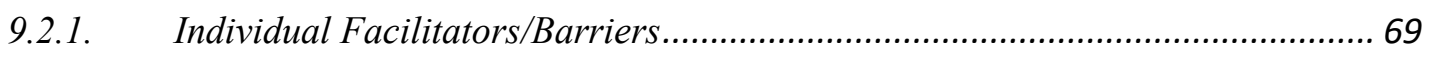




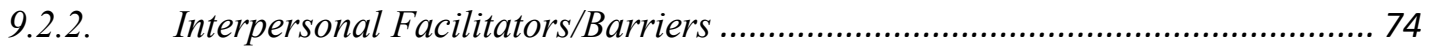

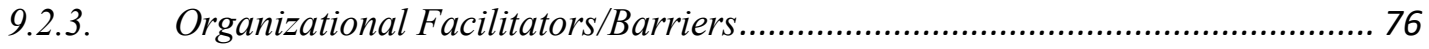

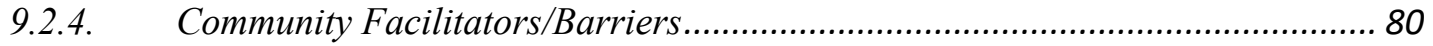

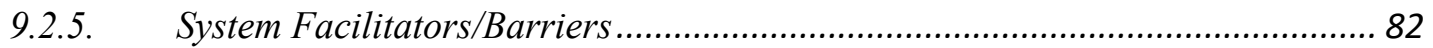

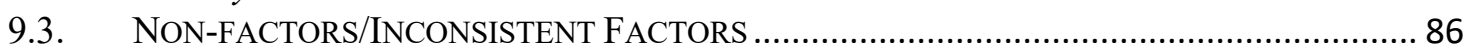

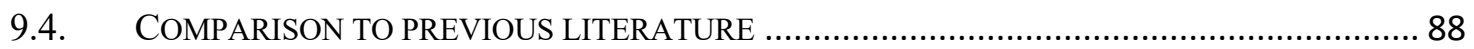

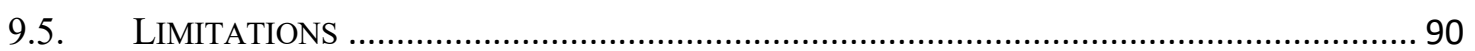

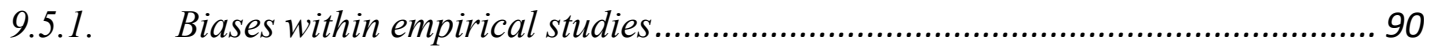

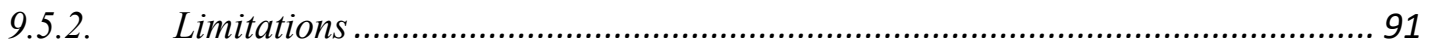

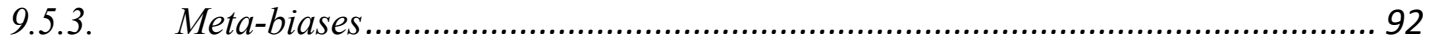

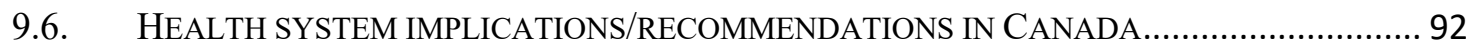

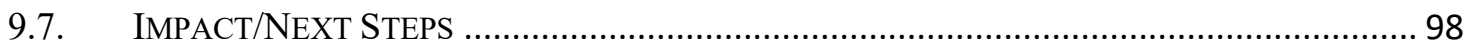

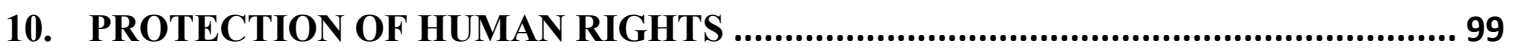

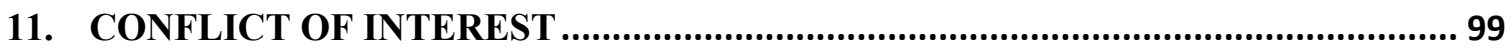

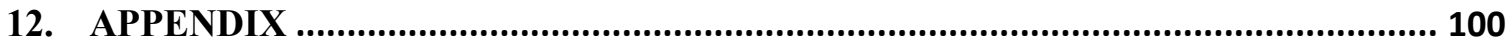

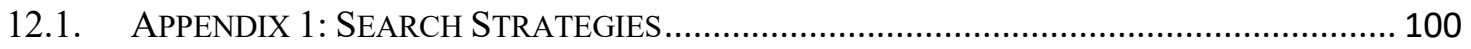

12.2. APPENDIX 2: CODING SCHEME FOR INCLUDED STUDIES ....................................... 105

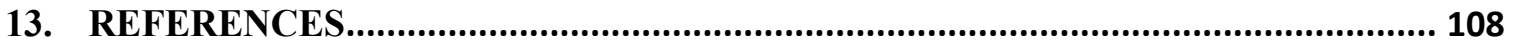




\section{List of Abbreviations}

CD: Celiac Disease

GF: Gluten-Free

GFD: Gluten-Free Diet

LOE: Level of Evidence

RCT: Randomized Control Trial

\section{List of Figures}

Figure 1: Prisma Flow Diagram

Figure 2: Number of studies included in systematic review, by year

Figure 3: Number of studies included in systematic review, by country

Figure 4: Categorization of facilitators and barriers

Figure 5: Social Ecological Model: GFD Adherence

\section{List of Tables}

Table 1: Inclusion/Exclusion Criteria

Table 2: General Study Information

Table 3: Quality of Empirical Studies

Table 4: Facilitators to GFD adherence in adults with CD

Table 5: Barriers to GFD adherence in adults with CD

Table 6: Non-factors to GFD adherence in adults with CD

Table 7: Magnitude/Level of Evidence of each facilitator and barrier 


\section{4. $\underline{\text { Abstract }}$}

Background: Celiac Disease (CD) is a chronic, autoimmune disease that prevents individuals from being able to process gluten. When individuals ingest gluten, their digestive system becomes severely damaged, leading to many adverse, health effects. It is, therefore, significantly crucial that individuals with CD adhere to a Gluten-Free diet (GFD). However, the adherence rate is well below optimal in the adult, CD population. Hence, it is crucial to identify and understand the factors that impact their ability to maintain a GFD.

Objective: To develop a systematic review that critically appraises and synthesizes evidence on the facilitators and barriers that affect adherence to GFD among the adult population with CD. Data Sources: Ovid Medline, CINAHL, PsychInfo, and Embase were included, using a combination of keywords to retrieve relevant articles. The Inclusion Criteria consisted of empirical studies that focus on Adults with CD. Only English studies were considered. A coding scheme was developed to retrieve uniform information from each of the included studies, including: study design, population characteristics, facilitators and barriers presented, limitations, and a summary of each study.

Results: Facilitators and Barriers were organized based on a Social ecological model, derived from the bioecological theory of development, which emphasizes that individuals make choices in their lives based on the impact of various ecological levels that exist. The ecological levels include: System, Community, Organizational, Interpersonal, and Individual. The studies included in this systematic review reported many facilitators and barriers that exist at the different ecological levels, which significantly affect adherence to GFD. Based on the frequency of articles that reported each facilitator and each of the studies' level of evidence, the most significant facilitators were: increased patient education; celiac association membership; financial compensation/food subsidies; and increased intention/self-regulatory efficacy. When taking into consideration the frequency of articles that reported each barrier along with each of the studies' 
level of evidence, the most significant barriers were: restaurant dining/supermarket shopping; poor patient education from practitioner; specific cultural factors; and low intention/motivation to adhere to a GFD. Although other factors have been reported, there was limited evidence to support them due to weak study designs, limited samples, and inconsistencies found across the different studies. It is important to understand that there are many additional facilitators and barriers retrieved in the systematic review that do not have as much evidence to support them. These are discussed in the thesis.

Conclusion: Introducing policy changes at a health systems level will have the most influential impact on all the ecological layers in an individual's life. Based on the magnitude of the results and the level of evidence of each of the studies, improvements to physician-patient communication, patient education interventions, and food subsidies, will create the most significant opportunity to positively impact the remaining ecological levels in one's life, with the ultimate goal of improving adherence rates to a GFD among adults with CD in Canada. Registration: Prospero registration ID number is CRD42018091854. 


\section{Introduction}

\subsection{Background}

Celiac Disease (CD) is a chronic, autoimmune disease that negatively impacts an individual's digestive system. Approximately $1 \%$ of the population worldwide have CD (Rampertab \& Mullin, 2014). CD has genetic linkages, which results in an increased risk in first and second-degree relatives, with first-degree relatives having a ten-times increase in the risk of having CD (J. Silvester \& Duerksen, 2013). The specific genes related to CD have been found and are well understood. Nearly all individuals who have CD have either the HLA-DQ 2 variant or the HLA-DQ 8 variant (Prince, 2006).

Serological testing is the most common way an individual is screened for CD. A tissue transglutaminase IgA test is the standard serological test to perform (Rostom, Murray, \& Kagnoff, 2006). The sensitivity of the test ranges from $90-96 \%$, along with a 95\% specificity (Rostom et al., 2006). On top of serological screening, a genetic test can be used to determine the presence of the HLA-DQ2 or HLA-DQ8 gene (Roy, Pallai, Lebwohl, Taylor, \& Green, 2016). While a positive genetic test does not guarantee a diagnosis due to a significant proportion of the population having these gene variants, a negative test result has a high negative predictive value. If an individual is still deemed to be at-risk after serological testing, an upper-intestinal biopsy is performed to confirm the diagnosis (Rostom et al., 2006).

For individuals who have $\mathrm{CD}$, there is an environmental trigger that leads to adverse health outcomes. The environmental trigger for $\mathrm{CD}$ is known as gluten. Gluten is a protein that is found in wheat, barley, and rye (J. A. Silvester \& Rashid, 2010). When 
an individual is exposed to gluten, the gluten will customarily transfer through the individual's digestive system until it reaches the small intestine. Once it reaches this point, the small intestine recognizes the gluten particles as foreign invaders. The incorrect recognition leads to the release of immune cells that attempt to destroy the gluten particles (Ciccocioppo, Di Sabatino, \& Corazza, 2005). As a result of this attack, the lining of the small intestine also gets damaged, leading to possible villous atrophy (Gujral, Freeman, \& Thomson, 2012). Villous atrophy can lead to many complications including significant levels of malabsorption, as the villi on the small intestine lose their surface area, becoming unable to properly absorb nutrients passing by (Gujral et al., 2012). After long-term states of malabsorption, the digestive health of an individual can plummet, leading to comorbidities (Gujral et al., 2012). Unfortunately, there is no universal display of symptoms. While the majority will display classic symptoms, such as diarrhea, malabsorption, and abdomen discomfort, some individuals can show atypical symptoms or even no symptoms at all (J. Silvester \& Duerksen, 2013). Some examples of atypical symptoms include bloating, fatigue, and rapid weight-loss. The most dangerous population consists of those individuals who display silent symptoms, such as iron-deficiency, or unexplained osteoporosis (J. Silvester \& Duerksen, 2013). It is probable that unless an individual with silent symptoms is a part of a high-risk group, they may not get tested for $\mathrm{CD}$, resulting in continuous damage to their health (S. Aggarwal, Lebwohl, \& Green, 2012).

If an individual follows a proper diet that involves completely removing gluten, theoretically the individual's digestive system slowly begins to heal itself, and ideally after a certain amount of time, the digestive system returns to a healthy state that is 
comparable to an individual without CD (Caruso, Pallone, Stasi, Romeo, \& Monteleone, 2013).

\subsection{Statement of problem/rationale}

Typically, when an individual is diagnosed with CD in Canada, they have a meeting scheduled with a gastroenterologist (i.e. specialist) who clarifies the details of the illness to the patient and provides them with the information they require, as well as a list of what types of food they need to avoid (CeliacFoundation, 2017). After this meeting, the patients are left to manage their disease on their own. Although this is a chronic, auto-immune disorder, the fact that the environmental trigger is known (i.e., gluten intake) can lead to the lack of any formalized, continuous-care and regular checkups (J. A. Silvester \& Rashid, 2010). Considering this is a massive lifestyle change for any individual, it places a heavy responsibility upon them throughout their day-to-day lives, as they experience many factors that influence their ability to follow treatment for CD (Bacigalupe \& Plocha, 2015; J. A. Silvester \& Rashid, 2010). There is no known cure for CD (Bascunan, Vespa, \& Araya, 2017). Therefore, stringent adherence to a gluten-free diet (GFD) is necessary to prevent adverse health effects from occurring (Bascunan et al., 2017). Although this is the case, the literature has shown that the adherence to a proper diet that is needed to maintain proper digestive health is not always maintained (Hall, Rubin, \& Charnock, 2009). Strict dietary compliance rates range between studies from $42-91 \%$, varying based on the method used to determine compliance, as well as the demographics of the individuals with CD (Hall et al., 2009). The low adherence rates mean that a significant portion of the population who has $\mathrm{CD}$ is 
doing damage to themselves, without any attempts to reverse the issues. Although regular check-ups with specialists and annual serological tests are recommended for those with $\mathrm{CD}$ to assure that dietary compliance is occurring, the onus is entirely on the patient to go through the process of requesting these meetings/tests (J. A. Silvester \& Rashid, 2010). In the case where the proper services are not in reach, and an individual fails to gain the knowledge needed to maintain adequate health, failure to adhere to the diet may occur ( $\mathrm{J}$. A. Silvester \& Rashid, 2010). At this point, damage to the digestive system may begin once again, leading to comorbidities such as anemia, severe malabsorption, and potentially various forms of malignancies (Green et al., 2003). Considering a GFD is the only way to manage the ill effects of the disease, it is essential to understand all of the factors that can influence the ability of a person with CD to adhere to a GFD.

The full impacts of CD have not been well-understood until recently. Even now, there is still much to be learned. Over the past few years, practitioners have become more familiar with the pathophysiology of the disease and its impacts on health (Fedorak, Switzer, \& Bridges, 2012). There has also been more societal awareness of CD and gluten. Hence, the facilitators and barriers to adhering to a GFD would have also changed over time. This research consists of a systematic review of studies that has been published on facilitators and barriers that impact adherence to a GFD in adults with CD.

\subsection{Research question/Objective}

What facilitators and barriers exist in the life of an adult with CD that impact their adherence to a GFD? What is the level of evidence to support each of the facilitators and barriers? 
The objective of this systematic review is to identify and synthesize the facilitators and barriers that adults with CD face that impact their adherence to a GFD. These facilitators and barriers ultimately impact their ability to maintain long-term, positive health outcomes. The systematic review may inform policymakers and health care practitioners as to what possible improvements can be made to prevent these adverse health outcomes, as well as the corresponding costs associated with them.

In this systematic review, a barrier will refer to any factor that negatively impacts an individual's ability to adhere to a GFD. A facilitator will refer to any factor that positively impacts an individual's ability to adhere to a GFD.

\section{Literature Review}

\subsection{Celiac Disease in Canada}

The actual prevalence of CD in Canada is not fully known, but it is believed to be around $1 \%$ of the population, comparing similarly to the United States and the rest of the world (Marshall, 2013). In Canada, the mean age of diagnosis is 45.4 years old. This age is nearly identical to the year 2002 when Canadian studies showed that the mean age of diagnosis was 46 years old (Marshall, 2013). However, the average diagnostic delay (the time at which it takes to diagnose an individual with $\mathrm{CD}$ after they begin to display symptoms) increased from 11.7 years in 2002 to over 12 years in 2012 (Marshall, 2013). While the time period is similar, the direction is moving in the opposite way expected.

CD was first recognized in Canada around 65 years ago. It was not until the past decade or so that its full impacts have been better understood (Marshall, 2013). Part of why there has been a recent increase in knowledge on CD is that there has been a significant increase in availability of serological testing in recent years, which enhances 
the ability to screen for CD in Canada. The sensitivity and specificity rates are above 90\% (Marshall, 2013). While the utilization of serological testing has increased from $20 \%$ in the 1990 s to over $60 \%$ among CD patients today, Canadian adults still face many negative symptoms after adhering to a GFD, stating the level of dietary adherence may not be high (Marshall, 2013).

Within Canada, maintaining a GFD is exceptionally complex, challenging, and socially isolating. A western diet (which exists in the lives of many Canadians) is challenging to maintain for an individual with $\mathrm{CD}$, due to the high level of crosscontamination occurring, with wheat being a ubiquitous staple (Marshall, 2013).

With a diagnostic delay of over 12 years, individuals in Canada with CD are doing severe damage to their health. Therefore, once correctly diagnosed, it is paramount that individuals begin treatment immediately. The diagnostic delay highlights the importance of determining what facilitators and barriers exist that impact an individual's adherence to a GFD.

\subsection{Importance of maintaining a gluten-free diet}

As stated, there is currently no cure for CD (Bascunan et al., 2017). A GFD is the only solution to prevent the manifestation of negative symptoms. If an individual with CD does not maintain a GFD, several health issues can arise, varying depending on the specific individual (Rampertab \& Mullin, 2014).

No matter what the clinical presentation is for the specific individual with $C D$, most individuals share a reduced bone mineral density (BMD), increasing fracture risk (Capriles, Martini, \& Areas, 2009). A GFD has been proven to increase an individual's 
$\mathrm{BMD}$ reasonably quickly. If an adult was not diagnosed with $\mathrm{CD}$ as a child, it is rare for their BMD to increase to normal levels, but it is vital that they increase to their maximum potential to prevent negative comorbidities (Capriles et al., 2009).

CD is strongly associated with gastrointestinal symptoms, most commonly, diarrhea. A study reports $75 \%$ of individuals with CD reporting having had diarrheal symptoms before beginning a GFD. After following a GFD, these symptoms rapidly dropped. Even in those who still reported having diarrheal symptoms, the frequency of these symptoms dropped to much lower levels (Murray, Watson, Clearman, \& Mitros, 2004). Other gastrointestinal symptoms such as nausea and bloating were reported to be resolved with a GFD (Murray et al., 2004). Abdominal pain is a consistent symptom reported among those diagnosed with $\mathrm{CD}$. In a specific study, $79 \%$ of individuals reported experiencing abdominal pain (Murray et al., 2004). 48\% of individuals met the criteria for irritable bowel syndrome. After following a GFD for six months, only two patients reported still meeting the criteria $(\mathrm{P}<0.0001)$. Over $95 \%$ of patients reported substantial relief or complete relief of pain. This relief of pain only took a few days after following a GFD in the majority of these patients (Murray et al., 2004).

One of the most commonly found improvements across studies includes an increase in quality of life after following a GFD (Martin, 2010).

Studies have shown that maintaining a GFD has also lead to a decrease in risk for many other symptoms, including the following: anemia, osteoporosis, malignancies, progressive hepatic failure, depression-anxiety symptoms, infertility, miscarriage, low birth-weight infants, and mortality (Martin, 2010). 
As stated, the symptoms of CD range from mildly tame repercussions to lifethreatening issues. The malignancies found typically included lymphoma (Freeman, 2004). The lymphoma can be due to the constant inflammation of the gut over an extended period. However, this is not the only malignancy known to occur in those with untreated CD (Freeman, 2004).

Not everyone who has CD shows similar negative repercussions when ingesting gluten. Clinical representations vary, lowering the ability to address adherence to a GFD (Sainsbury, Mullan, \& Sharpe, 2013c). An individual's willingness to adhere to a GFD is compromised in the situation where an individual does not show any symptoms when ingesting gluten, both short and long-term.

\subsection{Low Adherence among Celiac Population}

In previous studies, the rate of compliance with a GFD ranged between $42 \%$ and 91\% (Hall et al., 2009), which represents a broad range and considerable variability. It is important to note that this range of dietary adherence levels is not limited to those who intentionally consume gluten in their diet. It also includes accidental ingestion and crosscontamination risks, which is very prevalent in Canada (Marshall, 2013).

Although the vast majority of dietary adherence is measured through selfreporting, there are alternate methods. One way of measuring if an individual is following a GFD is by examining an individual's fecal material, by looking at gluten peptides that are present. In a study, the examination of fecal material found that $40 \%$ of young adults did not maintain a GFD (Freeman, 2017). There was also information showing that males were less likely to follow a GFD. A typical, yet invasive way to determine the level 
of adherence to a GFD is to perform a repeat biopsy. In $80 \%$ of individuals, biopsies showed improved mucosal recovery after two or more years on a GFD. The other $20 \%$ of individuals can be assumed not to be following a proper diet, or in some rare cases, the GFD is not correcting the damage that was initially caused by the gluten (Freeman, 2017). If the adherence to a GFD does not improve the health impacts of CD, there is likely an illness present, in addition to CD.

\subsection{Facilitators and Barriers: Adults versus Children}

Concerning adhering to a diet, the facilitators and barriers faced by adults vastly differ from those of children. These differences stem from the day-to-day schedule of a typical adult versus that of a typical child, as well as the typical responsibilities placed upon each age group (Bacigalupe \& Plocha, 2015). These differences will produce scenarios that present facilitators and barriers to each respective group of individuals.

A child, for example, is typically within a school setting for a lengthy amount of time every week. During this time, many food items are laying around that their peers brought from home. This influence could act as a barrier to the child, impacting their ability to adhere to a GFD (Bacigalupe \& Plocha, 2015). A child may be in the situation where they are without a caregiver who truly understands their diagnosis of CD, such as when on a field trip. The lack of proper supervision can place the child at risk. This barrier is not faced by the adult population, as they are better able to maintain their responsibility in adhering to their diet (Bacigalupe \& Plocha, 2015). In specific studies, children reported that their most significant barrier to maintaining a GFD was the lack of available food options within their school cafeteria (MacCulloch \& Rashid, 2014). 
Children also faced barriers to adhering to a specific diet when faced with competing foods, not aligned with their mandatory diet. The lack of exposure of a child to the specific foods on their diet influenced a child's adherence to their diet, meaning that if a child does not have access to safe foods, they would be more willing to go against their diet to eat. These factors are not present with the adult population (Nicklas et al., 2013). Adults also face unique barriers and facilitators for dietary compliance, not faced by children. Some main factors included what foods an individual grows up with eating. GFD was improved if they grew up with foods that were similar to those on a GFD and vice versa when they did not grow up with those types of foods (Nicklas et al., 2013). If a child began adhering to a specific diet at a young age, the transition of preparing and eating food as an adult would be facilitated compared to if the adult began adhering to a specific diet later in life. An adult's lack of preparation skills of particular foods required on a diet impacted their adherence to that diet (Nicklas et al., 2013). This lack of preparation skills often leads to an increase in eating outside of the house, which exposes individuals to more threats to dietary adherence, especially threats of cross-contamination (Nicklas et al., 2013).

Providing more proof that facilitators and barriers are different based on age, studies find that diagnosing individuals with CD during their teenage years leads to them having much lower levels of adherence to a GFD (Leffler et al., 2008). This lower level of adherence is most commonly stemming from social and environmental differences. Considering that the rates of dietary adherence are lower among teenagers with $\mathrm{CD}$, it can be noted that teenagers are facing more barriers to committing to a GFD, compared to their younger or older counterparts (Kurppa et al., 2012). 
For specific adults, the cost of food impacted dietary adherence, specifically those who did not grasp the importance of following a diet. Cost of food did not impact the dietary adherence of children in a direct way (Nicklas et al., 2013). Many cultural issues play a role in the dietary adherence of adults. Certain staples in a cultural diet prevent proper dietary adherence, as well as the ability of a particular culture to understand the severity of specific dietary restrictions. Cultural factors were not found to impact the dietary adherence of children (Nicklas et al., 2013).

A very significant facilitator exists for children that rarely exists for adults. Children report having a constant caregiver, mostly a parent or teacher to look out for them to assure they are maintaining a GFD (MacCulloch \& Rashid, 2014).

Due to the vast array of differences that exist between adherence to diet for an adult and a child, it is essential to narrow the scope of the systematic review to one of these specific populations. There is currently a systematic review underway that looks at the barriers and facilitators that are faced by children with CD (Myleus, 2016). The results of this systematic review are not published yet. This other systematic review emphasizes the importance to focus on the other population. This systematic review focusses on the adult population.

\subsection{Adherence to dietary restrictions for other conditions}

To understand the potential factors that can impact the adherence to a GFD in an individual with $\mathrm{CD}$, it is worth examining the factors impacting the adherence to a special diet for other conditions, which may further inform this research. However, it is important to note that the factors can widely vary across disease type. 


\section{Type-2 Diabetes}

A systematic review was conducted that analyzed the barriers and facilitators that impacted management of type-2 diabetes mellitus (Sohal, Sohal, King-Shier, \& Khan, 2015). The review found that language and communication discordance led to barriers in education on diabetes, and as a result, dietary adherence. Another barrier found that diabetic dietary information was not tailored to specific cultures (Fagerli, Lien, \& Wandel, 2005). The lack of cultural sensitivity resulted in many individuals not knowing what foods would be safe to consume, as they were not willing nor should be expected to abandon cultural diet. Lack of knowledge and misperceptions about treatment were also found to be barriers. The review found facilitators that existed as well. The facilitators included having trust in care providers. Having family members involved in the process of adhering to dietary restrictions also improved an individual's adherence level. For those who did receive culturally specific dietary advice, this was a determined facilitator (Sohal et al., 2015).

While this systematic review targeted specific Asian populations, it is of interest when looking at a broader population group. Within Canada and other nations, there are portions of the population who represent minorities. When examining the barriers and facilitators impacting an individual with $\mathrm{CD}$ and their adherence to a GFD, unique aspects of different cultures are important to note (Sohal et al., 2015).

Another study analyzing the facilitators and barriers to dietary treatment for type 2 diabetes provides further insight as to what the experience is like for individuals adhering to life-long dietary restrictions. The study highlighted barriers as follows: Practicality of making a lifestyle change, lack of motivation, lack of knowledge and 
understanding, social circumstances, negative perception of the new diet, and difficulty changing well-established habits (Booth, Lowis, Dean, Hunter, \& McKinley, 2013). The study determined that the facilitators presented were not discussed to the same extent that the barriers were. Feeling healthier in response to dietary change was viewed as a facilitator, as well as the desire to avoid long-term, adverse health outcomes. Having family members present in the patient's life was viewed as a facilitator (Booth et al., 2013). An additional facilitator found was the existence of follow-up appointments. Also, setting targets were seen as a motivator to change (Booth et al., 2013).

\section{Cardiac Rehabilitation}

Further insight on dietary adherence for a GFD will be given by highlighting barriers and facilitators for those following a strict diet as part of their cardiac rehabilitation. One study that looked at factors influencing dietary adherence noted barriers that existed. One barrier was the cost of food. The foods needed for cardiac rehabilitation were more expensive than other foods. This had a negative impact on dietary adherence. Individuals also felt more pressure when in social situations. In these situations, individuals were more likely to forget about maintaining their diet (Lappalainen, Koikkalainen, Julkunen, Saarinen, \& Mykkanen, 1998). Other barriers that existed included difficulty choosing foods in supermarkets, bland taste of proper foods, difficulty in retrieving information on nutrition, as well as lack of time to prepare foods that would satisfy the necessary diet (Lappalainen et al., 1998).

A separate study also looked at factors that impacted dietary adherence in cardiac rehabilitation. One of the most impactful barriers was found to be losing the ability to eat 
foods that an individual previously enjoyed (Sharp \& Salyer, 2012). This barrier could potentially exist for an individual with $\mathrm{CD}$. As stated, many individuals with $\mathrm{CD}$ are not diagnosed until later in their life and would have already come to know their favourite food items that they would no longer be able to consume once starting their GFD. Another common barrier found by this study included limited choices of food when eating outside of the individual's home (Sharp \& Salyer, 2012).

\section{Obesity}

Looking at barriers and facilitators to dietary adherence in those who are obese has the potential to shine a light on issues surrounding dietary adherence to a GFD in those with $\mathrm{CD}$. In both situations, dietary restriction is a mandatory component to treatment for the particular diseases.

A scoping review of the barriers and enablers of healthy eating linked to obesity exists (Munt, Partridge, \& Allman-Farinelli, 2017). From the collection of 34 articles, the main barriers found included: male apathy to diet, unhealthy diet of those surrounding you, the expectation to consume unhealthy foods in certain situations, low cost of unhealthy foods, lack of time to plan/shop/cook, no facilities to prepare healthy foods, and a lack of motivation (Munt et al., 2017). The scoping review found several facilitators as well. These included: female interest of a healthy diet, a healthy diet of those surrounding the individual, support from friends and family, a desire for improved health, a desire to lose weight, a desire for improved self-esteem, a desire for attractiveness, and possessing autonomous motivation to eat healthy (Munt et al., 2017). 
6.6. Existing evidence on factors affecting dietary adherence among adults

Before conducting a systematic review, it is essential to be familiar with what

literature is currently available. In the past, there have been many researchers that looked at factors affecting adherence to a GFD among adults with CD. A systematic review on a similar topic was published in 2009 (Hall et al., 2009). While the previous systematic review by Hall et al. (2009) focussed on adherence rates, it also highlighted factors that impacted adherence to a GFD in adults with CD:

Education: Education was a significant factor in adherence to a GFD (Ciacci, Cirillo, Cavallaro, \& Mazzacca, 2002). Individuals who had a higher level of education were more likely to adhere to a GFD.

Age: The current age of an individual was also found to impact adherence to a GFD. The literature both highlighted ageing as a facilitator (Hankey \& Holmes, 1994) and a barrier (Ciacci, Cirillo, et al., 2002). The age of diagnosis provided unclear conclusions as to whether it had a significant impact on adherence.

Gender: Gender was found to have no connection to adherence to a GFD (Leffler et al., 2008).

Psychological view: The beliefs and attitudes an individual had towards $\mathrm{CD}$ and treatment had a significant impact on an individual's adherence to a GFD. Barriers included feeling embarrassed during group meals, as well as feeling angry about having CD (Leffler et al., 2008).

Repercussions: Repercussions of the negative consequences of ingesting gluten was seen as a facilitator of adhering to a GFD in adults with CD (Ciacci, Cirillo, et al., 2002). 
Knowledge: Knowledge was shown to impact the adherence to a GFD. However, studies made a point to emphasize the fact that while many individuals were knowledgeable about $\mathrm{CD}$ and what constituted following a GFD, many chose voluntarily not to follow the GFD. The longer an individual was following a GFD, the more likely they were to maintain a GFD. Knowledge of reading food labels also impacted adherence (Leffler et al., 2008).

Cost: The ability of an individual to be able to afford GF foods increased the ability to maintain a GFD (Lee, Ng, Zivin, \& Green, 2007).

Confidence in Practitioner: A barrier at a higher health systems level included lacking confidence in the treatment advice provided to the patient by their gastroenterologist or dietician (Lamontagne, West, \& Galibois, 2001).

Location: The specific region one lived in had an impact on their adherence. The impact was shown to be due to availability and lifestyle compatibility (Viljamaa et al., 2005).

\subsection{Bio-ecological Theory of Development/Social Ecological Model}

The Bio-ecological theory of development originated from Urie Bronfenbrenner (Urie Bronfenbrenner, 2007). This theory was a progression from his original ecological systems theory. The theory's main underpinnings dictate that to understand human development and decision-making, one needs to explore the entire ecological system that encompasses their life. The origin of this theory stems from the mid-1970's (U. Bronfenbrenner, 1973), and its four main principles include the process, context, person, and time. 
First, the process refers to the frequency at which an individual interacts with their environment significantly impacts human development. These interactions allow an individual to comprehend diverse concepts of the world they live in, in addition to where they see they fit within the world (Urie Bronfenbrenner, 2007).

Second, the context refers to the differentiated, ecological levels that have unique influences on individuals throughout their lives. Bronfenbrenner systematizes the hierarchical levels into different categories (Urie Bronfenbrenner, 1979). An individual's microsystem encompasses the direct relations one has. The microsystem includes an individual's direct environment and all of the relationships an individual has in their direct environment (family, friends, co-workers) (Urie Bronfenbrenner, 1979). The mesosystem is the following level in the ecological model. The mesosystem designates the relationships among an individual's micro-system, describing how one part of an individual's life may have an impact on a different part of their life (Urie Bronfenbrenner, 1979). The exosystem describes how a closed-off part of an individual can have longterm impacts on decision-making. For example, a past relationship can impact other relationships in someone's life (Urie Bronfenbrenner, 1979, 2007). The macrosystem describes cultural impacts on an individual. The macrosystem includes how an individual was raised, as well as religious impacts. Finally, the chronosystem describes the interaction of factors at the other four levels of an individual's life and how they affect each other over time (Urie Bronfenbrenner, 2007).

One significant change from the transition from the ecological systems theory to the bioecological theory of development is the inclusion of individual factors. The bioecological theory of development stresses the importance of personal factors that impact 
decision-making and coping skills of individuals. The bio-ecological theory of development emphasizes that as an individual gets older and develops more lifeexperience, their environmental interactions become more complicated. As individuals move throughout life-events, their ability to understand and cope with challenges depend on several factors that exist in an individual's surrounding environment (Urie Bronfenbrenner, 2007).

One final important factor that the bioecological theory of development points out is the concept of time. All of the factors impacting an individual's life change over time. This change is accurate, whether solely focussing on the lifespan of one individual, or looking at how factors change over generations (Urie Bronfenbrenner, 2007).

Derived from the Bio-ecological theory of development is a Social-Ecological model. A Social-Ecological model incorporates the different components of the Bioecological theory of development into a visual that describes the development of individuals as they go through their lives, faced with both facilitators and barriers at the different ecological layers that encompass their lives. The model helps explain how people make certain choices that lead to specific outcomes. In the context of this systematic review, the purpose of the social ecological model will be to help explain the factors that are present in peoples' lives that end up impacting their adherence to a GFD. Individuals must alter their lifestyle when diagnosed with $\mathrm{CD}$ in an attempt to prevent adverse health outcomes. Several facilitators and barriers impact their ability to cope with their diagnosis. These facilitators and barriers will exist at various ecological levels that fit within comparable categories to those created in the bioecological theory of 
development. The relationship among these categories will help portray the experience of an adult with $\mathrm{CD}$ attempting to adhere to a GFD.

\section{Methodology}

\subsection{Protocol Registration}

The protocol for this systematic review was registered under PROSPERO on April $3^{\text {rd }}$, 2018. The ID number is CRD42018091854.

PROSPERO is a database that focusses on systematic reviews related to public and social health care. The purpose of PROSPERO is for authors to publish the protocol for their systematic reviews as soon as the research commences. This is done to help ensure that no duplication exists in research. This also helps ensure that authors stay true to their initial protocol. It can be a concern if a final systematic review differs from the protocol without making an amendment to the PROSPERO protocol. Before beginning this systematic review, the literature was thoroughly examined to ensure that no systematic review was currently being conducted on the topic.

\subsection{The relevance of a Systematic Review}

Systematic reviews provide the highest level of evidence on a particular topic. Their use can be significant in multiple ways, specifically in facilitating an update to clinical practice guidelines, as well as acting as a guideline for policy analysts, ultimately informing decision making with the new evidence (Moher, Liberati, Tetzlaff, Altman, \& Group, 2009). The strengths of a systematic review revolve around its rigour. A systematic review involves following a strict protocol, allowing it to be replicable (Moher 
et al., 2015). Several empirical studies analyze the factors that impact an individual's adherence to a GFD. However, there are diverging results across the various studies and limited information is available on the evidence of impacts of various factors, which may facilitate or hinder adherence to GFD among adults. To provide practical solutions to policymakers in the health care system regarding the lives of adults with $\mathrm{CD}$, a clear understanding of their day-to-day lifestyle is needed. Fully understanding the lifestyle of adults with CD can potentially improve dietary adherence, and as a result, improve the health of individuals with CD. There are many situations in which policy-makers can have an impact based on the results of the systematic review. A systematic review gathers together the data from all primary studies on the topic of facilitators and barriers that influence dietary adherence.

With the Prisma model providing guidance (Moher et al., 2009), a systematic review was conducted to critically appraise and synthesize existing evidence on the facilitators and barriers for adherence to GFD among adults with the celiac condition.

\subsection{Inclusion/Exclusion Criteria}

Table 1 shows the inclusion and exclusion criteria set for the studies in this systematic review. Included studies will focus on adults, whom have CD and no other illness. Only empirical studies will be included. All of the included studies will be published in English. 


\section{Table 1: Inclusion/Exclusion Criteria}

\begin{tabular}{|c|c|c|}
\hline Term & $\begin{array}{c}\text { Inclusion Criteria } \\
\text { Date of Articles }\end{array}$ & $\begin{array}{c}\text { Published until November } \\
15^{\text {th }}, 2017\end{array}$ \\
\hline $\begin{array}{c}\text { Age of participants } \\
\text { Study Design and } \\
\text { reporting }\end{array}$ & $\begin{array}{c}\text { Adult Population } \\
\text { Empirical studies that report } \\
\text { on facilitators and barriers }\end{array}$ & $\begin{array}{c}\text { Non-empirical studies (e.g., } \\
\text { opinion papers, policy } \\
\text { papers, review) }\end{array}$ \\
\hline $\begin{array}{c}\text { Participant Population } \\
\text { Condition }\end{array}$ & $\begin{array}{c}\text { Studies that solely focus on } \\
\text { patients with CD }\end{array}$ & $\begin{array}{c}\text { Studies where comorbid } \\
\text { disorders are present that } \\
\text { influences adherence to a } \\
\text { GFD }\end{array}$ \\
\hline Language & English Studies & Non-English Studies \\
\hline
\end{tabular}

PICO categories help narrows the scope of the systematic review. The PICO categories are Population, Intervention, Comparison, and Outcome. Identifying these categories will provide precise information as to what the systematic review will entail.

\section{Population:}

The included study population consists of individuals over 18 years old. If a study includes both populations under 18 years old, as well as populations above eighteen years old, the collected results must be reported separately to be included in the systematic review. A study will also be a part of the systematic review if the study population contains individuals under eighteen, but the author considers them to be adults. The studies must focus on individuals who have CD, and not those who have other gluten-related disorders.

\section{Intervention:}

This includes any intervention or exposure (facilitators or barriers) that influences the adherence rate of a GFD in adults with CD. 


\section{Comparison:}

The comparison will be individuals not being exposed to the facilitators or barriers included in the specific study.

\section{Outcome:}

The outcome will be the altered adherence level to a GFD.

\subsection{Search Strategy}

Ovid Medline, CINAHL, PsychInfo, and Embase are the databases used throughout the systematic review to collect data from primary research articles. These databases allow a wide range of potential studies to be highlighted, helping guarantee a saturated search.

\subsubsection{Stage 1 - Key Terms}

The initial search began with keywords. Keywords were used based on the objective of the systematic review. The variant keywords used included: Celiac, adherence, gluten-free, gluten, treatment, celiac, maintenance, compliance, barrier(s), facilitator(s), factor(s), and impacts. The initial search took place on April 16 $6^{\text {th }}, 2017$. The database used was Ovid Medline. The search continued by creating a word-map of all of the terms used in the relevant articles. After finishing the set of initial searches, the most frequent terms were noted, as well as any of their identical meanings. 


\subsubsection{Stage 2 - Databases}

After the essential terms were noted, the keywords were used to search through other databases. The databases searched in addition to Ovid Medline include CINAHL, PsychInfo, and Embase. The retrieved articles were relevant, justifying the search terms.

\subsubsection{Stage 3 - Additional search terms}

After using the relevant keywords as search terms in the three databases, the relevant articles were hand-searched for additional articles cited in the retrieved articles. The hand-search was done to see if any of the additional cited articles had terms not included in the search criteria. After this analysis, there was no retrieval of any additional search terms.

\subsubsection{Final Search Strategy}

After these three stages, the final list of keywords was determined, leading to a complete search strategy used in the systematic review. The final searches took place on November $15^{\text {th }}, 2017$. The search to be used during the systematic review is specific to each database (See Appendix 1).

A University of Ottawa librarian, an expert in the field, helped create the final search strategy. The assistance of the librarian helps ensure that proper steps were taken in developing an adequate search strategy. This ensures the systematic review obtains the desired results. 
Figure1 describes the final screening process of articles based on the search terms and databases used (Moher et al., 2009). 3937 search results were initially retrieved through the final search strategy. The search results were scanned for any possible duplicates. This left 2791 studies remaining. Following this, all of the article's abstracts and titles were screened to determine if they met the inclusion criteria. To determine if the studies should be included in the final systematic review, the entire texts of the remaining 352 articles were examined. There were additional articles excluded during the data extraction phase due to them not meeting the inclusion criteria. There are 40 studies included in the final systematic review.

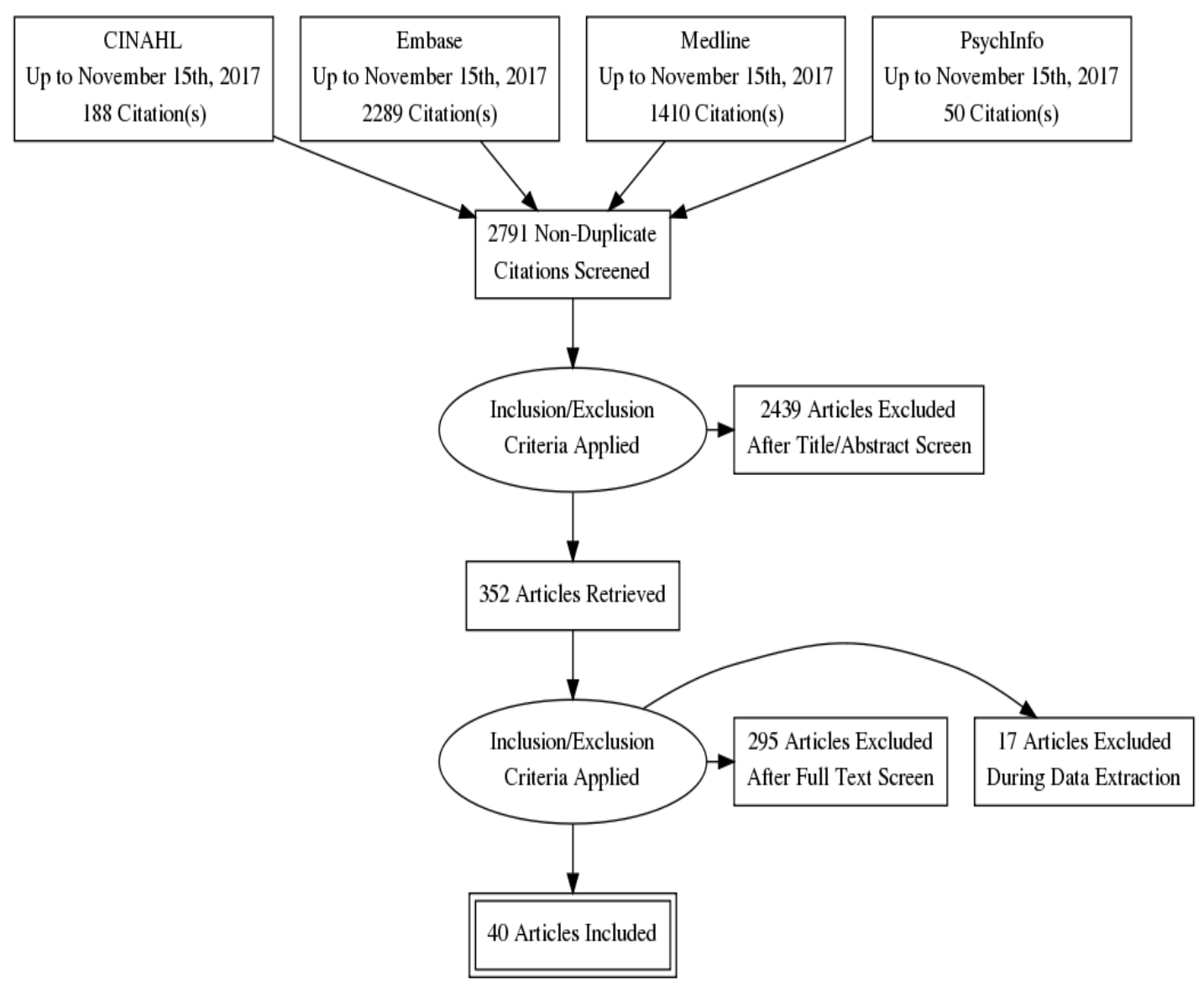

Figure 1. The PRISMA Flow Diagram 


\subsection{Data management}

Endnote $\mathrm{X} 7$ is the reference tool used throughout the write-up of this thesis.

\subsubsection{Data Extraction/Coding}

A coding scheme was developed to extract data from the included empirical studies

(Appendix 2). The following information was collected:

1. The country of origin for each of the articles. The country of origin allows differences among geographical location to be noted and taken into consideration.

2. The age range of the participants, as well as the mean age.

3. The population sample is included and broken down into its subsequent groups.

4. The design of the study.

5. Barriers identified in the study.

6. Facilitators identified in the study.

7. Barriers that are shown to influence adherence GFD (Barriers + ) significantly.

8. Facilitators that are shown to influence adherence to GFD (Facilitators + ) significantly.

9. Adherence to GFD, if included.

10. A summary section that discusses the results of each study.

11. Types of bias presented in the study.

The facilitators and barriers reported from each study were classified according to the social-ecological model. Hence the facilitators/barriers are presented according to the nature of each factor: Individual factors, Interpersonal factors, organizational factors, community factors and system-level factors. 


\subsubsection{Validation}

The author was responsible for coding all of the included articles. In order to ensure reliability, five were randomly selected and also coded by another researcher. An inter-rater reliability score was calculated to assess the agreement level. The coding between the two researchers has high inter-rater reliability, with $85 \%$ agreement.

\subsection{Risk of Bias/Assessment of Methodological Quality}

\subsubsection{Critical Appraisal}

For all of the included articles, a critical appraisal was conducted to assess the strength and rigour of the study. Depending on the design of the study, a specific checklist was used to assess the quality of each particular study (Programme, 2018). Based on these checklists, the quality of evidence and degree of recommendation of the article was evaluated (Treloar, Champness, Simpson, \& Higginbotham, 2000). The assessments analyzed sample selection, loss to follow-up, tertiary factor adjustment (ex. Age/sex), randomization where appropriate, and additional factors. The questions in the checklists helped attribute the impact of each reported result (Treloar et al., 2000). There were forty articles included in the systematic review, after completing the critical appraisals. Appendix 3 includes a table that organizes the general quality-factors analyzed for each of the studies. 


\subsection{Data Analysis/Synthesis}

A meta-analysis was not feasible. This is due to the fact that the studies included in this systematic review are very dissimilar. This high level of heterogeneity paired with the fact that the measures of GFD adherence vary based on the study, disallowing proper comparison through a meta-analysis. A systematic narrative synthesis was conducted (Popay, Roberts, Sowden, Petticrew, \& Arai, 2006). The results and specific characteristics are reported and summarized for each of the included studies. All of the information was compared across each of the included studies, as well as within each study (Moher et al., 2015). Throughout the comparison of the studies, the different reported facilitators and barriers were placed into different ecological layers. These ecological layers are described to explain what they consist of and how they fit into an individual's life.

\section{Results}

\subsection{General Overview of Empirical Studies}

Table 2 describes components of the study, including the author, year of publication, country of publication, sample size, age of participants, and the level of evidence of the studies. The strength of the study is based on JBI levels of evidence (LOE), which assesses the quality of the study based on the study's design (Institute, 2013). The LOE of the studies included in this systematic review ranged from 1.c-4.c. 1.c refers to a randomized controlled trial, 3.c refers to a cohort study, 3.d refers to a case-control study, 3.e refers to an analytical, cross-sectional study, 4.b refers to a descriptive, cross-sectional study, and 4.c refers to a narrative study. When making a statement that the LOE of a study is high, the range includes 1.c-3.d, wherease a low 
LOE range includes 3.e-4.c. The majority of the studies had observational/analytic designs, including case-control, cohort, and analytical cross-sectional studies. Only one randomized controlled trial was included in the review, although ten studies had nonrandomized control groups; six studies were descriptive in nature. The sample sizes ranged from 30 participants to 5912 participants. Certain studies had low sample sizes which can impact the significance of the results. Due to the nature of $\mathrm{CD}$, purposive sampling is used throughout the majority of the studies. 


\section{Table 2: General overview of empirical studies}

\begin{tabular}{|c|c|c|c|c|c|c|}
\hline Author & Year & Country & Study Design & $\begin{array}{l}\text { Participants/ } \\
\text { Sample Size }\end{array}$ & Age of Participants & $\begin{array}{l}\text { Level of } \\
\text { Evidence }\end{array}$ \\
\hline Twist \& Hackett & 1992 & UK & Case-Control & $\begin{array}{l}\text { Group 1: } 46 \\
\text { Group 2: } 46\end{array}$ & $14-40 * *$ & 3.d \\
\hline Lamontagne et al. & 2001 & Canada & Analytical, Cross-sectional & 230 & Mean $=49.6$ & 3.e \\
\hline $\begin{array}{c}\text { Ciacci, Iavarone, Siniscalchi, } \\
\text { Romano, \& Rosa }\end{array}$ & 2002 & Italy & Case-control & $\begin{array}{c}\text { Group 1:25 } \\
\text { Group 2: } 114\end{array}$ & Mean $=29.62$ & 3.d \\
\hline Ciacci et al. & 2003 & Italy & Analytical, Cross-sectional & 581 & Mean $=31.47$ & 3.e \\
\hline $\begin{array}{l}\text { Hogberg, Grodzinsky, \& } \\
\text { Stenhammar }\end{array}$ & 2003 & Sweden & Case-Control & $\begin{array}{l}\text { Group 1: } 15 \\
\text { Group 2: } 14\end{array}$ & Mean $=26$ & 3.d \\
\hline Butterworth et al. & 2004 & UK & Prospective, Cohort & $\begin{array}{l}\text { Group 1: } 66 \\
\text { Group 2: } 21\end{array}$ & $\begin{array}{c}\text { Mean Group 1: } 46.3 \\
\text { Mean Group 2: } 28.95\end{array}$ & 3.c \\
\hline Zarkadas et al. & 2006 & UK & Descriptive, Cross-sectional & 2681 & Mean $=56$ & 4.b \\
\hline Hauser, Stallmach, Caspary, \& Stein & 2007 & Germany & Analytical, Cross-sectional & 522 & Mean $=46.3$ & 3.e \\
\hline Hopman, Koopman, Wit, \& Mearin & 2009 & $\begin{array}{l}\text { Netherland } \\
\quad \mathrm{s}\end{array}$ & Case-Control & $\begin{array}{c}\text { Group 1: } 33 \\
\text { Group 2: } 8 \\
\text { Group 3: } 12\end{array}$ & $\begin{array}{l}\text { Mean Group 1: } 57 \\
\text { Mean Group 2: } 26 \\
\text { Mean Group 3: } 30\end{array}$ & 3.d \\
\hline Smith & 2009 & U.S.A & Descriptive, Cross-sectional & 156 & Mean $=51.5$ & $4 . b$ \\
\hline Barratt, Leeds, \& Sanders & 2011 & UK & Case-control & $\begin{array}{l}\text { Group 1: } 348 \\
\text { Group 2: } 225\end{array}$ & $18+$ & 3.d \\
\hline J. L. Black \& C. Orfila & 2011 & UK & Descriptive, Cross-sectional & 146 & $18-70$ & $4 . \mathrm{b}$ \\
\hline Sainsbury \& Mullan & 2011 & Australia & Analytical, Cross-sectional* & 265 & Mean $=45.1$ & 3.e \\
\hline Biagi et al. & 2012 & Italy & Retrospective, Cohort & 141 & Mean $=34$ & 3.c \\
\hline Casella et al. & 2012 & Italy & Prospective, Cohort & $\begin{array}{l}\text { Group 1: } 1166 \\
\text { Group 2: } 59\end{array}$ & $\begin{array}{c}\text { Group 1: } 18-64 \\
\text { Group 2: } 65+\end{array}$ & 3.c \\
\hline
\end{tabular}




\begin{tabular}{|c|c|c|c|c|c|c|}
\hline Ford, Howard, \& Oyebode & 2012 & UK & Analytical, Cross-sectional & 274 & $19-85$ & 3.e \\
\hline Lee, Ng, Diamond, Ciaccio, \& Green & 2012 & U.S.A & Case-Control & $\begin{array}{l}\text { Group 1: } 1179 \\
\text { Group 2:1743 }\end{array}$ & $18+$ & 3.d \\
\hline Ukkola et al. & 2012 & Finland & Prospective, Cohort & 698 & Median $=50$ & 3.c \\
\hline Hall, Rubin, \& Charnock & 2013 & UK & Analytical, Cross-sectional & 287 & Mean $=56.17$ & 3.e \\
\hline Mahadev et al. & 2013 & U.S.A & Analytical, Cross-sectional & 413 & $18+$ & 3.e \\
\hline Sainsbury, Mullan, \& Sharpe, a. & 2013 & Australia & Analytical, Cross-sectional & 390 & Mean $=44.2$ & 3.e \\
\hline Sainsbury, Mullan, \& Sharpe, b. & 2013 & Australia & Randomized Control Trial & $\begin{array}{l}\text { Experimental: } 101 \\
\text { Control: } 88\end{array}$ & Mean $=46.5$ & 1.c \\
\hline Verrill, Zhang, \& Kane & 2013 & U.S.A & Analytical, Cross-sectional & 1583 & $18-98$ & 3.e \\
\hline Zarkadas et al. & 2013 & Canada & Analytical, Cross-sectional & 5912 & $18+$ & 3.e \\
\hline Dowd et al. & 2014 & Canada & Descriptive, Cross-sectional & 203 & Mean $=42.13$ & 4.b \\
\hline Rose \& Howard & 2014 & UK & $\begin{array}{l}\text { Descriptive, Grounded } \\
\text { Theory }\end{array}$ & 130 & Mean $=52.7$ & 4.c \\
\hline Shah et al. & 2014 & U.S.A & Analytical, Cross-sectional & 341 & Mean $=51.14$ & 3.e \\
\hline Casellas et al. & 2015 & Spain & Analytical, Cross-sectional & 366 & Mean $=40$ & 3.e \\
\hline $\begin{array}{l}\text { Ferster, Obuchowicz, Jarecka, } \\
\text { Pietrzak, \& Karczewska }\end{array}$ & 2015 & Poland & Descriptive, Cross-sectional & 30 & $19-71$ & 4.b \\
\hline Kothe, Sainsbury, Smith, \& Mullan & 2015 & Australia & Analytical, Cross-sectional & 228 & Mean: 45.2 & 3.e \\
\hline Rajpoot et al. & 2015 & India & Prospective, Cohort & $\begin{array}{l}\text { Group 1: } 54 \\
\text { Group 2: } 92\end{array}$ & Mean= 28.9 & 3.c \\
\hline Sainsbury, Mullan, \& Sharpe & 2015 & Australia & Case-control & $\begin{array}{l}\text { Group 1: } 88 \\
\text { Group 2: } 101\end{array}$ & Mean $=46.5$ & 3.d \\
\hline Villafuerte-Galvez et al. & 2015 & U.S.A & Analytical, Cross-sectional & 355 & Mean $=53.6$ & 3.e \\
\hline Dowd, Jung, Chen, \& Beauchamp & 2016 & Canada & Prospective, Cohort & 212 & Mean $=42.08$ & 3.c \\
\hline $\begin{array}{l}\text { J. A. Silvester, Weiten, Graff, } \\
\text { Walker, \& Duerksen, a. }\end{array}$ & 2016 & Canada & Analytical, Cross-sectional & 82 & $18+$ & 3.e \\
\hline $\begin{array}{l}\text { J. A. Silvester, Weiten, Graff, } \\
\text { Walker, \& Duerksen, b. }\end{array}$ & 2016 & Canada & Analytical, Cross-sectional & 222 & $18+$ & 3.e \\
\hline
\end{tabular}




\begin{tabular}{|c|c|c|c|c|c|}
\hline $\begin{array}{c}\text { Ramirez-Cervantes, Romero-Lopez, } \\
\text { Nunez-Alvarez, \& Uscanga- } \\
\text { Dominguez }\end{array}$ & 2016 & Mexico & Analytical, Cross-sectional* & 56 & Mean=59.4 \\
\hline Dowd \& Jung & 2017 & Canada & Prospective, Cohort & 200 & Mean=44.02 \\
\hline $\begin{array}{c}\text { Hughey et al. } \\
\text { Muhammad, Reeves, Ishaq, } \\
\text { Mayberry, \& Jeanes }\end{array}$ & 2017 & U.S.A & Analytical, Cross-sectional & 1832 & $19-65$ \\
\hline
\end{tabular}

*=Although this was the primary design of the study, there is a lower LOE in the corresponding study for the results pertaining to factors influencing adherence to GFD in adults with CD. **Study considers those 14 and older to be adults and this study is therefore included in the systematic review (only one individual under 18 in study). 


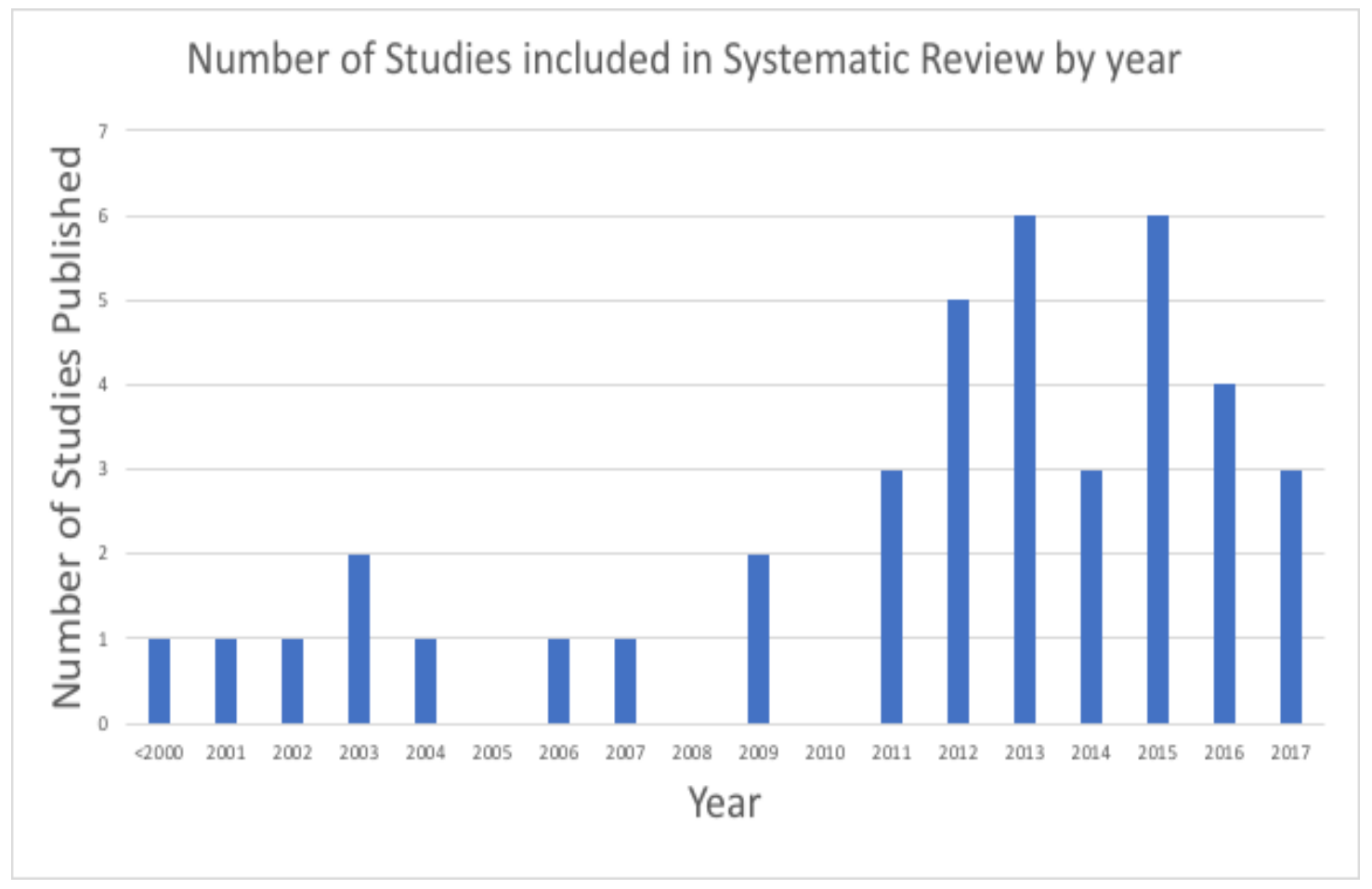

Figure 2. Number of Studies included in Systematic Review by year

More studies have been published in recent years, highlighting the increasing importance of a systematic review that helps categorize and synthesize the available data (Figure 2).

Figure 3 presents the distribution of the countries that each article included in the systematic review were published in. Considering that the systematic review focusses on studies written in English, it is understandable that the countries with the most published studies have English as their main language. Italy is a country where CD is very common, which explains why multiple studies are also published there. 
Number of Studies included in Systematic Review by Country

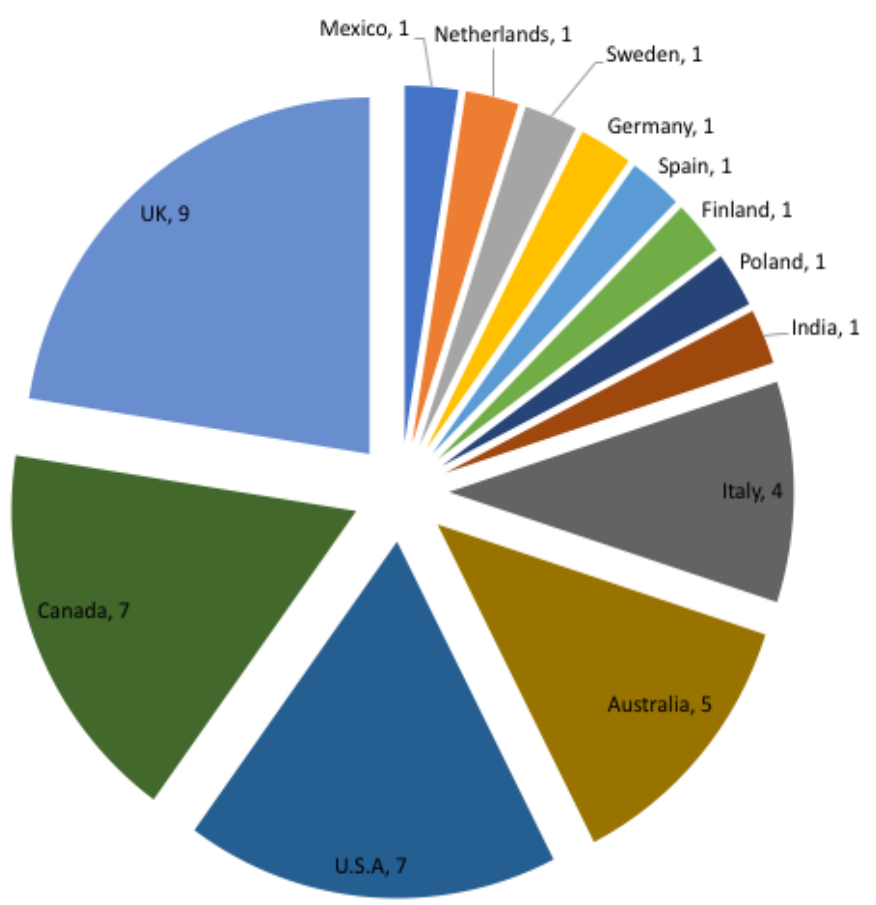

Figure 3. Number of Studies included in Systematic Review by Country

Table 3 presents the strengths and shortcomings of the quality of the different ecological studies. Critical Appraisal Skills Programme checklists were used to assess the quality of the ecological studies. If a category is labelled as 'yes', it met all of the criteria of that section of the questionnaire. If a category is labelled as 'partial', it met some of the criteria of that section of the questionnaire. If a category is labelled as 'no', it did not meet the criteria of that section of the questionnaire. 


\section{Table 3: Quality of Empirical Studies}

\begin{tabular}{|c|c|c|c|c|c|c|}
\hline Author & Year & $\begin{array}{l}\text { Appropriate } \\
\text { Research } \\
\text { Design }\end{array}$ & $\begin{array}{l}\text { Appropriate } \\
\text { Participant } \\
\text { Selection }\end{array}$ & $\begin{array}{l}\text { Sources of } \\
\text { Bias taken } \\
\text { into account }\end{array}$ & $\begin{array}{l}\text { Appropriate } \\
\text { form of data } \\
\text { collection }\end{array}$ & $\begin{array}{l}\text { Appropriate } \\
\text { data analysis }\end{array}$ \\
\hline (Twist \& Hackett, 1992) & 1992 & Yes & No & No & Partial & Yes \\
\hline (Lamontagne et al., 2001) & 2001 & Yes & No & Partial & Partial & Yes \\
\hline $\begin{array}{l}\text { (Ciacci, Iavarone, et al., } \\
\text { 2002) }\end{array}$ & 2002 & Yes & Yes & Yes & Yes & Yes \\
\hline (Ciacci et al., 2003) & 2003 & Yes & Yes & Yes & Yes & Yes \\
\hline (Hogberg et al., 2003) & 2003 & Yes & Yes & No & No & Partial \\
\hline (Butterworth et al., 2004) & 2004 & Yes & No & Yes & Yes & Yes \\
\hline (Zarkadas et al., 2006) & 2006 & Yes & Yes & Yes & Yes & Yes \\
\hline (Hauser et al., 2007) & 2007 & Yes & Yes & No & Yes & Yes \\
\hline (Hopman et al., 2009) & 2009 & Yes & Yes & Yes & Yes & Yes \\
\hline (Smith, 2009) & 2009 & Yes & No & Partial & Yes & Yes \\
\hline (Barratt et al., 2011) & 2011 & Yes & Yes & Yes & Yes & Yes \\
\hline $\begin{array}{l}\text { (J. L. Black \& C. Orfila, } \\
\text { 2011) }\end{array}$ & 2011 & Yes & Yes & Yes & Yes & Yes \\
\hline $\begin{array}{c}\text { (Sainsbury \& Mullan, } \\
\text { 2011) }\end{array}$ & 2011 & Yes & Yes & Yes & No & Yes \\
\hline (Biagi et al., 2012) & 2012 & Yes & Yes & Yes & Yes & Yes \\
\hline (Casella et al., 2012) & 2012 & Yes & No & No & Yes & Yes \\
\hline (Ford et al., 2012) & 2012 & Yes & Yes & Yes & Yes & Yes \\
\hline (Lee et al., 2012) & 2012 & Yes & Yes & No & No & Yes \\
\hline (Ukkola et al., 2012) & 2012 & Yes & Yes & Yes & Yes & Yes \\
\hline (Hall et al., 2013) & 2013 & Yes & Yes & Partial & Yes & Yes \\
\hline (Mahadev et al., 2013) & 2013 & Yes & Partial & Yes & Yes & Yes \\
\hline (Sainsbury et al., 2013a) & 2013 & Yes & No & Partial & Yes & Yes \\
\hline (Sainsbury et al., 2013b) & 2013 & Yes & Yes & Yes & Yes & Yes \\
\hline (Verrill et al., 2013) & 2013 & Yes & Yes & Yes & Yes & Yes \\
\hline (Zarkadas et al., 2013) & 2013 & Yes & Yes & Partial & Partial & Partial \\
\hline (Dowd et al., 2014) & 2014 & Yes & Yes & Yes & Yes & Yes \\
\hline
\end{tabular}




\begin{tabular}{|c|c|c|c|c|c|c|}
\hline (Rose \& Howard, 2014) & 2014 & Yes & No & Partial & Yes & Yes \\
\hline (Shah et al., 2014) & 2014 & Yes & No & Partial & Yes & Yes \\
\hline (Casellas et al., 2015) & 2015 & Yes & Yes & Yes & Yes & Yes \\
\hline (Ferster et al., 2015) & 2015 & Yes & Yes & No & Yes & Yes \\
\hline (Kothe et al., 2015) & 2015 & Yes & Yes & Yes & Yes & Yes \\
\hline (Rajpoot et al., 2015) & 2015 & Yes & Yes & No & Yes & Yes \\
\hline (Sainsbury et al., 2015) & 2015 & Yes & Yes & No & Yes & Yes \\
\hline $\begin{array}{c}\text { (Villafuerte-Galvez et al., } \\
\text { 2015) }\end{array}$ & 2015 & Yes & Yes & Yes & Yes & Yes \\
\hline (Dowd et al., 2016) & 2016 & Yes & Yes & Yes & Partial & Yes \\
\hline $\begin{array}{c}\text { (J. A. Silvester et al., } \\
\text { 2016a) }\end{array}$ & 2016 & Yes & Yes & Partial & Yes & Partial \\
\hline $\begin{array}{l}\text { (J. A. Silvester et al., } \\
\text { 2016b) }\end{array}$ & 2016 & Yes & Yes & Partial & Yes & Yes \\
\hline $\begin{array}{c}\text { (Ramirez-Cervantes et al., } \\
\text { 2016) }\end{array}$ & 2016 & Yes & Yes & No & Partial & Yes \\
\hline (Dowd \& Jung, 2017) & 2017 & Yes & No & Yes & Yes & Yes \\
\hline (Hughey et al., 2017) & 2017 & Yes & Yes & No & Partial & Yes \\
\hline (Muhammad et al., 2017) & 2017 & Yes & No & Yes & Partial & Yes \\
\hline
\end{tabular}

\subsection{Categorization of facilitators and barriers}

In some occurrences, the facilitators or barriers reported by multiple studies were very similar in nature. Due to this, these facilitators or barriers were combined to form an encompassing category. Figure 4 displays which facilitators or barriers formed each category. 


\begin{tabular}{|c|c|}
\hline & Dining outside of the home (Zarkadas et al., 2006; J. L. Black \& C. Orfila, 2011) \\
\hline & Potluck Dinners (Smith, 2009) \\
\hline & Events with Socialization (Barratt, Leeds, \& Sanders, 2009; Lee et al., 2012) \\
\hline & Ignorance of others at social activities (Rose \& Howard, 2014; Twist \& Hackett, 1992) \\
\hline & Embarrassment of CD around others (Ciacci et al., 2003) \\
\hline & Uncomfortable in social situations (Lee et al., 2012) \\
\hline & Support from friends (Sainsbury \& Mullan, 2011) \\
\hline$N$ & Family support (Verrill et al., 2013) \\
\hline & Knowing another individual with CD (J. A. Silvester, Weiten, Graff, Walker, \& Duerksen, 2016 b.) \\
\hline & Counselling Support (Rajpoot et al., 2015) \\
\hline
\end{tabular}

\section{Figure 4: Categorization of facilitators/barriers}

\subsection{Facilitators to GFD adherence in adults with $\mathrm{CD}$}

Table 4 presents the evidence on the facilitators to GFD adherence according to the various ecological layers presented in a social ecological model, derived from the bioecological theory of development. The individual layer represents factors that influence dietary adherence based on personal characteristics, irrespective of individuals' surrounding relationships and environment. The interpersonal layer represents factors that influence dietary adherence based on individuals' direct relationships in their lives. The organizational layer includes rules, regulations, and influences from one's surrounding environment on adherence to a GFD. The community layer refers to factors that are based on individuals' influences by their relationships with their surrounding 
society and social institutions. It also includes any cultural influence on dietary adherence. This layer also includes environmental boundaries. Finally, the system's layer represents factors that impact dietary adherence that originate from a macro, policy level (Derived from (Krug, Mercy, Dahlberg, \& Zwi, 2002)). In some instances, when a facilitator fell into multiple categories, it was recorded in all of the appropriate categories.

\section{Individual facilitators}

At the individual level, facilitators included: high knowledge on CD/GFD, good motivation/self-regulatory efficacy, high income/education level, and improved health status. Eight studies (20\%) reported that having a high level of knowledge on CD/GFD significantly increased adherence to a GFD; out of these studies, only one was a randomized control trial, whereas two had an observational-analytical design and two were descriptive. The randomized control trial found that individuals who had inadequate adherence to a GFD at baseline, whom after a knowledge-intervention, significantly improved dietary adherence producing a medium-large effect size of 0.69. Continuing, seven observational-analytical studies reported that good intention/ high selfregulatory efficacy significantly improved GFD adherence; the majority of them being conducted in Canada. In addition, two studies reported that high education level/income was significantly associated with higher GFD adherence (Barratt et al., 2011; Hall et al., 2013); both studies were observational-analytical in nature, one of which had a high LOE. Finally, two studies reported that improved health status was significantly related to improved GFD adherence (Barratt et al., 2011; Casellas et al., 2015). One of these 
studies consisted of a cohort design with a control group $(\mathrm{p}<0.05)$, and one study had an analytical cross-sectional design $(\mathrm{p}<0.001)$. Both sample-sizes in each respective study were large, further supporting the evidence.

\section{Interpersonal facilitators}

At an interpersonal level, facilitators included having social support and being confident in one's practitioner. Social support refers to having aid and support from a family or friend in regards to the individual's CD, as well as knowing another individual who has CD. Four studies (10\%) reported that increased social support is significantly associated with higher GFD adherence levels (Sainsbury \& Mullan, 2011; Verrill et al., 2013; J. A. Silvester et al., 2016b; Rajpoot et al., 2005). One of these studies had a cohort design with a control group $(\mathrm{p}=0.014)$ and three studies had an analytical, crosssectional design $(\mathrm{p}<0.0001)$. While three of these studies had a low LOE, the improved sample-sizes and rigour of the studies' methodologies improve the significance of this facilitator. Finally, one study reported that having confidence in one's practitioner was linked to having an increased ability to adhere to a GFD. While only one study reported this, its Canadian context should be emphasized.

\section{Organizational facilitators:}

At an organizational level, facilitators included being a member of a celiac association, having clear food labels, and living in an area with a high availability of GF foods. Celiac associations are organizations that are created to education individuals on 
$\mathrm{CD}$ and provide support when needed to guide an individual with $\mathrm{CD}$. To begin, five studies reported that celiac association membership was significantly associated with increased GFD adherence (Sainsbury \& Mullan, 2011; Butterworth et al., 2004.; J. A. Silvester, Weiten, Graff, Walker, \& Duerksen, 2016 b.; Muhammad et al., 2017; Hall et al., 2013). The majority of these studies have an observational-analytical design. While the majority of these studies were conducted in the UK, one study focussed on Canadian celiac association membership. In addition, three studies reported that clear labelling on food products were significantly associated with improved GFD adherence (Butterworth et al., 2004; Sainsbury \& Mullan, 2011; Zarkadas et al., 2013). Two of the studies had a descriptive design, and one study has an analytical, cross-sectional design; all of them, were conducted in the UK. Finally, two studies reported that having GF foods readily available is significantly associated with adults being able to adhere to a GFD (Zarkadas et al., 2013; Lamontagne et al., 2001). While the sample sizes of both studies are large, they have weak designs.

\section{Community facilitators:}

At the community level, three studies reported that high society awareness was significantly associated with increased GFD adherence (Dowd et al., 2016; Hall et al., 2013; J. A. Silvester et al., 2016a). This referred to areas where CD was more prevalent and the population was aware of CD and what a GFD entailed. All three of these studies had weaker designs, one having an analytical, cross-sectional design $(\mathrm{p}<0.05)$ and the 
other two studies having descriptive designs. In this systematic review, the community layer was the ecological layer with the least reporting of facilitators.

System facilitators:

At a systems level, facilitators included: improved patient education, financial reimbursement/food subsidies, and improved food label-laws. Nine studies reported that improved patient education/improved physician-patient communication was associated with higher GFD adherence (Butterworth et al., 2004; Dowd et al., 2014; Lamontagne et al., 2001; Villafuerte-Galvez et al., 2015; Zarkadas et al., 2013; Hughey et al., 2017; J. A. Silvester et al., 2016b; Sainsbury, Mullan, \& Sharpe, 2013 b.; Dowd, Jung, Chen, \& Beauchamp, 2016). The designs of these studies varied; one study was a randomized control trial $(\mathrm{p}<0.001)$, two studies had cohort designs, three studies had an analytical, cross-sectional design, and three studies were descriptive in nature. In total, $22.5 \%$ of the articles included in this systematic review reported on this facilitator, emphasizing its importance. In addition to many of these articles having strong designs, some of the studies were conducted in Canada. Continuing, three studies reported that financial reimbursement/food subsidies at a government level was associated with an increase in GFD adherence among adults with CD (Butterworth et al., 2004; Hall et al., 2013; Muhammad et al., 2017). All of these studies had observational-analytical designs and were conducted in the UK. Finally, two studies reported that improved food label-laws are associated with an improvement in GFD adherence (Sainsbury \& Mullan, 2011; Zarkadas et al., 2013). 


\section{Table 4: Facilitators to GFD Adherence in adults with CD}

\begin{tabular}{|c|c|c|c|c|c|}
\hline Author & Individual Facilitators & $\begin{array}{l}\text { Interpersonal } \\
\text { Facilitators }\end{array}$ & $\begin{array}{l}\text { Organizational } \\
\text { Facilitators }\end{array}$ & $\begin{array}{l}\text { Community } \\
\text { Facilitators }\end{array}$ & Systems Facilitators \\
\hline Twist \& Hackett & - & - & - & - & - \\
\hline Lamontagne et al. & $\begin{array}{c}\text { Older age increased a person's } \\
\text { ability to maintain a GFD }(\mathrm{P}<0.05)\end{array}$ & $\begin{array}{c}\text { Having a high level } \\
\text { confidence in } \\
\text { gastroenterologists and } \\
\text { dieticians was correlated } \\
\text { with a higher adherence to a } \\
\text { GFD }(\mathrm{P}<0.005)\end{array}$ & $\begin{array}{l}\text { Having a high level of } \\
\text { satisfaction with GF } \\
\text { products was correlated } \\
\text { with improved GFD } \\
\text { scores }(\mathrm{P}<0.01)\end{array}$ & - & $\begin{array}{l}\text { Having improved } \\
\text { communication with specialists } \\
\text { was correlated with a higher } \\
\text { adherence to a GFD }(\mathrm{P}<0.005)\end{array}$ \\
\hline $\begin{array}{l}\text { Ciacci, Iavarone, } \\
\text { Siniscalchi, } \\
\text { Romano, \& Rosa, } \\
2002\end{array}$ & $\begin{array}{l}\text { A longer time on a GFD was } \\
\text { correlated with a higher adherence } \\
\text { level to a GFD }(\mathrm{p}=0.0025)\end{array}$ & - & - & - & $\begin{array}{l}\text { A longer time on a GFD was } \\
\text { correlated with a higher } \\
\text { adherence level to a GFD } \\
(\mathrm{p}=0.0025)\end{array}$ \\
\hline Ciacci et al., 2003 & $\begin{array}{l}\text { A higher education level was } \\
\text { associated with an increase GFD } \\
\text { adherence ( } \mathrm{p}=0.0001) \\
\text { If an individual was diagnosed later } \\
\text { in life (after } 20) \text {, there was a } \\
\text { correlation with a higher level of } \\
\text { GFD adherence ( } \mathrm{p}=0.0001) \\
---- \\
\text { Women were statistically more } \\
\text { likely to be adherent to a GFD } \\
(\mathrm{p}=0.0025)\end{array}$ & - & - & - & - \\
\hline $\begin{array}{l}\text { Hogberg, } \\
\text { Grodzinsky, \& } \\
\text { Stenhammar }\end{array}$ & $\begin{array}{c}\text { A significant relationship found } \\
\text { between being diagnosed before the } \\
\text { age of } 4 \text { and having improved GFD } \\
\text { adherence }(\mathrm{p}=0.021)\end{array}$ & - & - & - & \\
\hline
\end{tabular}




\begin{tabular}{|c|c|c|c|c|c|}
\hline Butterworth et al. & - & - & $\begin{array}{c}\text { Membership in a Celiac } \\
\text { Society was correlated } \\
\text { with an increase in GFD } \\
\text { adherence. OR }(95 \% \mathrm{CI}) \\
2.94(1.72-5.26) \text { for } \\
\text { Caucasians } \\
---- \\
\text { Having a better } \\
\text { understanding of food } \\
\text { labelling was correlated } \\
\text { with an increase in GFD } \\
\text { adherence (OR }(95 \% \mathrm{CI}) \\
2.13 \text { (1.08-4.17)). } \\
----- \\
\text { Affordability of GF } \\
\text { products was correlated } \\
\text { with an increase in GFD } \\
\text { adherence ( OR }(95 \% \mathrm{CI}) \\
\text { (Caucasian: } 1.82(1.12- \\
2.86))\end{array}$ & - & $\begin{array}{c}\text { Obtaining GF products by } \\
\text { prescription was correlated to } \\
\text { increased adherence to a GFD } \\
\text { (OR (95\% CI): Caucasian: } 2.0 \\
(1.04-3.85) \\
---- \\
\text { A GFD was shown to improve } \\
\text { as more GF products were } \\
\text { prescribed. OR (95\% CI): } \\
\text { Caucasian: } 1.89 \text { (1.08-3.33) } \\
---- \\
\text { Detailed explanation post- } \\
\text { diagnosis was correlated with } \\
\text { better adherence to a GFD (OR } \\
\text { (95\% CI) 2.04 (1.16-3.57) } \\
----- \\
\text { Regular follow-up with a } \\
\text { practitioner or dietician showed } \\
\text { a correlation with increased } \\
\text { dietary adherence (OR ( } 95 \% \\
\text { CI): Caucasian: } 2.22 \text { (1.12- } \\
4.35)\end{array}$ \\
\hline $\begin{array}{l}\text { Zarkadas et al., } \\
2006\end{array}$ & $\begin{array}{l}\text { Descriptive data highlighted that } \\
\text { individuals were better able to } \\
\text { adhere to a GFD if they were } \\
\text { diagnosed earlier in life. }\end{array}$ & - & $\begin{array}{l}\text { Individuals in this study } \\
\text { stated that having better } \\
\text { access to GF foods in } \\
\text { supermarkets, as well as } \\
\text { restaurants, and } \\
\text { understanding food labels } \\
\text { increase their ability to } \\
\text { maintain dietary } \\
\text { adherence. }\end{array}$ & - & $\begin{array}{l}\text { Individuals in this study shared } \\
\text { what would improve their } \\
\text { ability to adhere to a GFD. } \\
\text { Factors included: Early } \\
\text { diagnosis, better food labelling, } \\
\text { and increased follow-up for } \\
\text { dietary counselling }\end{array}$ \\
\hline $\begin{array}{l}\text { Hauser, Stallmach, } \\
\text { Caspary, \& Stein }\end{array}$ & - & - & - & - & - \\
\hline $\begin{array}{c}\text { Hopman, } \\
\text { Koopman, Wit, \& } \\
\text { Mearin }\end{array}$ & - & - & - & - & - \\
\hline Smith & - & - & - & - & - \\
\hline $\begin{array}{l}\text { Barratt, Leeds, \& } \\
\text { Sanders }\end{array}$ & $\begin{array}{l}\text { Individuals who were from an } \\
\text { Affluent background had better } \\
\text { adherence to a GFD }(\mathrm{p}=0.0077 \text { : } \\
\text { OR }=0.3395 \% \mathrm{CI}(0.15-0.75))\end{array}$ & - & - & - & - \\
\hline
\end{tabular}




\begin{tabular}{|c|c|c|c|c|c|}
\hline $\begin{array}{l}\text { J. L. Black \& C. } \\
\text { Orfila }\end{array}$ & - & - & - & - & - \\
\hline $\begin{array}{l}\text { Sainsbury \& } \\
\text { Mullan, } 2011\end{array}$ & $\begin{array}{l}\text { Through a qualitative process, } \\
\text { participants shared factors that } \\
\text { increased their ability adhere to a } \\
\text { GFD. These factors included: } \\
\text { Increased knowledge of } \\
\text { ingredients/label reading, being } \\
\text { prepared and organized, the desire to } \\
\text { minimize CD symptoms and feel } \\
\text { physically better }\end{array}$ & $\begin{array}{l}\text { Participants shared factors } \\
\text { that increased their ability to } \\
\text { maintain a GFD including: } \\
\text { Support from friends and the } \\
\text { confidence to ask food- } \\
\text { handlers questions about } \\
\text { contamination }\end{array}$ & $\begin{array}{c}\text { Support from celiac } \\
\text { associations was } \\
\text { mentioned through } \\
\text { interviews as a facilitator } \\
\text { to adhering to a GFD. } \\
\text {--- } \\
\text { Clear labelling of foods } \\
\text { was a common response } \\
\text { by participants as a } \\
\text { facilitator to adhering to a } \\
\text { GFD. }\end{array}$ & - & $\begin{array}{l}\text { Clear labelling of foods was a } \\
\text { common response by } \\
\text { participants as a facilitator to } \\
\text { adhering to a GFD. }\end{array}$ \\
\hline Biagi et al. & - & - & - & - & - \\
\hline Casella et al. & - & - & - & - & - \\
\hline $\begin{array}{l}\text { Ford, Howard, \& } \\
\text { Oyebode }\end{array}$ & $\begin{array}{l}\text { A higher rating of self-efficacy was } \\
\text { correlated with increased adherence } \\
\text { to a GFD ( } \mathrm{P}=0.04) \text {; } \\
\text { There was a correlation between } \\
\text { Older age and increased adherence } \\
\text { to a GFD ( } \mathrm{p}=0.002) \text {; } \\
\text {---- } \\
\text { If an individual viewed the } \\
\text { consequences of Ingesting gluten as } \\
\text { more severe, there was a correlation } \\
\text { with increased adherence to a GFD } \\
\quad \text { ( } \mathrm{p}=0.009) \text {; } \\
----- \\
\text { The belief in the cyclical nature of } \\
\mathrm{CD} \text { was correlated with an increase } \\
\text { in GFD adherence }(\mathrm{p}=0.02)\end{array}$ & - & - & - & - \\
\hline $\begin{array}{l}\text { Lee, Ng, Diamond, } \\
\text { Ciaccio, \& Green }\end{array}$ & - & - & - & - & - \\
\hline Ukkola et al. & - & - & - & - & - \\
\hline
\end{tabular}




\begin{tabular}{|c|c|c|c|c|c|}
\hline $\begin{array}{l}\text { Hall, Rubin, \& } \\
\text { Charnock }\end{array}$ & $\begin{array}{l}\text { If an individual was diagnosed as an } \\
\text { adult, there was a correlation with an } \\
\text { increased level of GFD adherence } \\
\qquad(\mathrm{P}<0.05) \\
---- \\
\text { There was a correlation between } \\
\text { having a higher education and an } \\
\text { increased adherence level ( } \mathrm{p}=0.047) \\
\text {---- } \\
\text { If an individual was older they were } \\
\text { more likely to have a higher level of } \\
\text { GFD adherence }(\mathrm{p}<0.001)\end{array}$ & - & $\begin{array}{l}\text { Being a member of a } \\
\text { Celiac Society was } \\
\text { correlated with an } \\
\text { increase in GFD } \\
\text { adherence }(\mathrm{P}<0.001)\end{array}$ & - & $\begin{array}{l}\text { Regular follow-up with } \\
\text { practitioner was shown to be } \\
\text { correlated with an increase in } \\
\text { GFD adherence }(\mathrm{P}<0.01) \\
\text {----- } \\
\text { A correlation was shown with } \\
\text { time of diagnosis. A longer } \\
\text { time since diagnosis was } \\
\text { correlated with an increase in } \\
\text { GFD adherence ( } \mathrm{p}=0.019) \\
\text {---- } \\
\text { A correlation also showed a } \\
\text { relationship with being } \\
\text { diagnosed as an adult and } \\
\text { increased GFD adherence } \\
\text { ( }<<0.05) \\
\text {---- } \\
\text { A correlation was present } \\
\text { between receiving prescription } \\
\text { GF foods and better adhering to } \\
\text { a GFD }(\mathrm{p}<0.01)\end{array}$ \\
\hline Mahadev et al. & - & - & - & - & - \\
\hline $\begin{array}{l}\text { Sainsbury, Mullan, } \\
\text { \& Sharpe, } 2013 \text { a. }\end{array}$ & $\begin{array}{l}\text { Having higher intention to maintain } \\
\text { a GFD was correlated with an } \\
\text { increased likelihood of maintaining } \\
\text { a GFD }(\mathrm{P}<0.01) \\
\text { Having an increased level of } \\
\text { knowledge on CD and a GFD was } \\
\text { correlated with an increased level of } \\
\text { adherence to a GFD ( } \mathrm{P}<0.01) \\
\text {---- } \\
\text { If an individual had a high Perceived } \\
\text { behavioural control level, they were } \\
\text { more likely to also be following a } \\
\text { GFD at a higher level of adherence } \\
\quad(\mathrm{P}<0.001) \\
\quad---- \\
\text { This study also highlighted that } \\
\text { being female was linked to better } \\
\text { adherence to a GFD }(\mathrm{P}<0.05)\end{array}$ & - & - & - & - \\
\hline
\end{tabular}




\begin{tabular}{|c|c|c|c|c|c|}
\hline $\begin{array}{l}\text { Sainsbury, Mullan, } \\
\text { \& Sharpe, } 2013 \text { b. }\end{array}$ & $\begin{array}{l}\text { This RCT concluded that } \\
\text { Completing the Intervention was } \\
\text { linked with an improvement in } \\
\text { following a GFD }(\mathrm{P}<0.001) \\
\text { For those specifically who had low } \\
\text { GFD adherence levels prior to the } \\
\text { intervention, they were more likely } \\
\text { to follow a GFD following the } \\
\text { intervention }(\mathrm{P}=0.014)\end{array}$ & - & - & - & $\begin{array}{l}\text { This RCT concluded that } \\
\text { Completing the Intervention } \\
\text { linked to improvement in } \\
\text { following a GFD }(\mathrm{P}<0.001) \\
\text { For those specifically who had } \\
\text { low GFD adherence levels } \\
\text { prior to the intervention, they } \\
\text { were more likely to follow a } \\
\text { GFD after the intervention } \\
(\mathrm{P}=0.014)\end{array}$ \\
\hline $\begin{array}{l}\text { Verrill, Zhang, \& } \\
\text { Kane }\end{array}$ & $\begin{array}{l}\text { This study also found a correlation } \\
\text { between being Female and having an } \\
\text { improved level of GFD adherence } \\
\qquad(\mathrm{P}=0.013) \\
---- \\
\text { High self-rated health was also } \\
\text { linked to an improved level of GFD } \\
\text { adherence }(\mathrm{P}<0.0001)\end{array}$ & $\begin{array}{l}\text { This study found that having } \\
\text { Support from family and } \\
\text { friends was correlated to } \\
\text { improved adherence levels } \\
\text { to a GFD }(\mathrm{P}<0.0001)\end{array}$ & - & - & - \\
\hline $\begin{array}{c}\text { Zarkadas et al., } \\
2013\end{array}$ & $\begin{array}{l}\text { If an individual was following a } \\
\text { GFD for longer period of time, they } \\
\text { were less likely to make a mistake } \\
\qquad(\mathrm{P}<0.001) \\
---- \\
\text { If an individual had a high level of } \\
\text { strategy to maintain a GFD, they } \\
\text { were correlated with better } \\
\text { following a GFD ( } \mathrm{P}<0.001) \\
\quad---- \\
\text { Participants noted other reasons that } \\
\text { lead them to being extremely careful } \\
\text { with following a GFD: Preventing } \\
\text { long-term complications; Immediate } \\
\text { reactions; knowledge of GFD. }\end{array}$ & - & - & - & $\begin{array}{l}\text { A correlation was shown } \\
\text { between being on a GFD for } \\
\text { longer period and better being } \\
\text { able to adhere to that GFD } \\
\qquad(\mathrm{p}<0.001) \\
---- \\
\text { Participants shared that having } \\
\text { a higher knowledge level on } \\
\text { CD and a GFD post-diagnosis } \\
\text { increased their ability to } \\
\text { maintain a GFD. }\end{array}$ \\
\hline
\end{tabular}




\begin{tabular}{|c|c|c|c|c|c|}
\hline Dowd et al., 2014 & $\begin{array}{l}\text { A recent diagnosis decreased } \\
\text { likelihood of purposeful gluten } \\
\text { consumption ( } \mathrm{p}=0.002 \text { ), and having } \\
\text { a diagnosis further in the past } \\
\text { decreased accidental gluten } \\
\text { consumption ( } \mathrm{p}=0.001 \text { ) } \\
\text {----- } \\
\text { Participants listed the following as } \\
\text { facilitators: Pain due to CD, Hitting } \\
\text { rock bottom, and the need to gain or } \\
\text { lose weight }\end{array}$ & - & - & - & - \\
\hline Rose \& Howard & - & - & - & $\begin{array}{l}\text { Through narratives given } \\
\text { by individual's with } \mathrm{CD} \text {, } \\
\text { having access to the } \\
\text { Celiac Community } \\
\text { improved their ability to } \\
\text { adhere to a GFD }\end{array}$ & - \\
\hline Shah et al. & - & - & - & - & - \\
\hline Casellas et al. & $\begin{array}{l}\text { This study showed that there is a } \\
\text { correlation between an increased } \\
\text { Quality of Life score based on a } \\
\text { validated questionnaire and an } \\
\text { increase in GFD adherence }(\mathrm{p}<0.05)\end{array}$ & $\begin{array}{l}\text { This study showed that there } \\
\text { is a correlation between an } \\
\text { increased Quality of Life } \\
\text { score based on a validated } \\
\text { questionnaire and an } \\
\text { increase in GFD adherence } \\
\quad(\mathrm{p}<0.05)\end{array}$ & $\begin{array}{l}\text { This study showed that } \\
\text { there is a correlation } \\
\text { between an increased } \\
\text { Quality of Life score } \\
\text { based on a validated } \\
\text { questionnaire and an } \\
\text { increase in GFD } \\
\text { adherence }(\mathrm{p}<0.05)\end{array}$ & $\begin{array}{l}\text { There is a correlation } \\
\text { between an increased } \\
\text { Quality of Life score } \\
\text { based on a validated } \\
\text { questionnaire and an } \\
\text { increase in GFD } \\
\text { adherence }(\mathrm{p}<0.05)\end{array}$ & $\begin{array}{l}\text { This study showed that there is } \\
\text { a correlation between an } \\
\text { increased Quality of Life score } \\
\text { based on a validated } \\
\text { questionnaire and an increase } \\
\text { in GFD adherence }(\mathrm{p}<0.05)\end{array}$ \\
\hline $\begin{array}{c}\text { Ferster, } \\
\text { Obuchowicz, } \\
\text { Jarecka, Pietrzak, } \\
\text { \& Karczewska }\end{array}$ & - & - & - & - & - \\
\hline
\end{tabular}




\begin{tabular}{|c|c|c|c|c|c|}
\hline $\begin{array}{l}\text { Kothe, Sainsbury, } \\
\text { Smith, \& Mullan }\end{array}$ & $\begin{array}{l}\text { Having an improved attitude } \\
\text { towards a GFD was correlated with } \\
\text { higher adherence }(\mathrm{p}=0.029) \\
\text { Having a higher Perceived } \\
\text { behavioural control level was also } \\
\text { correlated to higher adherence to a } \\
\text { GFD ( } \mathrm{P}<0.001) \\
---- \\
\text { Higher intention to maintain a GFD } \\
\text { (when Perceived behavioural control } \\
\text { is low and habit is high) was a third } \\
\text { factor that was correlated to } \\
\text { maintaining a GFD }(\mathrm{P}<0.001)\end{array}$ & - & - & - & - \\
\hline Rajpoot et al. & - & $\begin{array}{l}\text { Having a Counselling } \\
\text { relationship improved an } \\
\text { individual's ability to } \\
\text { maintain a GFD }(\mathrm{P}=0.014)\end{array}$ & - & - & - \\
\hline $\begin{array}{l}\text { Sainsbury, Mullan, } \\
\text { \& Sharpe, } 2015\end{array}$ & $\begin{array}{l}\text { This study (follow-up to RCT) } \\
\text { showed that if individuals rated a } \\
\text { portion of the intervention as } \\
\text { interesting, it was more likely to } \\
\text { improve the adherence level to a } \\
\text { GFD }(\mathrm{P}<0.05)\end{array}$ & - & - & - & - \\
\hline $\begin{array}{l}\text { Villafuerte-Galvez } \\
\quad \text { et al. }\end{array}$ & $\begin{array}{l}\text { If an individual Perceived the } \\
\text { effectiveness of GFD as high, there } \\
\text { was a correlation with a higher GFD } \\
\text { adherence }(\mathrm{P}<0.0001) \\
\text { If an individual had a high level of } \\
\text { Knowledge of GFD and CD, there } \\
\text { was a correlation to being better able } \\
\text { to follow a GFD ( } \mathrm{P}<0.0001) \\
\text {---- } \\
\text { If individuals had a high Self- } \\
\text { effectiveness score at following } \\
\text { GFD, they were correlated to better } \\
\text { follow a GFD }(\mathrm{P}<0.0001)\end{array}$ & - & - & - & $\begin{array}{l}\text { If an individual had a high level } \\
\text { of Knowledge of GFD and CD, } \\
\text { there was a correlation to being } \\
\text { better able to follow a GFD } \\
\qquad(\mathrm{P}<0.0001)\end{array}$ \\
\hline
\end{tabular}




\begin{tabular}{|c|c|c|c|c|c|}
\hline $\begin{array}{l}\text { Dowd, Jung, Chen, } \\
\text { \& Beauchamp, } \\
2016\end{array}$ & $\begin{array}{l}\text { This study highlighted that having } \\
\text { greater symptom severity increased } \\
\text { GFD adherence }(\mathrm{p}<0.05) \\
\text { If an individual viewed CD as } \\
\text { having a lower perceived cost, GFD } \\
\text { adherence was increased ( } \mathrm{p}<0.05) \\
---- \\
\text { If an individual had a High self- } \\
\text { regulatory efficacy level based on a } \\
\text { validated questionnaire, GFD } \\
\text { adherence was shown to be higher } \\
\text { (P<0.001) } \\
---- \\
\text { If an individual had increased plans } \\
\text { to eat GFD, their adherence was } \\
\text { higher }(\mathrm{P}<0.001) \\
----- \\
\text { If an individual had Greater } \\
\text { knowledge of } \mathrm{CD} \text { and a GFD, their } \\
\text { adherence rates were higher } \\
\quad(\mathrm{p}<0.001) \\
-----\end{array}$ & - & - & - & $\begin{array}{c}\text { If an individual had Greater } \\
\text { knowledge of } C D \text { and a GFD, } \\
\text { their adherence rates were } \\
\text { higher }(\mathrm{p}<0.001)\end{array}$ \\
\hline $\begin{array}{l}\text { J. A. Silvester, } \\
\text { Weiten, Graff, } \\
\text { Walker, \& } \\
\text { Duerksen, } 2016 \text { a. }\end{array}$ & - & - & - & $\begin{array}{l}\text { This study found a } \\
\text { correlation between } \\
\text { having a Patient- } \\
\text { advocacy group and } \\
\text { better adhering to a GFD } \\
(\mathrm{P}<0.005)\end{array}$ & - \\
\hline $\begin{array}{l}\text { J. A. Silvester, } \\
\text { Weiten, Graff, } \\
\text { Walker, \& } \\
\text { Duerksen, 2016 b. }\end{array}$ & $\begin{array}{c}\text { Participants shared that having } \\
\text { access to Internet-based advice on } \\
\text { CD and a GFD, as well as } \\
\text { Magazines, increased their ability to } \\
\text { maintain a GFD. }\end{array}$ & $\begin{array}{c}\text { Participants shared that } \\
\text { knowing another person on } \\
\text { GFD increased their ability } \\
\text { to follow a GFD. }\end{array}$ & $\begin{array}{l}\text { It was stated that being a } \\
\text { member of the Canadian } \\
\text { Celiac Association } \\
\text { allowed adherence to be } \\
\text { improved; This was also } \\
\text { mentioned for local Local } \\
\text { CD groups. }\end{array}$ & $\begin{array}{l}\text { Participants shared that } \\
\text { having access to } \\
\text { complementary medicine } \\
\text { professionals such as } \\
\text { naturopaths increased } \\
\text { their ability to adhere to } \\
\text { their GFD }\end{array}$ & $\begin{array}{l}\text { Participants clearly articulated } \\
\text { the importance of having } \\
\text { access to practitioners when } \\
\text { help was needed. This } \\
\text { includes: Access to Family } \\
\text { doctor/specialist, Dieticians } \\
\text { and Complementary medicine } \\
\text { professionals. Having this open } \\
\text { communication was stated to } \\
\text { improve the participant's } \\
\text { ability to maintain a GFD. }\end{array}$ \\
\hline
\end{tabular}




\begin{tabular}{|c|c|c|c|c|c|}
\hline $\begin{array}{c}\text { Ramirez- } \\
\text { Cervantes, } \\
\text { Romero-Lopez, } \\
\text { Nunez-Alvarez, \& } \\
\text { Uscanga- } \\
\text { Dominguez }\end{array}$ & - & - & - & - & - \\
\hline $\begin{array}{c}\text { Dowd \& Jung, } \\
2017\end{array}$ & $\begin{array}{l}\text { If an individual had a higher level of } \\
\text { Self-compassion based on a } \\
\text { validated questionnaire, their } \\
\text { adherence levels were higher } \\
(\mathrm{p}<0.01 \mathrm{GFD}) \\
---- \\
\text { If an individual had a higher level of } \\
\text { self-regulatory efficacy based on a } \\
\text { validated questionnaire, their } \\
\text { adherence levels were higher } \\
(\mathrm{p}<0.001)\end{array}$ & - & - & - & - \\
\hline Hughey et al. & - & - & - & - & $\begin{array}{l}\text { Visiting a health care } \\
\text { practitioner in the last } 5 \text { years } \\
\text { was correlated with an increase } \\
\text { in an individual's ability to } \\
\left.\text { maintain a GFD ( } \mathrm{p}=3.6^{*} 10^{\wedge}-4\right)\end{array}$ \\
\hline $\begin{array}{l}\text { Muhammad, } \\
\text { Reeves, Ishaq, } \\
\text { Mayberry, \& } \\
\text { Jeanes }\end{array}$ & $\begin{array}{l}\text { This study found that being of an } \\
\text { older age increased the ability to } \\
\text { adhere to a GFD, slightly ( } \mathrm{p}=0.03 \text { ) }\end{array}$ & - & $\begin{array}{l}\text { This study found that } \\
\text { being a member of the } \\
\text { UK Celiac Society was } \\
\text { correlated with an } \\
\text { increase in GFD } \\
\text { adherence }(\mathrm{P}<0.001)\end{array}$ & - & $\begin{array}{l}\text { This study found a correlation } \\
\text { between a General practitioner } \\
\text { prescribing GF foods and an } \\
\text { individual's ability to maintain } \\
\text { a GFD }(\mathrm{p}<0.001)\end{array}$ \\
\hline
\end{tabular}




\subsection{Barriers to GFD adherence in adults with $\mathrm{CD}$}

Table 5 organizes the barriers into the ecological layers used in the facilitators section. In some situations, a barrier fell into multiple categories and was recorded in all of the appropriate categories. The barriers presented at the individual level include lack of knowledge on $\mathrm{CD} / \mathrm{GFD}$, low intention/carelessness, low health status, and low education level/income status. At an interpersonal level, social fear/ignorance acted as a barrier. At the environmental level, barriers included, restaurant dining/supermarket shopping, low affordability of GF products, and unclear labels. At a community level, barriers included cultural factors/low society awareness, travelling, and living in an urban residence. At a systems level, barriers included poor patient education, poor label laws, and the lack of financial reimbursement.

\section{Individual Barriers:}

To begin, fourteen studies reported that a lack of knowledge of CD/GFD was associated with hindering the ability of an adult with CD to adhere to a GFD (J. L. Black \& C. Orfila, 2011; Ciacci et al., 2003; Rajpoot et al., 2015; Ramirez-Cervantes et al., 2016; J. A. Silvester et al., 2016a; Ukkola et al., 2012; Hopman et al., 2009; Rose \& Howard, 2014; Shah et al., 2014; Dowd et al., 2014; Hall et al., 2013; Lee et al., 2012; Biagi et al., 2012). The majority of these studies were analytical in nature, having strong designs, while five studies had weaker, descriptive designs. The studies that reported this barrier represents $35 \%$ of the total studies included in the systematic review. Continuing, 
seven studies reported that having low intention/carelessness is associated with lower GFD adherence (Ford et al., 2012; Hall et al., 2013; Ramirez-Cervantes et al., 2016; Ciacci et al., 2003; J. L. Black \& C. Orfila, 2011; Biagi et al., 2012; Sainsbury \& Mullan, 2011). The strength of the designs of these studies varied from a cohort study to descriptive studies. In addition, four studies reported that poor taste of GF foods was significantly associated with lower GFD adherence (Muhammad et al., 2017; Dowd et al., 2014; Lee et al., 2012; Smith, 2009). One of these studies had an analytical, crosssectional design $(p=0.028)$, one study had a case-control design $(p=0.001)$, and two studies had a descriptive design, none of them being conducted in Canada. Emotions were also potential barriers to GFD adherence. If an individual was angry about their diagnosis were less likely to be following a proper GFD (Ciacci, Iavarone, et al., 2002). Also, individuals who were worried about planning and cooking GF meals reported making mistakes on their GFD (Lamontagne et al., 2001). Finally, three studies reported that having a low health status was associated with lower GFD adherence (Hauser et al., 2007; Sainsbury, Mullan, \& Sharpe, 2013 a.; Barratt, Leeds, \& Sanders, 2011). All of these studies had high sample sizes, while the strengths of the designs varied from cohort studies, to descriptive studies.

Interpersonal Barriers:

At an interpersonal level, seven studies reported that participating in various social activities negatively impacted the ability for an adult with CD to adhere to a GFD (J. L. Black \& C. Orfila, 2011; Lee et al., 2012; Smith, 2009; Zarkadas et al., 2006; Rose 
\& Howard, 2014; Barratt et al., 2011; Twist \& Hackett, 1992). Social activities refer to the attendance of events where food is offered, including weddings, potluck dinners, or parties among peers. Two of these studies had control groups, with a case-control design, while the other five studies were descriptive in nature. In addition, two studies reported that social fear was a barrier to GFD adherence (Lee et al., 2012; Ciacci et al., 2003). Social fear refers to situations where individuals are scared to disclose their diagnosis of $\mathrm{CD}$ to peers due to not wanting to feel isolated or a burden onto others. Neither of these two studies, that were analytical in nature, were conducted in Canada.

\section{Organizational Barriers:}

At an organizational level, twelve studies reported that dining in a restaurant/supermarket shopping was significantly associated with lower adherence to a GFD for adults with CD (Barratt et al., 2011; J. Black \& C. Orfila, 2011; Ciacci et al., 2003; Dowd et al., 2014; Ferster et al., 2015; Lee et al., 2012; Rajpoot et al., 2015; Rose \& Howard, 2014; Smith, 2009; Twist \& Hackett, 1992; Ukkola et al., 2012; Verrill et al., 2013). The vast majority of these studies are descriptive in nature (ten studies), with the remaining two studies consisting of a case-control design $(\mathrm{p}=0.01)$ and an analytical, cross-sectional design. While most studies have a low LOE, it is important to take into consideration that $30 \%$ of the studies in this systematic review noted this as being a barrier, many of them being conducted in Canada. In addition, four studies reported that when GF foods in someone's city are very expensive, these individuals are less likely to adhere to a GFD (Villafuerte-Galvez et al., 2015; Rajpoot et al., 2015; Dowd et al., 2014; 
Smith, 2009). However, the studies that reported this had weak designs. Finally, four studies reported that unclear labelling when trying to purchase GF foods negatively impacted the ability to adhere to a GFD (Muhammad et al., 2017; Ferster et al., 2015; Dowd et al., 2014; Ukkola et al., 2012 ). All of these studies had weak designs, but were methodically rigorous. It is also important to take into consideration that all of these studies that examined the negative impact of unclear labelling were conducted in Europe.

\section{Community Barriers:}

To begin, five studies reported that specific cultural factors/low society awareness of CD was significantly associated with lower GFD adherence (Muhammad et al., 2017; Ramirez-Cervantes et al., 2016; Rajpoot et al., 2015; Butterworth et al., 2004; Twist \& Hackett, 1992). None of these studies were conducted in Canada, with one of them having a cohort design $(\mathrm{p}=0.04)$, three having an analytical, cross-sectional design, and the remaining two studies having descriptive designs. In addition, five studies reported that travelling negatively impacted the ability for an adult to adhere to a GFD (Rajpoot et al., 2015; Ferster et al., 2015; Dowd et al., 2014; Barratt et al., 2011; Smith, 2009). The LOE of these studies are low, with all of the studies reporting descriptive data, limiting the significance of this barrier. Finally, one study reported that living in an urban residence negatively impacted GFD adherence (Lamontagne et al., 2001). This study had an analytical, cross-sectional design $(\mathrm{p}<0.02)$. The weak design of this study, paired with the fact that only one study reported this barrier, limits its significance. 


\section{System Barriers:}

At the final ecological level, seven studies (17.5\%) reported that poor patient education/poor physician-patient communication negatively impacted the ability for an adult with CD to adhere to a GFD (J. A. Silvester et al., 2016a; Rajpoot et al., 2015; Ferster et al., 2015; Shah et al., 2014; Ukkola et al., 2012; Lee et al., 2012; Hopman et al., 2009). The strength of the designs of these studies varied greatly, from a cohort design $(\mathrm{p}<0.001)$, to a descriptive design. In addition, four studies reported that poor label laws lowered the ability for those with CD to adhere to a GFD (Muhammad et al., 2017; Ferster et al., 2015; Ukkola et al., 2012; Rajpoot et al., 2015). One of these studies has an analytical, cross-sectional design $(\mathrm{p}<0.001)$, and the remaining three articles have descriptive designs. While the studies have weak designs, the rigorous methodology of the studies improves the significance of the results. It should be taken into consideration that all of these studies were conducted in Europe. Finally, two studies reported that the lack of financial reimbursement/food subsidies acted as a barrier to GFD adherence (Ferster et al., 2015; Twist \& Hackett, 1992). While there were only two studies that reported this, both of them have a high LOE with cohort designs. 
Table 5: Barriers to GFD Adherence

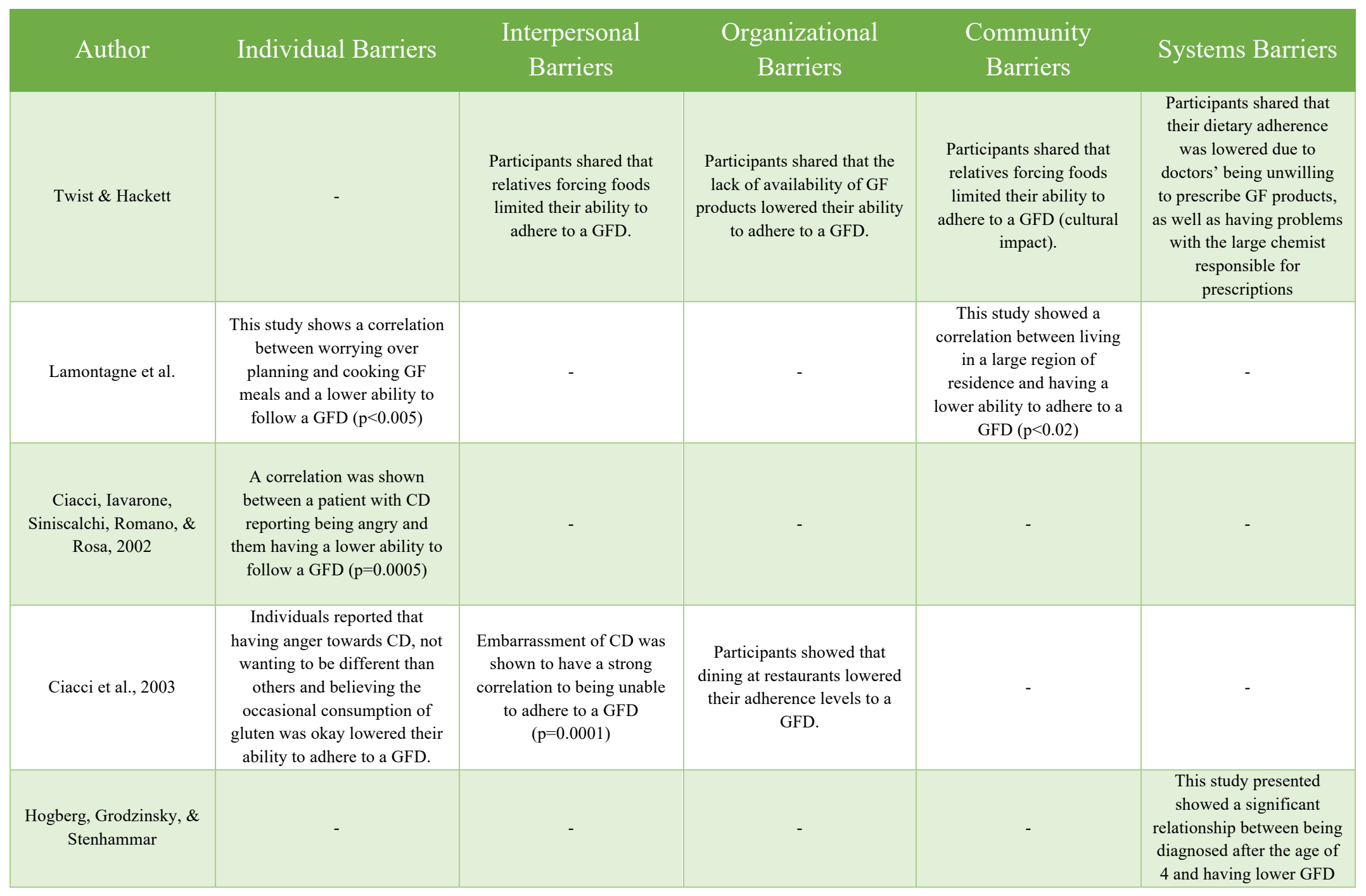




\begin{tabular}{|c|c|c|c|c|c|}
\hline & & & & & $\begin{array}{l}\text { adherence levels } \\
\qquad(\mathrm{p}=0.021)\end{array}$ \\
\hline Butterworth et al. & - & - & - & $\begin{array}{l}\text { The study highlighted that } \\
\text { being of a South Asian } \\
\text { background, lowered the } \\
\text { ability to follow a GFD } \\
\text { (p=0.04) }\end{array}$ & - \\
\hline Zarkadas et al., 2006 & - & $\begin{array}{l}\text { This study highlights that } \\
\text { participants find that dining } \\
\text { outside home limited their } \\
\text { ability to maintain a GFD. }\end{array}$ & $\begin{array}{l}\text { This study highlights that } \\
\text { participants find that dining } \\
\text { outside home limited their } \\
\text { ability to maintain a GFD. }\end{array}$ & - & $\begin{array}{c}\text { This study highlights that } \\
\text { patients find Hospital } \\
\text { stays lower their GFD } \\
\text { adherence }\end{array}$ \\
\hline $\begin{array}{l}\text { Hauser, Stallmach, } \\
\text { Caspary, \& Stein }\end{array}$ & $\begin{array}{l}\text { This study showed a } \\
\text { correlation between a Reduced } \\
\text { Health related quality of life } \\
\text { score and having a lower } \\
\text { likelihood to follow a GFD } \\
\text { ( } \mathrm{p}=0.01)\end{array}$ & $\begin{array}{l}\text { This study showed a } \\
\text { correlation between a } \\
\text { Reduced Health related } \\
\text { quality of life score and } \\
\text { having a lower likelihood to } \\
\text { follow a GFD }(\mathrm{p}=0.01)\end{array}$ & $\begin{array}{l}\text { This study showed a } \\
\text { correlation between a } \\
\text { Reduced Health related } \\
\text { quality of life score and } \\
\text { having a lower likelihood to } \\
\text { follow a GFD }(\mathrm{p}=0.01)\end{array}$ & $\begin{array}{l}\text { This study showed a } \\
\text { correlation between a } \\
\text { Reduced Health related } \\
\text { quality of life score and } \\
\text { having a lower likelihood to } \\
\text { follow a GFD }(\mathrm{p}=0.01)\end{array}$ & $\begin{array}{c}\text { This study showed a } \\
\text { correlation between a } \\
\text { Reduced Health related } \\
\text { quality of life score and } \\
\text { having a lower likelihood } \\
\text { to follow a GFD }(\mathrm{p}=0.01)\end{array}$ \\
\hline $\begin{array}{l}\text { Hopman, Koopman, Wit, } \\
\text { \& Mearin }\end{array}$ & $\begin{array}{l}\text { This study reported that } \\
\text { individuals were less likely to } \\
\text { follow a GFD when they had } \\
\text { no symptoms when ingesting } \\
\text { gluten, as well as if they were } \\
\text { diagnosed with CD at a } \\
\text { younger age. }\end{array}$ & - & - & - & $\begin{array}{c}\text { This study reported that } \\
\text { GFD adherence was } \\
\text { negatively impacted by } \\
\text { poor medical advice } \\
\text { (statements that CD was } \\
\text { cured) }\end{array}$ \\
\hline Smith & $\begin{array}{l}\text { Participants shared reasons as } \\
\text { to why they did not adhere to a } \\
\text { GFD. This included the } \\
\text { dislike of the taste of GF foods }\end{array}$ & $\begin{array}{l}\text { Participants found that } \\
\text { problems outside the home, } \\
\text { including social } \\
\text { events/potluck dinners } \\
\text { contributed to non- } \\
\text { adherence to a GFD. }\end{array}$ & $\begin{array}{l}\text { Participants in this study } \\
\text { shared that dining at } \\
\text { restaurants and the high cost } \\
\text { of GF foods impacted their } \\
\text { ability to adhere to a GFD. }\end{array}$ & $\begin{array}{l}\text { Participants shared that } \\
\text { whenever they traveled, } \\
\text { their ability to adhere to a } \\
\text { GFD was lowered. }\end{array}$ & - \\
\hline $\begin{array}{l}\text { Barratt, Leeds, \& } \\
\quad \text { Sanders }\end{array}$ & $\begin{array}{l}\text { Reductions in QOL paired } \\
\text { with risk of anxiety and } \\
\text { depression were correlated } \\
\text { with a lower level of GFD } \\
\text { adherence }(\mathrm{p}<0.001)\end{array}$ & $\begin{array}{l}\text { Individuals reported that } \\
\text { eating out, personal } \\
\text { relationships, home } \\
\text { environment, and } \\
\text { socializing lowered their } \\
\text { ability to adhere to a GFD. }\end{array}$ & $\begin{array}{l}\text { Individuals reported that } \\
\text { eating out and an individual's } \\
\text { workplace environment } \\
\text { lowered their ability to } \\
\text { adhere to a GFD. }\end{array}$ & $\begin{array}{l}\text { Individuals reported that } \\
\text { traveling lowered their } \\
\text { ability to adhere to a GFD. }\end{array}$ & - \\
\hline J. L. Black \& C. Orfila & $\begin{array}{l}\text { Individuals reported that a lack } \\
\text { of care, as well as lacking } \\
\text { knowledge of GF options } \\
\text { lowered their ability to follow } \\
\text { a GFD; }\end{array}$ & $\begin{array}{l}\text { Individuals reported that } \\
\text { dining of outside home } \\
\text { lowered their ability to } \\
\text { adhere to a GFD. }\end{array}$ & $\begin{array}{l}\text { Individuals reported that } \\
\text { specifically, dining at } \\
\text { restaurants lowered their } \\
\text { ability to adhere to a GFD. }\end{array}$ & - & - \\
\hline $\begin{array}{c}\text { Sainsbury \& Mullan, } \\
2011\end{array}$ & $\begin{array}{l}\text { Participants shared that overly } \\
\text { trusting non-celiac individuals }\end{array}$ & - & - & - & - \\
\hline
\end{tabular}




\begin{tabular}{|c|c|c|c|c|c|}
\hline & $\begin{array}{l}\text { with their food preparation } \\
\text { lowered an individual's ability } \\
\text { to follow a GFD. }\end{array}$ & & & & \\
\hline Biagi et al. & $\begin{array}{l}\text { A questionnaire that asked } \\
\text { specific questions about an } \\
\text { individual with CD was linked } \\
\text { to not adhering to a GFD. The } \\
\text { questions included: } 1 \text {. Not } \\
\text { informing cook about allergy, } \\
\text { 2. Not checking labels. 3. Eat } \\
\text { packaged food not certified by } \\
\text { Celiac Association, } 4 \text {. Desire } \\
\text { to taste gluten-containing food. } \\
(\mathrm{p}=0.001)\end{array}$ & - & - & - & - \\
\hline Casella et al. & - & - & - & - & - \\
\hline $\begin{array}{l}\text { Ford, Howard, \& } \\
\text { Oyebode }\end{array}$ & $\begin{array}{l}\text { This study reported a } \\
\text { correlation between having a } \\
\text { Low self-efficacy rating and } \\
\text { lower adherence to a GFD } \\
\qquad(\mathrm{p}=0.04)\end{array}$ & - & - & - & - \\
\hline $\begin{array}{l}\text { Lee, Ng, Diamond, } \\
\text { Ciaccio, \& Green }\end{array}$ & $\begin{array}{l}\text { Individuals in the study stated } \\
\text { that finding a GFD Difficult to } \\
\text { follow, and finding GF foods } \\
\text { Tasteless lowered their } \\
\text { adherence to a GFD. }\end{array}$ & $\begin{array}{l}\text { Several interpersonal } \\
\text { factors limited participant's } \\
\text { ability to maintain a GFD. } \\
\text { These included: Social } \\
\text { activities, spending time } \\
\text { with friends, and being } \\
\text { uncomfortable in social } \\
\text { settings }\end{array}$ & $\begin{array}{l}\text { Dining at Restaurants and } \\
\text { finding a GFD too expensive } \\
\text { were highlighted as barriers } \\
\text { to a GFD. } \\
\text {--- } \\
\text { A correlation was also shown } \\
\text { between finding a GFD too } \\
\text { restrictive and low adherence } \\
\text { to a GFD }(\mathrm{p}=0.01)\end{array}$ & & $\begin{array}{l}\text { Participants in this study } \\
\text { reported that their dietary } \\
\text { adherence was lowered } \\
\text { due to not learning about } \\
\text { CD from physicians. }\end{array}$ \\
\hline Ukkola et al. & $\begin{array}{l}\text { Lack of knowledge on GF } \\
\text { foods was highlighted by } \\
\text { participants that lowered their } \\
\text { likelihood of following a GFD. }\end{array}$ & - & $\begin{array}{l}\text { Participants helped highlight } \\
\text { that the poor labelling of GF } \\
\text { products and difficulties in } \\
\text { identifying GF food when } \\
\text { dining out lowered their } \\
\text { ability to adhere to a GFD. }\end{array}$ & - & $\begin{array}{l}\text { At a systems level, Lack } \\
\text { of knowledge of CD and a } \\
\text { GFD, as well as poor } \\
\text { labelling of GF products } \\
\text { decrease the ability to } \\
\text { adhere to a GFD. }\end{array}$ \\
\hline Hall, Rubin, \& Charnock & $\begin{array}{l}\text { This study shows a correlation } \\
\text { between people who believe } \\
\text { they have a Perceived } \\
\text { tolerance to gluten and lower } \\
\text { GFD adherence }(\mathrm{p}<0.001) \\
\text {----- }\end{array}$ & - & - & - & - \\
\hline
\end{tabular}




\begin{tabular}{|c|c|c|c|c|c|}
\hline & $\begin{array}{l}\text { Another correlation was found } \\
\text { between having a Low Self- } \\
\text { efficacy score and having a } \\
\text { lower adherence level to a } \\
\text { GFD }(\mathrm{p}<0.01) \\
\text {---- } \\
\text { A third correlation was shown } \\
\text { between an individual having } \\
\text { Low Intention with following } \\
\text { a GFD, and actively following } \\
\text { a GFD }(\mathrm{p}<0.001)\end{array}$ & & & & \\
\hline Mahadev et al. & - & - & - & - & - \\
\hline $\begin{array}{l}\text { Sainsbury, Mullan, \& } \\
\text { Sharpe, } 2013 \text { a. }\end{array}$ & $\begin{array}{l}\text { This study showed a } \\
\text { correlation between depression } \\
\text { and a lower ability to adhere to } \\
\text { a GFD ( } \mathrm{p}<0.01) \\
\text {---- } \\
\text { If an individual was at-risk for } \\
\text { an eating risk disorder, a } \\
\text { correlation showed they were } \\
\text { also less likely to adhere to a } \\
\text { GFD }(\mathrm{p}<0.05)\end{array}$ & - & - & - & - \\
\hline $\begin{array}{l}\text { Sainsbury, Mullan, \& } \\
\text { Sharpe, } 2013 \text { b. }\end{array}$ & - & - & - & - & - \\
\hline Verrill, Zhang, \& Kane & $\begin{array}{l}\text { This study showed that a } \\
\text { greater consumption of } \\
\text { packaged, processed foods was } \\
\text { associated with participants } \\
\text { being less likely to adhere to a } \\
\text { GFD. }\end{array}$ & - & $\begin{array}{l}\text { This study showed that a } \\
\text { greater consumption of } \\
\text { packaged, processed foods } \\
\text { was associated with } \\
\text { participants being less likely } \\
\text { to adhere to a GFD. }\end{array}$ & - & - \\
\hline Zarkadas et al., 2013 & - & - & - & - & - \\
\hline Dowd et al., 2014 & $\begin{array}{l}\text { Individuals who had a belief in } \\
\text { being less sensitive, the desire } \\
\text { to taste gluten-containing } \\
\text { foods, the desire to travel, and } \\
\text { being exposed to alcohol, } \\
\text { reported having a lower } \\
\text { adherence level to a GFD. }\end{array}$ & - & $\begin{array}{l}\text { This study highlighted } \\
\text { organizational factors that } \\
\text { limited adherence to a GFD. } \\
\text { These include: Dining at } \\
\text { restaurants, GF foods being } \\
\text { too expensive and cross- } \\
\text { contamination risks. }\end{array}$ & $\begin{array}{l}\text { The study highlighted that } \\
\text { travelling lowered } \\
\text { individual's ability to } \\
\text { adhere to a GFD. }\end{array}$ & - \\
\hline
\end{tabular}




\begin{tabular}{|c|c|c|c|c|c|}
\hline Rose \& Howard & $\begin{array}{l}\text { This study shared participants } \\
\text { views that those who did not } \\
\text { have visible symptoms, were } \\
\text { less likely to adhere to a GFD. }\end{array}$ & $\begin{array}{l}\text { Participants found that the } \\
\text { ignorance of others limited } \\
\text { their ability to maintain a } \\
\text { GFD }\end{array}$ & $\begin{array}{l}\text { Participants shared that the } \\
\text { Ignorance of others and the } \\
\text { lack of GF options impacted } \\
\text { their ability to maintain a } \\
\text { GFD }\end{array}$ & - & - \\
\hline Shah et al. & $\begin{array}{l}\text { This study displayed several } \\
\text { correlations that were linked } \\
\text { with lower adherence to a } \\
\text { GFD. These included: Having } \\
\text { an income less than } \$ 200,000 \\
(\mathrm{p}=0.047) \text {, being unemployed } \\
(\mathrm{p}=0.05) \text {, having increased } \\
\text { severity of CD symptoms } \\
\quad(\mathrm{p}<0.001), \\
\text { having a lower perceived } \\
\text { importance of treatment } \\
\quad(\mathrm{p}<0.001) \\
\text { And having a greater treatment } \\
\text { burden score }(\mathrm{p}<0.001)\end{array}$ & - & - & - & $\begin{array}{l}\text { Having a lower perceived } \\
\text { importance of treatment } \\
\text { was correlated with a } \\
\text { lower level of adherence } \\
\text { to a GFD }(\mathrm{p}<0.001)\end{array}$ \\
\hline Casellas et al. & - & - & - & - & - \\
\hline $\begin{array}{l}\text { Ferster, Obuchowicz, } \\
\text { Jarecka, Pietrzak, \& } \\
\text { Karczewska }\end{array}$ & - & - & $\begin{array}{l}\text { This study showed various } \\
\text { factors that participants } \\
\text { found limited their ability to } \\
\text { adhere to a GFD. These } \\
\text { include: Inadequate food } \\
\text { labelling, and cross- } \\
\text { contamination risks from } \\
\text { mass catering establishments, }\end{array}$ & $\begin{array}{l}\text { This study highlighted that } \\
\text { travelling (both within the } \\
\text { country and international) } \\
\text { were linked as factors that } \\
\text { lowered the ability for an } \\
\text { adult with CD to adhere to a } \\
\text { GFD. }\end{array}$ & $\begin{array}{l}\text { This study highlighted that } \\
\text { Inadequate food labelling, } \\
\text { having no governmental } \\
\text { reimbursement plan and } \\
\text { having limited access to } \\
\text { nutritionist's advice } \\
\text { lowered their ability to } \\
\text { adhere to a GFD. }\end{array}$ \\
\hline $\begin{array}{c}\text { Kothe, Sainsbury, Smith, } \\
\text { \& Mullan }\end{array}$ & - & - & - & - & - \\
\hline Rajpoot et al. & $\begin{array}{l}\text { Individuals in this study } \\
\text { reported that their lack of } \\
\text { understanding of gluten and } \\
\mathrm{CD} \text {, and issues with their } \\
\text { regular eating habits, lowered } \\
\text { their ability to follow a GFD. }\end{array}$ & - & $\begin{array}{l}\text { Individuals in this study } \\
\text { reported that the lack of } \\
\text { availability of GF products } \\
\text { and high costs of GF foods } \\
\text { lowered their ability to } \\
\text { adhere to a GFD. }\end{array}$ & $\begin{array}{l}\text { Participants stated that } \\
\text { travelling, set eating habits, } \\
\text { as well as social/cultural } \\
\text { factors negatively impacted } \\
\text { their ability to adhere to a } \\
\text { GFD. }\end{array}$ & $\begin{array}{l}\text { Individuals in this study } \\
\text { reported that their lack of } \\
\text { understanding of gluten } \\
\text { and CD initiating from } \\
\text { poor communication with } \\
\text { physicians lowered their } \\
\text { ability to adhere to a GFD }\end{array}$ \\
\hline $\begin{array}{l}\text { Sainsbury, Mullan, \& } \\
\quad \text { Sharpe, } 2015\end{array}$ & - & - & - & - & - \\
\hline
\end{tabular}




\begin{tabular}{|c|c|c|c|c|c|}
\hline Villafuerte-Galvez et al. & - & - & $\begin{array}{l}\text { This study shoed a clear link } \\
\text { between participants finding } \\
\text { the Cost of a GFD being high } \\
\text { and their likelihood of not } \\
\text { following a GFD ( } \mathrm{p}<0.0001) \text {. }\end{array}$ & - & - \\
\hline $\begin{array}{l}\text { Dowd, Jung, Chen, \& } \\
\text { Beauchamp, } 2016\end{array}$ & - & - & - & - & - \\
\hline $\begin{array}{l}\text { J. A. Silvester, Weiten, } \\
\text { Graff, Walker, \& } \\
\text { Duerksen, } 2016 \text { a. }\end{array}$ & $\begin{array}{l}\text { This study showed a clear link } \\
\text { between the lack of knowledge } \\
\text { of gluten-containing foods and } \\
\text { not being able to adhere to a } \\
\text { GFD. Every single participant } \\
\text { was unaware of all gluten- } \\
\text { containing products. }\end{array}$ & - & - & - & $\begin{array}{l}\text { This study showed a clear } \\
\text { link between the lack of } \\
\text { knowledge of gluten- } \\
\text { containing foods and not } \\
\text { being able to adhere to a } \\
\text { GFD. Every single } \\
\text { participant was unaware of } \\
\text { all gluten-containing } \\
\text { products. }\end{array}$ \\
\hline $\begin{array}{l}\text { J. A. Silvester, Weiten, } \\
\text { Graff, Walker, \& } \\
\text { Duerksen, } 2016 \text { b. }\end{array}$ & - & - & - & - & - \\
\hline $\begin{array}{l}\text { Ramirez-Cervantes, } \\
\text { Romero-Lopez, Nunez- } \\
\text { Alvarez, \& Uscanga- } \\
\text { Dominguez }\end{array}$ & $\begin{array}{l}\text { This study explained that } \\
\text { participants low intention with } \\
\text { following a strict diet and } \\
\text { having lower knowledge on } \\
\text { CD decreased their ability to } \\
\text { follow a GFD. }\end{array}$ & - & - & $\begin{array}{l}\text { This study showed that } \\
\text { cultural differences } \\
\text { decreased participants' } \\
\text { abilities to adhere to a GFD. }\end{array}$ & - \\
\hline Dowd \& Jung, 2017 & - & - & - & - & - \\
\hline Hughey et al. & - & - & - & - & - \\
\hline $\begin{array}{l}\text { Muhammad, Reeves, } \\
\text { Ishaq, Mayberry, \& } \\
\text { Jeanes }\end{array}$ & $\begin{array}{l}\text { The study reported a decrease } \\
\text { in ability to follow a GFD for } \\
\text { south Asian patients compared } \\
\text { to Caucasian patients. } \\
\text { A correlation was found } \\
\text { between an individual finding } \\
\text { unpleasant taste when it comes } \\
\text { to GF foods and their } \\
\text { adherence to a GFD ( } \mathrm{p}=0.028)\end{array}$ & - & $\begin{array}{c}\text { This study reported that poor } \\
\text { food labelling was correlated } \\
\text { with a lower ability to adhere } \\
\text { to a GFD }(\mathrm{p}<0.001)\end{array}$ & $\begin{array}{l}\text { The study reported a } \\
\text { decrease in ability to follow } \\
\text { a GFD for south Asian } \\
\text { patients compared to } \\
\text { Caucasian patients. }\end{array}$ & $\begin{array}{l}\text { This study reported that } \\
\text { poor food labelling was } \\
\text { correlated with a lower } \\
\text { ability to adhere to a GFD } \\
\qquad(\mathrm{p}<0.001) .\end{array}$ \\
\hline
\end{tabular}




\subsection{Non-Factors to GFD adherence}

Table 6 presents non-factors to adherence to a GFD in adults with CD. The most common non-factors presented included sex, age, length of time on GFD, and health status.

Sex:

In total, five studies reported that sex was not linked to GFD adherence. This consisted of two case-control studies ( $\mathrm{p}=0.07$ and $\mathrm{P}>0.05)$ (Hopman, Koopman, Wit, \& Mearin, 2009; Barratt, Leeds, \& Sanders, 2011), an analytical, cross sectional study $(p=0.105)$ (Villafuerte-Galvez et al.) and two descriptive studies (Lamontagne et al., 2001, Ciacci, 2003).

Age:

In total, five studies reported that age was not significantly correlated with GFD adherence. These studies consist of a cohort study reported $(\mathrm{p}=0.32)$ (Casella et al, 2012), an analytical, cross sectional study ( $\mathrm{p}=0.8517)$ (Villafuerte-Galvez et al.), and three descriptive studies (Ciacci, 2003; Verrill, Zhang, \& Kane, 2013; Dowd, 2014) . BMI:

Two studies reported that BMI was not significantly correlated to GFD adherence. One study had a case-control design( $\mathrm{p}=0.2)$ (Hopman, Koopman, Wit, \& Mearin). Another analytical study also reported a lack of significant correlation between BMI and GFD adherence (95\% CI OR 0.66 (0.36-1.21)) (Mahadev et al., 2013).

\section{Gastrointestinal symptoms:}

Two studies reported that gastrointestinal symptoms were not significantly correlated with GFD adherence. These two studies consisted of a case-control design 
$(\mathrm{p}=0.23-0.92)$ (Hopman, Koopman, Wit, \& Mearin, 2009), along with an analytical, cross-sectional design (Sainsbury, Mullan, \& Sharpe, 2013 a.). While these two studies found no correaltion, other studies did find significant correlations, as stated in previous sections.

\section{Education:}

Four studies reported that education was not correlated to GFD adherence. A case-control study reported that having a University Education was not shown to lead to a higher adherence to a GFD ( $\mathrm{p}=0.064)$ (Barratt, Leeds, \& Sanders, 2011). An additional analytical study reported that increased education in general did not impact GFD adherence (95\% CI OR 0.74 (0.32-1.71)) (Mahadev et al., 2013). Two descriptive studies reported this as well (Lamontagne et al., 2001; Verrill, Zhang, \& Kane, 2013).

\section{Table 6: Non-factors to GFD adherence}

\begin{tabular}{|c|c|}
\hline Non-Factor & Evidence \\
\hline Sex & $\begin{array}{l}\text { Five studies: Two case-control studies }(\mathrm{p}=0.07 \text { and } \mathrm{P}>0.05) \text {, One analytical, cross sectional } \\
\text { study }(\mathrm{p}=0.105) \text { and two descriptive studies. }\end{array}$ \\
\hline Age & $\begin{array}{l}\text { Five studies: One cohort study ( } \mathrm{p}=0.32) \text {, one analytical, cross sectional study }(\mathrm{p}=0.8517) \\
\text { and three descriptive studies. }\end{array}$ \\
\hline BMI & Two studies: One case-control study $(\mathrm{p}=0.2)$ and one analytical, cross-sectional study. \\
\hline Gastrointestinal Symptoms & $\begin{array}{l}\text { Two studies: One case-control study ( } \mathrm{p}=0.23-0.92) \text { and one analytical, cross-sectional } \\
\text { study. }\end{array}$ \\
\hline Education & $\begin{array}{l}\text { Four studies: One case control study }(\mathrm{p}=0.064) \text {, one analytical, cross-sectional study ( } 95 \% \\
\text { CI OR } 0.74(0.32-1.71) \text { ) and two descriptive studies. }\end{array}$ \\
\hline
\end{tabular}




\subsection{Synthesis of Facilitators and Barriers}

Table 7 summarizes the number of studies that reported each facilitator and barrier that impacted dietary adherence in adults with $\mathrm{CD}$, in addition to the range of LOE for the studies that reported each facilitator or barrier based on the JBI levels of evidence. The LOE scores are based on the JBI levels of evidence. Taking into consideration the magnitude of the significance, the LOE, and the quality of each study based on participant selection, data collection/analysis, and study-biases, the facilitators and barriers with the most supporting evidence at each ecological layer can be identified.

At the individual level, knowledge of $C D / G F D$ was the most significant factor. It was reported by eight studies as a facilitator, and 14 studies reported lack of knowledge of $\mathrm{CD} / \mathrm{GFD}$ as a barrier. The designs of the studies varied greatly, with some studies having strong designs, while other descriptive studies also providing important information through rigorous methodologies.

At the interpersonal level, social support the most significant facilitator (four studies). All of these studies had analytical designs. The most significant barrier presented at the interpersonal level were social fear. While other interpersonal barriers such as social activities were reported by a higher number of studies than social fear was reported, the strength of the designs and methodologies of the studies reporting the barrier of social fear increase its significance.

At the environmental level, Celiac Association membership was the most significant facilitator, reported by five studies, with both strong and weak study designs. Restaurant dining/supermarket shopping were the most significant reported barriers 
(reported by twelve studies). While the majority of these studies had weak designs, a high number of studies reported this barrier. In addition to this, many of these studies were conducted in Canada, as well as having very rigorous methodologies.

At the community level, high society awareness was the most significant (reported by three studies), although the majority of these studies had weak designs. Cultural factors were the most significant barriers at the community level (five studies) with reporting from both analytical and descriptive studies. It is clear that the reporting of facilitators and barriers at the community level are very low, based on the results of the systematic review.

Finally, at the systems level, patient education/ physician-patient communication was the most significant factor reported. Ten studies reported that improved patient education from physician to patient was a facilitator to GFD adherence and seven studies reported that poor patient education/lack of physician-patient communication was a barrier to GFD adherence. These studies varied in their designs and LOE, ranging from an RCT to descriptive studies, including studies reporting from a Canadian context.

Overall, it is important to note that while some studies may have a low LOE, in some instances, a high number of studies may have reported a specific factor. This emphasizes the importance of analysing the rigour of the studies that reported that factor, taking into consideration sample-sizes, potential biases, and data extraction techniques. Also, even if many articles report a factor as being a facilitator or barrier, if the majority of the articles have a low LOE, the facilitator or barrier needs to be interpreted with caution. 


\section{Table 7: Magnitude/LOE of Facilitators/Barriers}

\begin{tabular}{|c|c|c|c|c|c|}
\hline & Individual & Interpersonal & Organizational & Community & Systems \\
\hline Facilitators & $\begin{array}{c}\text { High knowledge of CD/GFD: } \\
8 / 40(20 \%) \\
\text { LOE: }\{1 . c-4 . b\} \\
---- \\
\text { Good Motivation/Self Regulatory } \\
\text { Efficacy: } \\
7 / 40(17.5 \%) \\
\text { LOE: }\{3 . c-3 . e\} \\
---- \\
\text { High education level/income: } 2 / 40(5 \%) \\
\text { LOE: } 3 . e \\
---- \\
\text { Improved Health Status: } \\
2 / 40(5 \%) \\
\text { LOE: }\{3 . c-3 . e\}\end{array}$ & $\begin{array}{c}\text { Social Support: } \\
4 / 40(10 \%) \\
\text { LOE: }\{3 . c-3 . e\} \\
---- \\
\text { Confident in } \\
\text { Practitioner: } 1 / 40 \\
(2.5 \%) \\
\text { LOE: } 3 . \mathrm{e}\end{array}$ & $\begin{array}{c}\text { Celiac Association } \\
\text { Membership: } 5 / 40(12.5 \%) \\
\text { LOE: }\{3 . c-4 . b\} \\
---- \\
\text { Clear labels: } 3 / 40(7.5 \%) \\
\text { LOE: }\{3 . c-4 . b\} \\
---- \\
\text { High Availability of GF } \\
\text { foods: } 2 / 40(5 \%) \\
\text { LOE: }\{3 . e-4 . b\}\end{array}$ & $\begin{array}{c}\text { High society } \\
\text { awareness: } \\
3 / 40(7.5 \%) \\
\text { LOE: }\{3 . e-4 . c\}\end{array}$ & $\begin{array}{c}\text { Improved patient } \\
\text { education from } \\
\text { physician/communication } \\
/ 40(22.5 \%) \\
\text { LOE: }\{1 . \mathrm{c}-4 . \mathrm{b}\} \\
---- \\
\text { Financial } \\
\text { Reimbursement/Food } \\
\text { Subsidies: } 3 / 40(7.5 \%) \\
\text { LOE: }\{3 . c-3 . e\} \\
---- \\
\text { Improved food label- } \\
\text { laws: } 2 / 40(5 \%) \\
\text { LOE: } 4 . b\end{array}$ \\
\hline Barriers & $\begin{array}{c}\text { Lack of knowledge of CD/GFD: } 14 / 40 \\
(35 \%) \\
\text { LOE: }\{3 . c-4 . c\} \\
--- \\
\text { Low intention/Carelessness: } 7 / 40 \\
(17.5 \%) \\
\text { LOE: }\{3 . c-4 . b\} \\
---- \\
\text { Poor taste of GF foods: } 4 / 40(10 \%) \\
\text { LOE: }\{3 . c-4 . b\} \\
---- \\
\text { Low Health Status: } 3 / 40(7.5 \%) \\
\text { LOE: }\{3 . d-3 . e\} \\
---- \\
\text { Low education level/income: } 1 / 40 \\
(2.5 \%) \\
\text { LOE: } 3 . \mathrm{e}\end{array}$ & $\begin{array}{c}\text { Social Activities: } \\
7 / 40(17.5 \%) \\
\text { LOE: }\{3 . d-4 . c\} \\
---- \\
\text { Social Fear: } \\
2 / 40(5 \%) \\
\text { LOE: }\{3 . d-3 . e\}\end{array}$ & $\begin{array}{c}\text { Restaurant } \\
\text { Dining/Supermarket } \\
\text { Shopping: } 12 / 40(30 \%) \\
\text { LOE: }\{3 . \mathrm{d}-4 . \mathrm{c}\} \\
--- \\
\text { Low Affordability of GF } \\
\text { foods: } 4 / 40(10 \%) \\
\text { LOE: }\{3 . \mathrm{e}-4 . \mathrm{b}\} \\
---- \\
\text { Unclear Labels: } 4 / 40(10 \%) \\
\text { LOE: }\{3 . \mathrm{e}-4 . \mathrm{b}\}\end{array}$ & $\begin{array}{c}\text { Specific cultural } \\
\text { factors/low society } \\
\text { awareness: } 5 / 40 \\
(12.5 \%) \\
\text { LOE: }\{3 . c-4 . b\} \\
---- \\
\text { Travelling: } 5 / 40 \\
(12.5 \%) \\
\text { LOE: } 4 . b \\
---- \\
\text { Urban Residence: } 1 / 40 \\
(2.5 \%) \\
\text { LOE: } 3 . \mathrm{e}\end{array}$ & $\begin{array}{c}\text { Poor patient education } \\
\text { from physician/poor } \\
\text { communication: } 7 / 40 \\
(17.5 \%) \\
\text { LOE: }\{3 . c-4 . b\} \\
---- \\
\text { Poor Label Laws: } 4 / 40 \\
(10 \%) \\
\text { LOE: }\{3 . e-4 . b\} \\
--- \\
\text { Lack of financial } \\
\text { reimbursement: } 2 / 40 \\
(5 \%) \\
\text { LOE: } 4 . b\end{array}$ \\
\hline
\end{tabular}




\section{Discussion}

The main objective of this systematic review is to critically appraise and synthesize the facilitators and barriers that adults with CD face that impact their adherence to a GFD. The contributions of the systematic review will be to inform policymakers and health care practitioners as to what possible improvements can be made to prevent these adverse health outcomes resulting from poor adherence to GFD.

The facilitators and barriers extracted from each of the studies were organized and sorted depending on the different layers of an individual's life, in alignment with the categories in a social-ecological model, derived from the bioecological theory of development (Urie Bronfenbrenner, 2007). These include the following layers: Individual, Interpersonal, Organizational, Community, and Systems. Although all the studies were combined together, the impact the study has on the results took into consideration the design and quality of the respective study.

\subsection{Social Ecological Model}

Figure 5 shows a social ecological model that organizes the various facilitators and barriers into ecological layers (based on the data from Tables 2-5) and displays relationships that exist across many layers in an individual's life, and specifically within the health system (McLeroy, Bibeau, Steckler, \& Glanz, 1988). When an individual is diagnosed with $\mathrm{CD}$, they are faced with many facilitators and barriers that impact their ability to adhere to a GFD. This model reports what area of one's life each facilitator and 
barrier fits into, highlighting where improvements can be made to make positive changes. Green-coloured factors represent facilitators and red-coloured factors represent barriers. Yellow-coloured factors show contradictory or unclear results. From the viewpoint of someone with $\mathrm{CD}$, the most evident facilitators and barriers that impact dietary adherence exist at the individual layer. This is because the individual layer represents the factors that are constantly surrounding an adult in their day-to-day life, therefore being the most apparent (Urie Bronfenbrenner, 2007). The interpersonal layer is the next layer that encompasses an individual, as these factors correspond to the relationships that exist in an adult's everyday life. The organizational structure that surrounds an adult with CD represents the next layer, and includes the interactions adults make in their environment and how those end up influencing GFD adherence. The community layer is past the organizational level, and this relates to society's impact on an adult with CD. This layer includes any geographical impacts, as well as cultural differences. The final layer, which is most distant from the individual, is the systems layer. The systems layer includes any laws or policies in place that end up impacting an adult with CD. While this layer is the most distant, it also has the most substantial impact, as the structure of this layer has an impact on every other layer of an individual's life (Urie Bronfenbrenner, 2007). The fact that the systems layer has the most substantial impact on an adult is the reason to introduce policy-level changes to try and impact the overall life of an adult with CD and their ability to follow a GFD. 


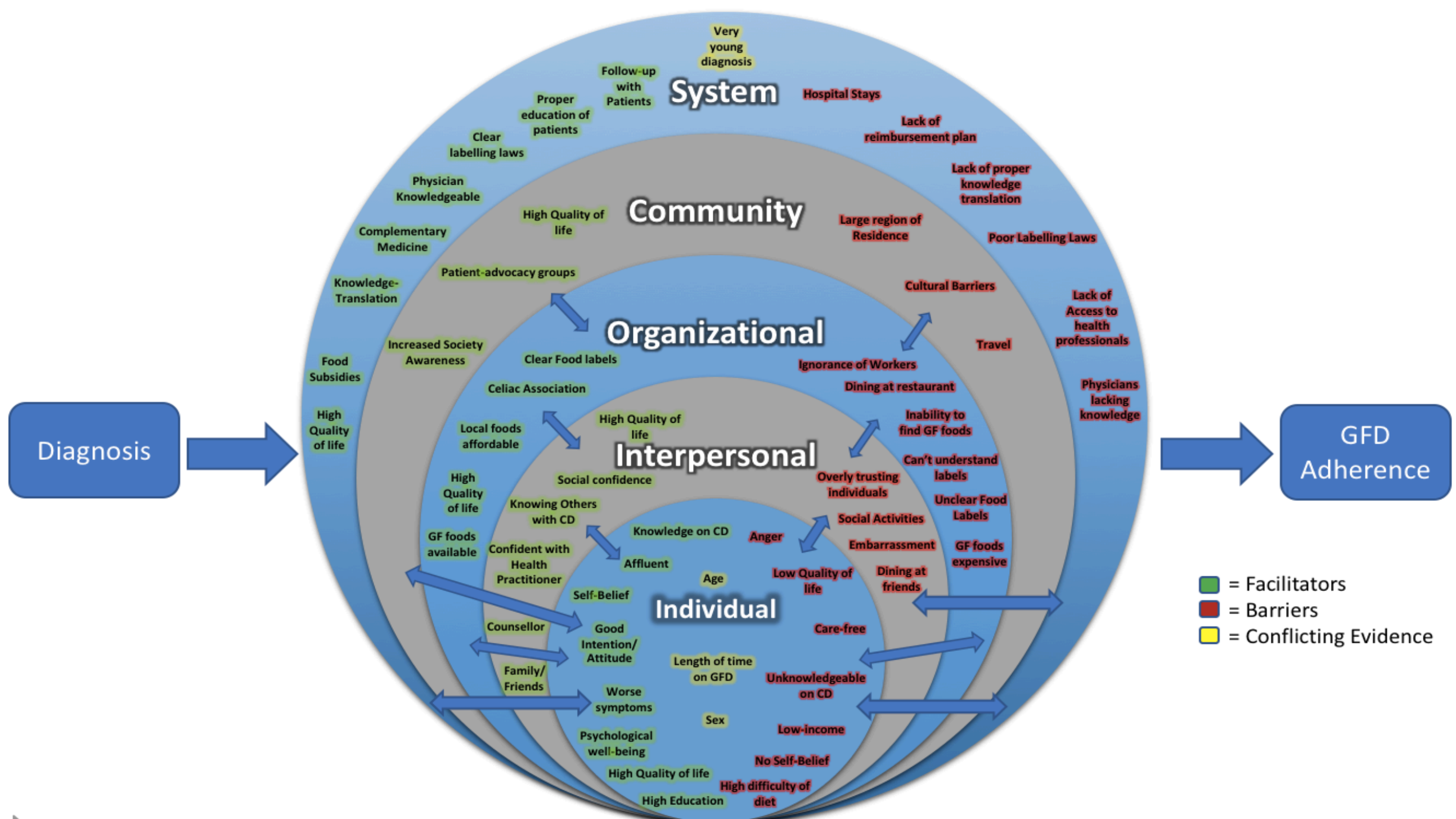

Figure 5. Social Ecological Model: GFD Adherence 


\subsection{Facilitators/Barriers}

The facilitators are factors that increase the ability of an adult with CD to adhere to a GFD, whereas the barriers are factors that lower the ability of an adult with CD to adhere to a GFD. When analyzing how significant a specific facilitator or barrier is, it is important to take into consideration the number of articles that reported the facilitator or barrier as impacting GFD adherence, as well as the level of evidence of the corresponding articles. These facilitators and barriers can fall into multiple ecological layers in the situation where they influence several aspects of an individual's life.

\subsubsection{Individual Facilitators/Barriers}

\section{Education level/Income:}

Multiple studies highlighted that higher education level/income was statistically correlated to an individual's ability to adhere to a GFD (Barratt et al., 2011; Ciacci et al., 2003; Hall et al., 2013). Considering the complexities of CD, it can be expected that individuals who are better educated may have an increased understanding of the vast array of potential adverse health impacts that can exist if an individual does not follow a GFD. Individuals with a high level of education/ high income may also be less likely to be impacted by the high costs associated with GF foods. If an individual cannot afford to purchase these types of foods, they can potentially resort to choosing food that can potentially be contaminated with gluten, lowering their dietary adherence. Additionally, factors such as having access to internet-based support were reported by participants as being able to improve their ability to adhere to a GFD (J. A. Silvester et al., 2016b) given the potential to improve CD awareness. 
While only three studies directly discussed the impact of income on GFD, financial barriers are reported at different ecological layers. In addition, previous research found that a higher level of education/ high income acted as a facilitator to treatment adherence in people with chronic diseases (Hodeib et al., 2015). This helps validate the findings from this systematic review. It is therefore important to consider the education level and income of a patient who is diagnosed with CD when discussing the treatment plan.

\section{Health Status:}

An adult's overall health and their adherence levels to a GFD were shown to be correlated. (Barratt et al., 2011; Casellas et al., 2015). Other studies validated that individuals who had a reduced health-related quality of life score were also less likely to be following a GFD (Hauser et al., 2007). Validated questionnaires determined the ratings of quality of life. Adults' perspectives on their health influenced their adherence level to a GFD. This emphasizes the importance of facilitating constant patientpractitioner communication in order to ensure patients are knowledgeable about their health status. Individuals who reported a higher burden from symptoms due to CD when not adhering to a GFD were statistically more likely to be following a GFD at a stricter level (Dowd et al., 2016). Individuals with CD display a wide variety of symptoms when they ingest gluten. Some individuals experience a much higher level of pain than others. It is understandable that the individuals who experience the most pain when ingesting gluten will put more effort to prevent a dietary mistake from being made. Although all adults with CD will experience some form of an adverse health effect, apparent 
symptoms drive an individual to try and mitigate the adverse health effect versus a silent symptom that someone can easily ignore.

The LOE is very low for most of the articles that reported improved health status as a facilitator and the articles that reported lower health status as a barrier. Most of the studies are limited to having a cross-sectional design. The cross-sectional nature of the studies' designs cannot determine directionality. This makes it unclear whether improved physical and mental health status makes someone more willing to follow a GFD, or if following a GFD increases psychological and physical health status. Further research is vital to determine directionality between health status and adherence levels. Until the future research is conducted, it is inappropriate to assume that health status has an impact on GFD adherence.

\section{Knowledge:}

As shown in the results, correlations exist between individuals' knowledge levels of CD and a GFD and their ability to adhere to a GFD. For example, understanding how the consumption of gluten can have adverse health risks to someone with $\mathrm{CD}$ was linked to a higher ability to adhere to a GFD (Ford et al., 2012). If the severity of CD isn't known, someone may not be willing to put in the effort to follow a GFD (J. L. Black \& C. Orfila, 2011; Ciacci et al., 2003; Rajpoot et al., 2015; Ramirez-Cervantes et al., 2016; J. A. Silvester et al., 2016a; Ukkola et al., 2012). An example of lacking knowledge includes individuals who believe that because they do not have severe symptoms, they should not adhere to a strict, GFD (Hopman et al., 2009; Rose \& Howard, 2014; Shah et al., 2014). Previous systematic reviews on similar topics share a similar finding that 
many individuals diagnosed with $\mathrm{CD}$ do not know the full impact the disease can have on their health (Hall et al., 2009).

Being educated on an illness allows individuals to be able to make a more informed decision on how seriously they take their treatment protocol. The large number of studies that report on facilitators and barriers related to knowledge paired with the wide range of study designs including those with high LOE, it is important to consider knowledge as an important factor. Previously published literature shares that increasing a patient's knowledge on the components of a novel diet due to a chronic disease increases the patient's ability to adhere to that diet (Karaeren et al., 2009). This emphasizes the importance to educate adults properly when they are diagnosed with CD.

\section{Intention/Motivation:}

Adults who had positive intentions when starting out with a GFD were shown to have an increased likelihood in following a GFD correctly (Dowd et al., 2016; Dowd \& Jung, 2017; Ford et al., 2012; Kothe et al., 2015; Muhammad et al., 2017; Sainsbury et al., 2013a; Villafuerte-Galvez et al., 2015). This data was gathered through high ratings of self-regulatory efficacy and an increased level of perceived behavioural control. Studies also showed that those who had poor intention/ a poor level of self-efficacy were also found to have a lower likelihood of following a GFD (Ford et al., 2012; Hall et al., 2013; Ramirez-Cervantes et al., 2016). The belief an individual had, as to whether a GFD would improve their CD outcomes impacted adherence levels. Individuals believing that a GFD will improve CD outcomes correlated to an increase in GFD adherence (Villafuerte-Galvez et al., 2015), and individuals believing that a GFD will not 
improve CD outcomes correlated to them being less likely to follow a GFD (Ciacci et al., 2003; Dowd et al., 2014; Hall et al., 2013; Shah et al., 2014). Individuals who were less careful with maintaining precautions such as informing their cooks about their allergies, were less likely to adhere to a GFD (Biagi et al., 2012).

Emotions existed as potential barriers to GFD adherence. Studies showed that those who were angry about their diagnosis were less likely to be following a proper GFD (Ciacci, Iavarone, et al., 2002). Correlations showed that as people perceived a GFD to be more difficult, their dietary adherence lowered (Lee et al., 2012). Individuals who were worried about planning and cooking GF meals reported making mistakes on their GFD (Lamontagne et al., 2001).

While many of the articles that present facilitators and barriers related to intention/motivation are cross-sectional in nature, some of the studies have stronger designs (ex. Case-control/Cohort). In addition, there are a high number of articles that report these factors. This highlights the importance of taking intention into consideration. All of these factors emphasize the importance of the beginning of one's life after diagnosis. This category links to the previous theme of knowledge. Unprepared individuals with $\mathrm{CD}$ at the beginning of their diagnosis will not have the motivation needed for treatment, and commitment to a GFD will be lower. If individuals are prepared with adequate knowledge to deal with CD appropriately, they can potentially increase their level of intent to maintain their diet, and therefore their future ability to maintain a GFD will be impacted positively. Previously conducted research validates that self-efficacy is a crucial factor in ensuring proper treatment adherence for people with chronic illnesses (Martos-Mendez; Jose, 2016). 


\subsubsection{Interpersonal Facilitators/Barriers}

\section{Confidence in Practitioner:}

Confidence in a practitioner was reported to be correlated to GFD adherence. If patients trust their health care practitioner, they will have a higher belief that their diagnosis was correct and will be more willing to listen to the treatment plan (a GFD) provided to them. A patient's confidence in a practitioner is likely linked to the physician's knowledge on $\mathrm{CD}$, which can impact their ability to prepare an adult for a life with CD. This systematic review only has one study that reports this facilitator and it has an analytical, cross-sectional design. This makes it difficult to place too much emphasis on the impact it has on GFD adherence. However, the literature helps validates this facilitator. A study external to this systematic review reported that placing confidence and trust in one's practitioner was linked to better treatment adherence (Kerse et al., 2004). Therefore, this facilitator should be noted, but taken with caution.

\section{Social Support:}

Individuals with CD reported that it is easier to follow a GFD when they had a high level of support from family and friends (Sainsbury \& Mullan, 2011; Verrill et al., 2013). Some individuals reported that knowing someone else with CD improved their own ability to follow a GFD (J. A. Silvester et al., 2016b). Having increased support from surrounding relationships lowers the risk of isolation and allows individuals to adhere to their health needs without feeling alienated.

There are many instances in peoples' lives where they will rely on other individuals preparing their food for them. Individuals who were confident enough to ask 
the people who were preparing food for them about contamination issues were also shown to be the individuals who were more likely to adhere to a GFD (Sainsbury \& Mullan, 2011). Social confidence allows an individual with CD to communicate their dietary restrictions and helps ensure that those preparing the food take proper precautions.

While the LOE of the studies are not extremely high, 10\% of the studies report social support as being a facilitator. In addition, a previous review validates this facilitator in stating that family/social support can aid an individual in dietary therapy for chronic disease by helping mitigate the stress of a new lifestyle (Miller \& Dimatteo, 2013). It is therefore important to view social support as a potential influence on GFD adherence.

\section{Social Fear:}

It is human nature to act differently when in the presence of others (Moussaid, Kammer, Analytis, \& Neth, 2013). It is common for people with CD to engage in behaviour that can influence their adherence to a GFD. One study highlighted a significant correlation between low levels of adherence to a GFD and embarrassment of having CD and sharing about the need to be on a GFD with others around them (Barratt et al., 2011; Ciacci et al., 2003). Two studies reported social fear as being a barrier to GFD adherence. One of them being an analytical, cross-sectional design and one being a case-control design. It is vital that more research is conducted in order to determine the impact social fear has on GFD adherence. 


\section{Social Activities:}

Individuals with CD shared many concerns they faced with their diet when placed in a social situation. People reported that participating in social activities, including dining outside of the home and spending time with friends had a negative impact on their ability to maintain a GFD (J. L. Black \& C. Orfila, 2011; Lee et al., 2012; Smith, 2009; Zarkadas et al., 2006). Reasons included overly trusting others with food preparation (Sainsbury \& Mullan, 2011) and the overall ignorance of others in understanding the severity of their disease (Rose \& Howard, 2014). It is common for an individual with $\mathrm{CD}$ to feel isolated and different from those around them. The need for inclusivity causes individuals to neglect their illness and risk adverse health outcomes. Social support has a strong influence on dietary adherence. A previous study directly links the lack of proper social support for an individual adhering to a new diet and nonadherence (B. Aggarwal, Liao, Allegrante, \& Mosca, 2010). While most of the studies reporting social activities as a barrier to GFD adherence are descriptive studies, there are also higher studies with strong designs. Considering also that $17.5 \%$ of the articles discuss social activities as impacting GFD adherence, it is an important barrier to consider.

\subsubsection{Organizational Facilitators/Barriers}

\section{Celiac Association Membership:}

At an organizational level, the most significant facilitator mentioned was becoming a member of a celiac association. There are various types of celiac associations, existing at both a national and local level. A narrative study (Rose \& 
Howard, 2014) further found that merely the exposure to others with CD improved the lives of many people with $\mathrm{CD}$, and as a result, improved GFD adherence. Celiac associations allow this exposure to occur. This correlation is reasonable, considering a celiac association can provide the knowledge and support needed for individuals who are going through a substantial, novel experience in their lives. It provides a shared space for individuals to connect and be able to share experiences. It is understandable that being a member of an association would facilitate following a GFD.

\section{Affordability:}

Studies also highlighted the importance of gluten-free foods in their towns being affordable. In many cases, when GF foods are too expensive, cheaper alternatives that are not guaranteed to be GF are selected. This can be linked to the impact that education level and income has on GFD adherence at the individual layer. It is important to note that three out of the four studies that reported affordability of GF foods to be a barrier to a GFD are descriptive in nature. This low LOE impacts the extent this barrier has. While all of the studies have weak designs, financial barriers are reported at other ecological layers in this systematic review and therefore, the barriers reported at the organizational layer should be taken into consideration.

\section{Restaurants/Supermarkets:}

Supporting this finding, when examining the alternate side of GF product availability, studies showed correlations between the inability to find GF products in stores and restaurants to a lower likelihood in following a GFD (J. Black \& C. Orfila, 
2011; Ciacci et al., 2003; Dowd et al., 2014; Lee et al., 2012; Rajpoot et al., 2015; Rose \& Howard, 2014; Smith, 2009; Twist \& Hackett, 1992; Ukkola et al., 2012). Even in situations where there are GF options, participants shared that the poor taste of the items impacted adherence levels to a GFD (Biagi et al., 2012; Lee et al., 2012). Statistically significant correlations were also shown to describe the negative impact that poor taste has on adhering to a GFD (Muhammad et al., 2017; Smith, 2009). In many situations, individuals rely on packaged, processed food items when doing their groceries, as these are simple items to prepare. Unfortunately, these items tend to be more likely to contain gluten. Adults on a GFD reported making more mistakes when the foods they relied on were packaged items (Verrill et al., 2013). Without access to sufficient food items, consumption of products containing gluten is more likely to occur. Availability of GF foods is linked to societies' awareness of CD. In societies where CD is not prevalent or well known, availability of products will unlikely be sufficient.

Many individuals in multiple studies reported that dining establishments were unable to provide a safe experience for them correctly and as a result, they made a mistake on their GFD (Barratt et al., 2011). These mistakes include the risk of crosscontamination (Dowd et al., 2014; Ferster et al., 2015). Overall, when individuals with CD interact with local establishments, they are facing difficulty in getting others to understand what $\mathrm{CD}$ is, the severity of it, and receiving safe, GF options. To mitigate the adverse health impacts from unclear communication, food preparation techniques and staff-knowledge need to be improved.

While many of the studies that reported the negative impact restaurant dining/supermarket shopping has on GFD adherence are descriptive in design and 
therefore have a low LOE, $30 \%$ of the studies in this systematic review noted this barrier. This emphasizes the fact that this barrier needs to be taken into consideration. Future studies with a higher LOE can further support these findings.

\section{Clear Food Labels:}

As stated, gluten is found in multiple, hidden ingredients, making it very difficult to identify GF foods. Individuals report it much easier to find GF foods when the labelling of the products in supermarkets or restaurants are clear (Butterworth et al., 2004; Sainsbury \& Mullan, 2011). If allergens are explicitly listed, individuals will know to avoid those products. Individuals with CD can instantly identify a product as being safe to consume if there is a GF claim on the product.

Individuals who stated they could not understand the labelling in food establishments were correlated with also being less likely to follow a GFD (Ferster et al., 2015; Muhammad et al., 2017). Other studies highlighted that adults with CD who find food labelling confusing, do not adhere as well to a GFD (Ukkola et al., 2012). A study external to this systematic review reported the buying patterns of individuals with dietary allergies. A significant portion of the population does not follow allergy labels correctly, with more than $40 \%$ of individuals still purchasing foods that may contain an allergen they cannot ingest (Marchisotto et al., 2017).

While label issues do seem apparent, only four studies reported unclear food labels as being a barrier and three of them have weak designs. Food labelling should be further examined to determine its potential impact on GFD adherence. 


\subsubsection{Community Facilitators/Barriers}

Society Awareness:

Regarding the facilitators and barriers found at the community level, there was a significant correlation found between society's general knowledge of what gluten and CD are and an adult's ability to maintain a GFD (Dowd et al., 2016; Hall et al., 2013). In more $\mathrm{CD}$ friendly communities, individuals were able to find better options on foods to eat and to communicate their dietary restrictions. In individual communities, patientadvocacy groups exist which provide outlets for individuals with CD to share concerns. Having access to patient-advocacy groups was correlated with an increase in GFD adherence (J. A. Silvester et al., 2016a). Improved society awareness translates to improved knowledge of employees at restaurants and other food establishments. When restaurant employees are knowledgeable about $\mathrm{CD}$, they can provide better options for those with $\mathrm{CD}$, ensuring a GFD is maintained. There is also an increased chance that peers will be more knowledgeable about $\mathrm{CD}$ due to them being a part of a CD-friendly society. This translates to better support from peers to those with $\mathrm{CD}$, furthering a potential increase in GFD adherence. The studies that reported on society's awareness as a facilitator to GFD adherence have a low LOE, with only one study being analytical in nature. While this does not mean that society awareness is not important, future research needs to be conducted to determine if there is a direct impact on GFD adherence.

\section{Geographical Location:}

While one may assume that those living in more rural areas would have a harder time adhering to a GFD, a study identified the opposite, showing that living in a large 
region was associated with a lower likelihood of adhering to a GFD (Lamontagne et al., 2001). In rural settings, there may be fewer options available that are GF, but in urban areas where there are plentiful options, mistakes can be prevalent as individuals can potentially be less careful or workers can be less diligent on ensuring GF foods are not contaminated. The lack of caution can be attributed to other diets that include the removal of gluten for non-CD reasons. It is important to note that only one study reported this and more research is needed to understand the impacts geographical location can have on GFD adherence.

\section{Culture:}

Studies also displayed the impact that cultural factors can play on adherence to a GFD. Being of the South-Asian background was shown to significantly be correlated to a lower likelihood of following a GFD (Butterworth et al., 2004; Muhammad et al., 2017). Individuals also reported that cultural factors lowered their likelihood to follow a GFD (Rajpoot et al., 2015; Ramirez-Cervantes et al., 2016; Twist \& Hackett, 1992). Cultural factors included relatives forcing them to eat foods containing gluten, not understanding how harmful they can be. In certain cultures, where gluten-containing foods make up a significant proportion of the culture's staple foods, adhering to a proper GFD is very difficult. While none of the studies that reported cultural barriers were conducted in Canada, the diversity within the Canadian population increases the generalizability of the results. For example, the degree of difficulty is especially tough in situations where individuals immigrate to a new country, where CD was non-existent in their origin country (Rajpoot et al., 2015). 
In addition to the articles in this systematic review, articles external to this systematic review report similar findings, stating that culture has a significant impact on an individual's ability to maintain a specific diet that is needed for treatment of chronic disease (Foley \& BeLue, 2017). While more research with improved strength of design would provide further evidence to this factor, it still needs to be highlighted as a barrier.

Travelling:

Continuing on the point that different cultures view CD and a GFD differently, many articles reported that those with CD face many tough challenges when they are travelling (Barratt et al., 2011; Dowd et al., 2014; Ferster et al., 2015; Rajpoot et al., 2015; Smith, 2009). Travelling can be stressful due to several factors including not speaking the same language or lack of that country's familiarity on CD. Travelling also exposes individuals to the cultural barriers that may be present in other geographical locations. However, all five studies that reported travelling as a barrier to GFD adherence are descriptive in nature. This limits the ability to emphasize travelling as an important factor in GFD adherence.

\subsubsection{System Facilitators/Barriers}

Physician-Patient Knowledge Communication/ Follow-up:

The most prominent system-level barrier found in the systematic review was the lack of knowledge that individuals recently diagnosed with $\mathrm{CD}$ had with their disease and the composition of a GFD. While this is also an individual barrier, this is a systematic issue. At a system level, this lack of knowledge stems from patient-practitioner 
communication. This lack of knowledge was significantly correlated with lower adherence to a GFD (Lee et al., 2012; Rajpoot et al., 2015; Shah et al., 2014; J. A. Silvester et al., 2016a; Ukkola et al., 2012). Several studies showed that providing recently diagnosed patients with detailed descriptions of what CD was and what a GFD entailed, correlated to them being more likely to be able to accurately follow a GFD (Butterworth et al., 2004; Dowd et al., 2014; Lamontagne et al., 2001; Villafuerte-Galvez et al., 2015; Zarkadas et al., 2013). These studies' findings emphasize that there needs to be proper communication channels open with a patient once they are diagnosed, to make sure they entirely are aware of the extent of their disease and that they know how to handle their diet correctly. One RCT included in this systematic review showed high efficacy regarding patient education for individuals diagnosed with CD. These individuals completed an online intervention, which provided lots of information on CD and a GFD. After the intervention, the individuals were significantly more likely to adhere to a GFD than the control group who did not receive the intervention (Sainsbury et al., 2013b).

This systematic review found that many individuals are left to manage their disease on their own without support. At an early stage of following a GFD, it is imperative that individuals have a support system and accurate knowledge on how to progress with their new, life-changing diet. This lack of communication continues postdiagnosis. Studies have shown that when adults with $\mathrm{CD}$ are looking for aid from a practitioner, they are not always readily available, leading to lower adherence rates to a GFD (Ferster et al., 2015). Some individuals reported receiving improper medical advice that suggested it was okay to ingest gluten on occasion (Hopman et al., 2009). People 
also reported that when staying in a hospital, they were given foods that contained gluten (Zarkadas et al., 2006). Hospital staff, whom one assumes would have the highest knowledge-level on dietary restrictions, can negatively impact GFD adherence.

Many studies reported on the benefit of consistent follow-up with practitioners, post-diagnosis. Correlations existed that showed that when individuals had constant follow-up appointments with their physicians (whether that be a general practitioner or a specialist), they were more likely to continue adhering to a strict GFD (Butterworth et al., 2004; Hall et al., 2013; Hughey et al., 2017; Zarkadas et al., 2006). On top of statistical data, studies (J. A. Silvester et al., 2016b; Zarkadas et al., 2006) highlighted that being able to access practitioners when needed, allowed adults with $\mathrm{CD}$ to increase their knowledge on $\mathrm{CD}$ and therefore better adhere to a GFD. Considering there are no mandated follow-up appointments set in Canada, this is a vital issue to be examined at a systems level.

$25 \%$ of the articles in this systematic review report improved patient education from physician to patient as being a facilitator to GFD adherence and $17.5 \%$ of the studies in this systematic review report that poor patient education from physician to patient acts as a barrier to GFD adherence. Many of these studies have a high LOE. Also, a previously conducted meta-analysis validates these findings, showing substantial evidence that links strong patient-physician communication with better treatment adherence (Zolnierek \& Dimatteo, 2009). This emphasizes patient education/physicianpatient communication as a significant factor that impacts GFD adherence and this needs to be examined when attempting to improve GFD adherence. 


\section{Financial Reimbursement:}

Finances clearly impact multiple layers in an adult's life. A lack of financial reimbursement acts as a barrier to adhering to a GFD at a systems level. While certain individuals had access to reimbursement plans to help offset the high costs of GF foods, the lack of adequate reimbursement provided by the government lowered the ability to follow a GFD (Ferster et al., 2015; Twist \& Hackett, 1992). Correlations were shown between the supply of prescription foods, and an improved ability to maintain a GFD (Hall et al., 2013; Muhammad et al., 2017). Individuals who receive these subsidies do not need to worry about determining safe foods, as they have options laid out for them. In many countries, physicians provide prescriptions for various GF foods that individuals with CD have access to (Pinto-Sanchez et al., 2015). These foods are discounted and ensured to be safe, creating peace of mind concerning safety and affordability for those with CD.

Overall, three studies reported that financial reimbursement/food subsidies are a facilitator to GFD adherence and two studies reported that the lack of financial reimbursement acts as a barrier to GFD adherence. All of these studies were conducted in the UK. This emphasizes the importance to examine the process and context of financial reimbursement and food subsidies in the UK in order to try and determine if this is applicable in Canada. The LOE of these studies vary and more research would clarify the full extent of the impact of financial compensation/food subsidies. With the evidence provided of financial barriers presented at different ecological levels, it can still be assumed that financial compensation/food subsidies do have an impact on GFD adherence. 


\section{Poor Label-Laws:}

It is important to note that food-labelling issues also exist at a systems level (Ferster et al., 2015; Muhammad et al., 2017; Ukkola et al., 2012). Ingredients that contain gluten are extensive. There are also many claims of potential contamination with gluten on food items. While food labels impact the organizational level of an individual's life, they stem from systematic issues. Food label laws are put in place to ensure the proper health of citizens, and it is crucial that is addressed to achieve proper health. Addressing the systems-level barrier will also impact the organizations that sell food items to those with CD. With that understood, the majority of the studies that report poor label laws as a barrier to GFD adherence have a low LOE, which limits the extent to which they can be deemed a true barrier to GFD adherence. Canadian law now has stricter guidance for foods that are labelled as GF. The enhanced label-law helps assure that if a food item states it is GF, that it actually is (Agency, 2018). It is important to note that this is only the case for a product that has a GF claim, and not the case for the majority of food products purchased by those with CD. Further research can help justify if additional label-laws can further improve dietary adherence.

\subsection{Non-factors/Inconsistent Factors}

Age/Length of time on GFD

An individual's age, as well as how long they were on a GFD seemed to have mixed results throughout the various studies as to the relationship it has to GFD. Some studies highlighted that age had no impact on dietary adherence (Casella et al., 2012; Dowd \& Jung, 2017; Verrill et al., 2013), whereas some displayed that older individuals 
were more likely to adhere to a GFD (Ford et al., 2012; Hall et al., 2013; Lamontagne et al., 2001). Some studies showed correlations between an increase in GFD adherence for those who were more recently diagnosed (Dowd \& Jung, 2017), whereas some studies reported a correlation between increased dietary adherence and a longer time since diagnosis (Ciacci, Iavarone, et al., 2002; Zarkadas et al., 2006; Zarkadas et al., 2013). One study that explains this discrepancy reported that an increased time since diagnosis could act as a facilitator in the sense that people are more aware of the food items they must avoid. However, it can also act as a barrier in the sense that people tend to purposely consume gluten in situations where they are comfortable taking risks since they have been on the GFD diet for a long time (Dowd et al., 2014).

While the impact of length of time since diagnosis may be inconclusive, being diagnosed as a child instead of an adult may have more impact on dietary adherence. Hogberg reported that diagnosing individuals at a very young age (before the age of four) led to them being better prepared at continuing on a GFD throughout their life (Hogberg et al., 2003). Based on its critical appraisal, this study was deemed to have poor, overall quality which lowers the weight it carries. It is still essential to consider this study, as it examines an crucial factor. In some countries, laws are in place that mandate infants be tested for $\mathrm{CD}$ when they are at risk. Initializing this in Canada, can facilitate the process of adhering to a GFD, and prevent health complications from occurring later in life, and from an economic perspective, prevent wasting money due to these adverse health effects.

Further studies need to be conducted to examine the potential impact that age and time on a GFD have on an adult's adherence level to a GFD. 


\section{Gender}

Some studies reported that females were more likely to adhere to a GFD than males (Ciacci et al., 2003; Sainsbury et al., 2013a; Verrill et al., 2013), whereas many showed no significant correlation between sex and dietary adherence (Hopman et al., 2009; Lamontagne et al., 2001; Villafuerte-Galvez et al., 2015). No studies reported that males were better able to adhere to a GFD. It cannot be stated with any confidence that gender impacts GFD adherence.

\section{Psychological/Physical Health Status}

While some studies showed correlations and statistical significance between GFD adherence and an individual's health status, it is important to note that some studies did not show this relationship. Non-correlations were shown between an individual's physical health status and adherence to a GFD (Hauser et al., 2007; Hopman et al., 2009). Non-correlations were also shown between an individual's psychological health and their adherence to a GFD (Ford et al., 2012; Hauser et al., 2007). The inconsistency of these findings paired with the weak designs mitigates any confidence in stating that health status impacts GFD adherence.

\subsection{Comparison to previous literature}

When comparing the results of this systematic review to previous research on dietary adherence in other chronic conditions mentioned earlier, it is clear that there are many shared facilitators and barriers. Cultural barriers impacted dietary adherence for multiple chronic disease in addition to $\mathrm{CD}$, including type-II diabetes mellitus and 
Cardiac health issues. Another common barrier to dietary adherence among multiple chronic illnesses is the inability to identify and find proper foods that align with the specific diet. Relating to this, financial issues represented barriers to purchasing foods that align with proper diet for the specific chronic disease. A common barrier that was shared between CD and type-II diabetes mellitus was ineffective communication between practitioners and the patients with the chronic diseases. On the other hand, literature shows that having confidence in practitioners acts as a facilitator to dietary adherence. It is evident that there are many shared factors that influence dietary adherence across various chronic illnesses.

When comparing the results of this systematic review to results found from previous literature on potential facilitators and barriers to GFD in people with $\mathrm{CD}$, there are also many similarities. Common facilitators found between this systematic review and previous literature include: confidence in practitioners, high education level/ high income, and adequate support from friends/family. Common barriers include: Poor patient education, low intention/motivation, and high costs of GF foods.

While many facilitators and barriers are consistent to previous research on $\mathrm{CD}$ and other chronic diseases, certain novel facilitators and barriers were captured in this systematic review. This includes the positive influence that membership of celiac associations has to adherence to a GFD. This also includes the negative impact that social activities/social fear can have to GFD adherence.

While highlighting novel facilitators and barriers, this systematic review shares many common results to reviews that examined the facilitators and barriers to dietary adherence to other chronic diseases as well as previous literature that reports facilitators 
and barriers to GFD adherence to those with CD. This helps strengthen the overall evidence of the results of this systematic review.

\subsection{Limitations}

\subsubsection{Biases within empirical studies}

Selection bias: The individuals, who are willing to take part in a CD study, are more likely to follow a GFD, in comparison to someone who does not take their diagnosis seriously. Selection bias could impact the results. However, the facilitators and barriers that impact the higher-adhering population will ultimately impact the population that struggles even further with adherence.

Attrition bias: There is a high chance that if someone asks an individual a question about their adherence to a GFD and he or she do not follow a GFD carefully, he or she is more likely to leave the study. Therefore, the population may not representative. However, many of the tests that assess dietary adherence do not directly ask an individual if they consume gluten or not. This lowers the risk that the individuals will drop out of the studies.

Performance bias: Individuals are more likely to answer questions the way that they believe the interviewer wants them to. The performance bias could result in individuals who do not follow a GFD, stating that they do follow a GFD. Considering that many barriers were still found throughout the studies, this bias shows not to be overly significant. 


\subsubsection{Limitations}

Despite the comprehensiveness of this systematic review and attention given to the nature of the empirical studies included, there is a risk of potential bias introduced by the fact that only one researcher was mostly involved the search and extraction steps. The limitation could potentially lead to the exclusion of specific studies that may have been included in the situation where a second researcher was conducting the systematic review. Nevertheless, this limitation may be mitigated by the fact that the inclusion and exclusion criteria set a strict process of screening the articles. In addition, the rigor in the steps followed in the development of this systematic review, including the data extraction sheet, along with the inter-rater reliability that was calculated between the two researchers also helps mitigate these risks. In addition to the search and extraction, only one author was responsible for coding the facilitators and barriers into the various ecological categories. This risk of bias is also mitigated by having a second researcher code a portion of the total articles. The definitions of the different ecological layers are very strictly defined, allowing for the process of categorization to be facilitated.

In the coding and data extraction from the empirical studies, the researcher relied on the information presented by the authors of the included studies, which may have not always been complete or detailed. For example, if an article did not state the specific design of the study, the content of the article was examined to assess the correct study design.

The only studies included in the systematic review are in English. While English published articles comprise the majority of studies, there is a chance that specific studies in the systematic review are not included due to another language of publication. This 
limitation is mitigated by the fact that many international studies that were found throughout the search process were also published in English.

Throughout analyzing the studies included in the systematic review, there were certain assumptions made. There is an assumption that the diagnosis of CD for the individuals in the studies is through a valid process; either a serological test or an upperintestinal endoscopy. Some of the studies may not include the method of the participants' diagnoses. The lack of clarity means that there is potential that an individual self-reports as having $\mathrm{CD}$, when they may not have a valid diagnosis. There is also an assumption that the information shared through interview or survey is conveyed truthfully, without the previously mentioned biases.

\subsubsection{Meta-biases}

There is a risk of publication bias without scanning grey literature. The systematic review has the potential to leave out any studies not published due to potentially being deemed non-informative.

It is important to note that reporting bias will also potentially occur in the studies included in the systematic review. Non-significant outcomes can be left out. However, many articles captured non-factors. The presence of non-factors suggests that publication and reporting bias may not have a substantial impact on the results of the systematic review.

\subsection{Health system implications/recommendations in Canada}

It is evident that $\mathrm{CD}$ is a prominent issue in Canada. This is highlighted by the increase in diagnosis of $\mathrm{CD}$, as well as the low GFD adherence rates in Canada. There 
has been an increase in studies that look at facilitators and barriers to a GFD in an attempt to understand how to improve dietary adherence. Having access to this information helps guide where changes can be made. This systematic review helps organize and synthesize this information in a novel way that facilitates the understanding of facilitators and barriers that impact adults with CD attempting to adhere to a GFD. The facilitators and barriers with the highest magnitude, based on the frequency of articles reporting them, along with the LOE of those studies, highlighted where changes could be made to make the largest, positive impact on GFD adherence. Based on the Bioecological theory of development and Social Ecological model, introducing policy changes at a health systems level will create the best opportunity to impact all of the areas in one's life. If policy changes remove barriers and introduce facilitators at a health systems level, the barriers and facilitators at the community, organizational, interpersonal, and individual levels should also be impacted (Urie Bronfenbrenner, 2007). This domino effect has the potential to drastically improve the health status of adults with CD by improving dietary adherence. It is important to be aware of the immense levels of difficulties that exist when attempting to make policy-level changes; while potentially having the most impact.

Based on the literature, it is clear that the most significant system-level factor is patient education. Individuals are not adequately prepared to follow a GFD after being diagnosed with CD. This lack of proper communication between health care practitioners and patients leads to the creation of a variety of other barriers at other levels in an individual's life. This can be exemplified by the studies reporting when symptoms of gluten ingestion are severe, individuals are more likely to adhere to a GFD. It is probable that these individuals are not educated sufficiently to comprehend the more 
severe, possibly hidden complications that will result from ingesting gluten, no matter what physical symptoms are presented. As shown by an RCT included in this systematic review, introducing a form of training intervention for an adult with CD immediately after diagnosis can help ensure that the individual is prepared to commence their novel lifestyle. It is important to understand that changing physician's behavior is very difficult to achieve. It is vital that any potential changes made to increase patient education are as non-invasive as possible to physicians. Considering the vast amounts of supports and services available to Canadian's with CD highlighted in this systematic review, such as: Celiac Associations, dieticians, and patient-advocacy groups, it is essential that at diagnosis, practitioners help connect their patients to these services. Any interventions can be done through these other services in order to mitigate the impact on the physician. Furthering this, it should be mandated that a follow-up appointment is set to assess treatment progression and address any patient concerns that exist. Literature reviews have shown that positive health-outcomes drastically improve when there is adequate communication set between patients and their practitioners (Ha \& Longnecker, 2010).

Based on the results from the systematic review, many studies at various ecological layers reported finances being a factor in GFD adherence. Introducing compensation for those with CD who are forced to purchase expensive, GF products, can increase dietary adherence. While some small tax credits are available to Canadians with $\mathrm{CD}$, these are not sufficient. A form of compensation can be income-adjusted to specifically target those who have lower income. This is vital, as this population is struggling the most with adhering to a GFD, as shown in this review. In areas where there is financial compensation, rates of GFD adherence were shown to be much higher. 
Forms of compensation can include prescriptions of safe, GF food for those who need assistance. Other nations, such as the UK, implement this model (Kurien, White, Trott, \& Sanders, 2016). While tax-payers' money will need to be utilized to implement these forms of subsidies, the prevention of long-term, adverse health effects will compensate for any immediate monetary loss. It is important to understand that there are great difficulties when trying to implement tax-rebates nation-wide. There is a plethora of factors that need to be considered before any tax-rebate can be introduced. Further research needs to be conducted to determine exact cost-savings potential by introducing these changes.

While the literature showed conflicting information on whether the length of time on a GFD was correlated to GFD adherence, a number of studies indicated that diagnosing individuals at a very young age leads to the patients being more likely to adhere to a GFD. The Canadian health care system should look into more proficient ways of ensuring those at risk get tested for $\mathrm{CD}$ at a very young age. Even in the situation where diagnosing early does not improve GFD adherence rates, diagnosing an individual with CD early still mitigates potential years of adverse health effects, and therefore negatively impacting Canada's healthcare system.

It is a very strenuous process to check if a specific food is GF. Reading through every ingredient in every product is very tedious. Not only this, but gluten is present in a wide variety of ingredients, some of which, people with $\mathrm{CD}$ are unaware of. The complexity of gluten-containing ingredients creates a lack of GFD adherence. Introducing better labelling laws for those who have allergies, including those with CD, will help clarify if products are safe for consumption. While the evidence provided in 
this systematic review should be supported by additional, future research, it is still imperative that this factor is examined. International allergy labelling laws differ greatly. In some countries, all potential sources of gluten are required to be present on all food items, whether in a grocery store or a restaurant (Gendel, 2012). Making allergens clear facilitates the process of choosing foods that are safe. While Canada has strict guidelines for making gluten-free claims on foods, the vast majority of foods purchased by those with $\mathrm{CD}$ do not have a gluten-free claim, even though they are safe for consumption. If a food item in Canada contains one of the top eight allergens, it must be stated (Agency, 2018). This is the case for wheat, which contains gluten. However, there are many gluten-containing ingredients other than wheat which are not always explicitly stated. Adjusting laws to explicitly state any gluten-source in a food item will simplify the process of selecting safe GF foods.

A GFD is imperative to someone with CD to ensure that they have no adverse health outcomes. Based on the literature, there are a wide variety of facilitators and barriers that exist. Based on the bioecological theory of development, each of these facilitators and barriers exists at a different layer of one's life. These layers include individual, interpersonal, organizational, community, and systems. While all of these levels are connected, the systems level is the top-level and has a direct impact on every other level (Urie Bronfenbrenner, 2007). If the barriers found at this level are improved and if the facilitators found at this level are incorporated into the lives of those with CD, the levels of GFD adherence should be improved, thereby lowering the adverse health outcomes individuals with CD will face, and thereby lowering the usage of health systems resources. 
Figure 3 describes an example as to how improvements made at a systems level can be made to the life of an adult with CD to potentially improve the other areas of their life, ultimately with the goal of improving their adherence to a GFD. The bioecological theory of development and social-ecological model emphasize that the system-level factors in an individual's life have an impact on all of the other ecological layers within someone's life. Making changes at this level can therefore, have the largest impact on GFD adherence levels in adults with CD. While making changes at the other areas of one's life can still lead to improvements in GFD adherence, the root of the majority of these facilitators and barriers lies within the system level.

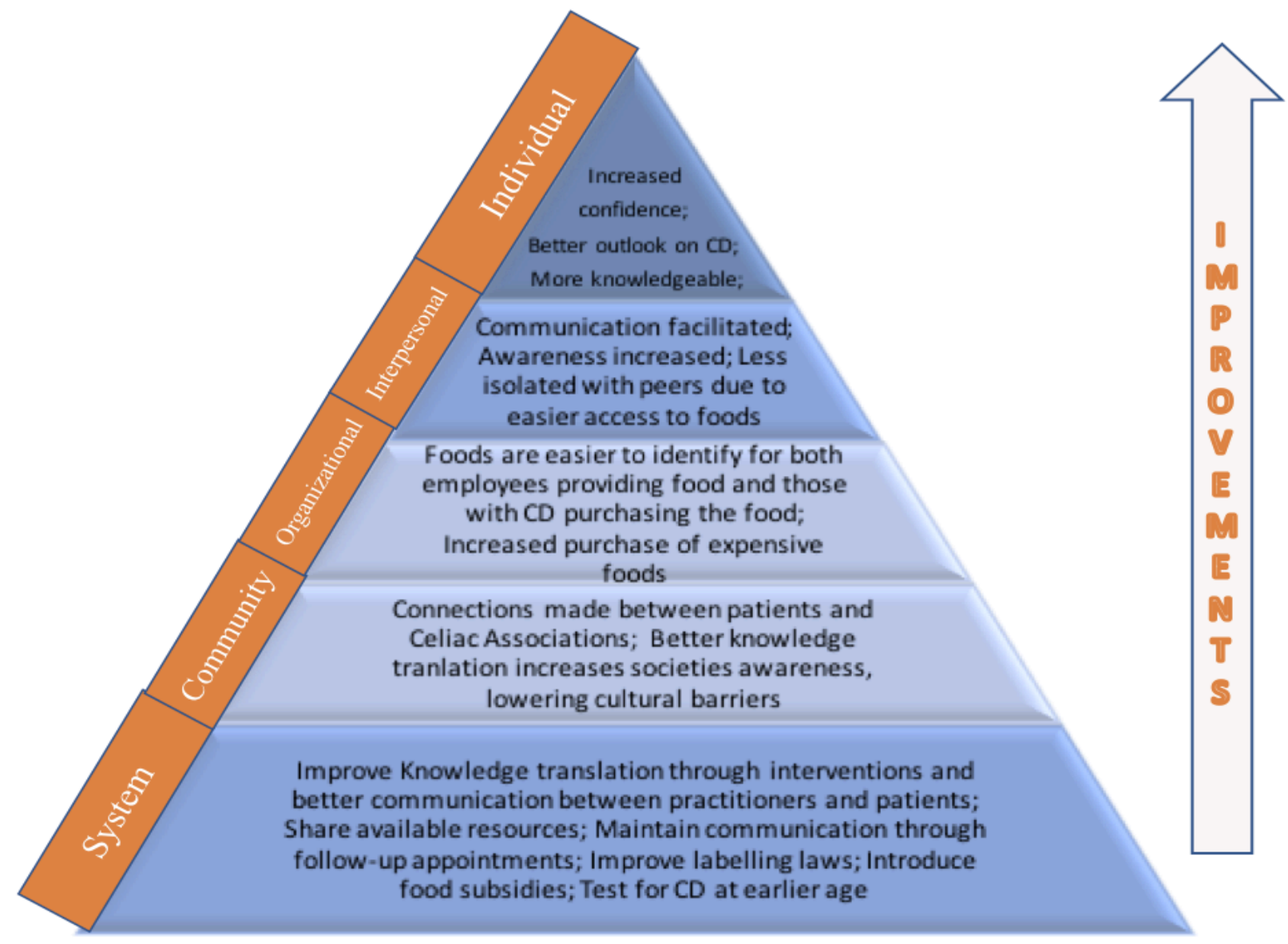

Figure 3. Improvements at various ecological layers 


\subsection{Impact/Next Steps}

Overall, creating an up-to-date systematic review on the topic of facilitators and barriers that will impact an adult with CD and their ability to maintain a GFD is of importance at a broader, health systems level. Understanding the existing barriers will provide decision-makers with knowledge on where to target aid and future research. Identifying the existing facilitators will provide decision makers with examples of how to improve adherence.

In this systematic review, the facilitators and barriers to GFD adherence among adults with CD are organized into a social ecological model that helps portray a clear picture of what an adult with $\mathrm{CD}$ is faced with following diagnosis. When assessing GFD adherence, the ecological studies in this systematic review refer to GFD adherence levels as ordinal data, meaning that someone's dietary adherence rate can be slightly improved to a level that is not perfect, but still better than it was. While an individual's adherence level to a GFD needs to be perfect, this information is still important to note. Factors that help improve GFD adherence, even if only slightly, need to be highlighted in order to understand ways to potentially achieve perfect adherence to a GFD. Targeted, future research onto specific facilitators and barriers highlighted in this systematic review is encouraged in order to provide additional evidence and support. Examples of future research include conducting an empirical study that examines the impact of implementing a program that increases patient-education. GFD rates can be calculated before the program is completed as well as after the program is completed, including assessing the long-term effects that the program has on GFD adherence. Studies need to be conducted that examine physician knowledge-levels of $\mathrm{CD}$ and the impact that improving the 
knowledge levels of CD/GFD in physicians can have on the GFD adherence rates of people with CD. Future studies need to be conducted on assessing the impact of financial compensation and label-laws. These future studies need to have a high LOE in order to support the currently-available body of evidence. Finally, future research needs to be conducted with rigorous methodology and a high LOE that assesses the impact that restaurant/supermarket awareness and customer-experience has on GFD adherence rates in adults with CD. While it is clear there are issues at this organizational level, further evidence is needed to support these claims. This additional research will help enhance awareness and knowledge on what impacts the GFD adherence of an adult with CD in Canada, creating an opportunity to improve the health outcomes of the CD population. Facilitators and Barriers presented in this systematic review also potentially impact individuals who are facing dietary restrictions due to other chronic illnesses in their daily lives.

\section{Protection of Human Rights}

There were no threats to confidentiality or anonymity raised through the systematic review. All ethical requirements are maintained within each included article. Therefore, no ethical approval is necessary to conduct this research.

\section{Conflict of Interest}

This systematic review has been completed under supervision from the University of Ottawa to complete the requirements of a thesis for an MSc. in Health Systems. There is no conflict of interest as there is no external funding provided to complete the systematic review. 


\section{2. $\underline{\text { Appendix }}$}

\subsection{Appendix 1: Search Strategies}

\section{Ovid Medline Search Strategy:}

1. Celiac Disease/

2. celiac disease.tw, kw.

3. coeliac disease.tw, kw.

4. celiac.tw,kw.

5. coeliac.tw,kw.

6. gluten sensitive entero*.tw,kw.

7. 1 or 2 or 3 or 4 or 5 or 6

8. Patient Compliance/

9. patient compliance.tw,kw.

10. adher*.tw,kw.

11. nonadher*.tw,kw.

12. maint*.tw,kw.

13. compliance.tw,kw.

14. noncompliance.tw,kw.

15. coopera*.tw, kw.

16.8 or 9 or 10 or 11 or 12 or 13 or 14 or 15

17. Diet, Gluten-Free/

18. gluten free diet.tw,kw.

19. Diet/ 
20. treatment.tw, kw.

21. gluten.tw,kw.

22. diet*.tw,kw.

23.17 or 18 or 19 or 20 or 21 or 22

24. 7 and 16 and 23

PsychInfo Search Strategy:

1. Celiac Disease/

2. celiac disease.tw.

3. coeliac disease.tw.

4. celiac.tw.

5. coeliac.tw.

6. gluten sensitive entero*.tw.

7. 1 or 2 or 3 or 4 or 5 or 6

8. Treatment Compliance/

9. adher*.tw.

10. nonadher*.tw.

11. maint*.tw.

12. compliance.tw.

13. noncompliance.tw.

14. coopera*.tw.

15.8 or 9 or 10 or 11 or 12 or 13 or 14

16. Diets/ 
17. gluten free diet.tw.

18. diet*.tw.

19. gluten.tw.

20. treatment.tw.

21.16 or 17 or 18 or 19 or 20

22. 7 and 15 and 21

\section{Embase Search Strategy:}

1. celiac disease/

2. celiac disease.tw,kw.

3. coeliac disease.tw, kw.

4. celiac.tw,kw.

5. coeliac.tw, kw.

6. gluten sensitive entero*.tw,kw.

7. 1 or 2 or 3 or 4 or 5 or 6

8. patient compliance/

9. patient compliance.tw,kw.

10. adher*.tw,kw.

11. nonadher*.tw,kw.

12. maint*.tw,kw.

13. compliance.tw,kw.

14. noncompliance.tw,kw.

15. coopera*.tw,kw. 
16.8 or 9 or 10 or 11 or 12 or 13 or 14 or 15

17. gluten free diet/

18. gluten free diet.tw,kw.

19. diet/

20. treatment.tw,kw.

21. gluten.tw,kw.

22. $\operatorname{diet}^{*} \cdot \mathrm{tw}, \mathrm{kw}$.

23. 17 or 18 or 19 or 20 or 21 or 22

24.7 and 16 and 23

CINAHL Search Strategy:

1. (MH “Celiac Disease”)

2. celiac disease

3. coeliac disease

4. celiac

5. coeliac

6. gluten sensitive entero*

7. 1 or 2 or 3 or 4 or 5 or 6

8. (MH "Patient Compliance")

9. patient compliance

10. adher

11. nonadher

12. maint 
13. compliance

14. noncompliance

15. coopera*

16.8 or 9 or 10 or 11 or 12 or 13 or 14 or 15

17. (MH "Diet, Gluten-Free")

18. gluten free diet

19. (MH "Diet")

20. treatment

21. gluten

22. $\operatorname{diet}^{*}$

23.17 or 18 or 19 or 20 or 21 or 22

24. 7 and 16 and 23 
12.2. Appendix 2: Coding Scheme for Included Studies

\section{Barriers/Facilitators to GFD: Adult with CD Thesis Coding Scheme}

Original Date:

Dates Revised:

Title:

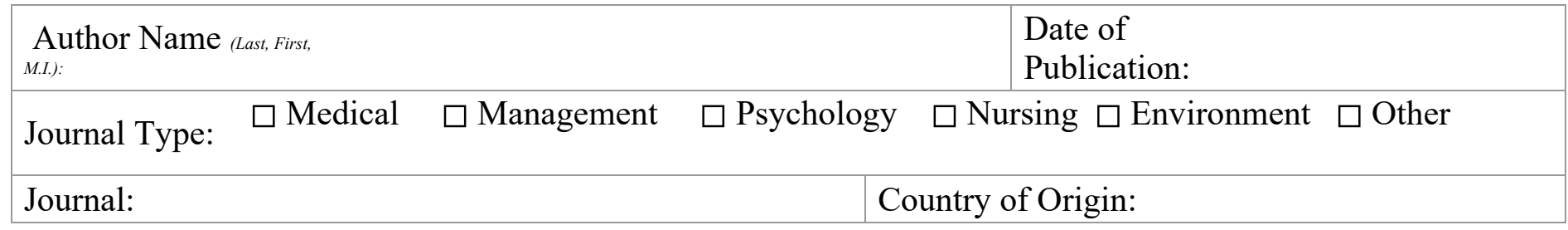

\section{Study Characteristics}

\section{Main Objective of the Study}

Study Design:

Study Environment

(confounders):

Inclusion Criteria

\section{Measurement:}

\section{Intervention:}

Reports facilitators or barriers

Study in English

Other

\section{Participants}

\begin{tabular}{|l|l|l|l|l|}
\hline Age: & Range: & Mean: & $\begin{array}{l}\text { M: } \\
\text { F: }\end{array}$ & GFD Adherence: \\
\hline Groups: & $\begin{array}{l}\text { Control Group } \\
\square \mathrm{Y}\end{array}$ & $\begin{array}{l}\text { Control Population } \\
\text { size: }\end{array}$ & $\begin{array}{l}\text { Experime } \\
\text { ntal }\end{array}$ & Additional Information: \\
\hline
\end{tabular}




\begin{tabular}{|l|l|l|l|}
\hline$\square \mathrm{N}$ & $\begin{array}{l}\text { Population } \\
\text { size: }\end{array}$ & \\
\hline
\end{tabular}

\begin{tabular}{|c|c|c|}
\hline \multicolumn{3}{|c|}{ List of Facilitators } \\
\hline \multirow[t]{6}{*}{$\begin{array}{l}\text { Significant? } \\
\text { (Magnitude) }\end{array}$} & Facilitator & Category \\
\hline & & $\begin{array}{l}\square \text { Individual } \square \text { Interpersonal } \square \text { Organizational } \\
\square \text { Community } \square \text { System } \square \text { Other }\end{array}$ \\
\hline & & $\begin{array}{l}\square \text { Individual } \square \text { Interpersonal } \square \text { Organizational } \\
\square \text { Community } \square \text { System } \square \text { Other }\end{array}$ \\
\hline & & $\begin{array}{l}\square \text { Individual } \square \text { Interpersonal } \square \text { Organizational } \\
\square \text { Community } \square \text { System } \square \text { Other }\end{array}$ \\
\hline & & $\begin{array}{l}\square \text { Individual } \square \text { Interpersonal } \square \text { Organizational } \\
\square \text { Community } \square \text { System } \square \text { Other }\end{array}$ \\
\hline & & $\begin{array}{l}\square \text { Individual } \square \text { Interpersonal } \square \text { Organizational } \\
\square \text { Community } \square \text { System } \square \text { Other }\end{array}$ \\
\hline \multicolumn{3}{|c|}{ List of Barriers } \\
\hline \multirow[t]{6}{*}{$\begin{array}{l}\text { Significant? } \\
\text { (Magnitude) }\end{array}$} & Barrier & Category \\
\hline & & $\begin{array}{l}\square \text { Individual } \square \text { Interpersonal } \square \text { Organizational } \\
\square \text { Community } \square \text { System } \square \text { Other }\end{array}$ \\
\hline & & $\begin{array}{l}\square \text { Individual } \square \text { Interpersonal } \square \text { Organizational } \\
\square \text { Community } \square \text { System } \square \text { Other }\end{array}$ \\
\hline & & $\begin{array}{l}\square \text { Individual } \square \text { Interpersonal } \square \\
\text { Organizational } \quad \square \text { Community } \square \text { System } \square \\
\text { Other }\end{array}$ \\
\hline & & $\begin{array}{l}\square \text { Individual } \square \text { Interpersonal } \square \\
\text { Organizational } \quad \square \text { Community } \square \text { System } \square \\
\text { Other }\end{array}$ \\
\hline & & $\begin{array}{l}\square \text { Individual } \square \text { Interpersonal } \square \text { Organizational } \\
\square \text { Community } \square \text { System } \square \text { Other }\end{array}$ \\
\hline \multicolumn{3}{|l|}{ Non-Factors } \\
\hline \multirow[t]{4}{*}{ Significant? } & Factor & Category \\
\hline & & $\begin{array}{l}\square \text { Individual } \square \text { Interpersonal } \square \text { Organizational } \\
\square \text { Community } \square \text { System } \square \text { Other }\end{array}$ \\
\hline & & $\begin{array}{l}\square \text { Individual } \square \text { Interpersonal } \square \text { Organizational } \\
\square \text { Community } \square \text { System } \square \text { Other }\end{array}$ \\
\hline & & $\begin{array}{l}\square \text { Individual } \square \text { Interpersonal } \square \text { Organizational } \\
\square \text { Community } \square \text { System } \square \text { Other }\end{array}$ \\
\hline
\end{tabular}


Implications/Limitations

\begin{tabular}{|l|l|l|}
\hline & Author Opinion & Personal Opinion \\
\hline $\begin{array}{l}\text { Who does } \\
\text { this study } \\
\text { help? }\end{array}$ & & \\
\hline $\begin{array}{l}\text { How does } \\
\text { this study } \\
\text { help? }\end{array}$ & & \\
\hline $\begin{array}{l}\text { Limitatio } \\
\text { ns/Bias }\end{array}$ & & \\
\hline
\end{tabular}

Summary of study/general comments 


\section{3. $\underline{\text { References }}$}

Agency, C. F. I. (2018). Compliance and Enforcement of Gluten-Free Claims. Retrieved from http://www.inspection.gc.ca/food/labelling/food-labelling-forindustry/allergens-and-gluten/gluten-freeclaims/eng/1340194596012/1340194681961

Aggarwal, B., Liao, M., Allegrante, J. P., \& Mosca, L. (2010). Low social support level is associated with non-adherence to diet at 1 year in the Family Intervention Trial for Heart Health (FIT Heart). J Nutr Educ Behav, 42(6), 380-388. doi:10.1016/j.jneb.2009.08.006

Aggarwal, S., Lebwohl, B., \& Green, P. H. (2012). Screening for celiac disease in average-risk and high-risk populations. Therap Adv Gastroenterol, 5(1), 37-47. doi:10.1177/1756283X11417038

Bacigalupe, G., \& Plocha, A. (2015). Celiac is a social disease: family challenges and strategies. Fam Syst Health, 33(1), 46-54. doi:10.1037/fsh0000099

Barratt, S. M., Leeds, J. S., \& Sanders, D. S. (2011). Quality of life in Coeliac Disease is determined by perceived degree of difficulty adhering to a gluten-free diet, not the level of dietary adherence ultimately achieved. J Gastrointestin Liver Dis, 20(3), 241-245.

Bascunan, K. A., Vespa, M. C., \& Araya, M. (2017). Celiac disease: understanding the gluten-free diet. Eur J Nutr, 56(2), 449-459. doi:10.1007/s00394-016-1238-5

Biagi, F., Bianchi, P. I., Marchese, A., Trotta, L., Vattiato, C., Balduzzi, D., . . Corazza, G. R. (2012). A score that verifies adherence to a gluten-free diet: a crosssectional, multicentre validation in real clinical life. British Journal of Nutrition, 108(10), 1884-1888. doi:10.1017/S0007114511007367

Black, J., \& Orfila, C. (2011). Impact of coeliac disease on dietary habits and quality of life. Journal of Human Nutrition and Dietetics, 24(6), 582-587.

Black, J. L., \& Orfila, C. (2011). Impact of coeliac disease on dietary habits and quality of life. Journal of Human Nutrition \& Dietetics, 24(6), 582-587.

Booth, A. O., Lowis, C., Dean, M., Hunter, S. J., \& McKinley, M. C. (2013). Diet and physical activity in the self-management of type 2 diabetes: barriers and facilitators identified by patients and health professionals. Prim Health Care Res Dev, 14(3), 293-306. doi:10.1017/S1463423612000412

Bronfenbrenner, U. (1973). Developmental research and public policy. Res Publ Assoc Res Nerv Ment Dis, 51, 352-380.

Bronfenbrenner, U. (1979). The ecology of human development : experiments by nature and design. Cambridge, Mass.: Harvard University Press.

Bronfenbrenner, U. (2007). The Bioecological Model of Human Development: John Wiley \& Sons, Inc.

Butterworth, J. R., Banfield, L. M., Iqbal, T. H., \& Cooper, B. T. (2004). Factors relating to compliance with a gluten-free diet in patients with coeliac disease: comparison of white Caucasian and South Asian patients. Clinical Nutrition, 23(5), 11271134. 
Capriles, V. D., Martini, L. A., \& Areas, J. A. (2009). Metabolic osteopathy in celiac disease: importance of a gluten-free diet. Nutr Rev, 67(10), 599-606. doi:10.1111/j.1753-4887.2009.00232.x

Caruso, R., Pallone, F., Stasi, E., Romeo, S., \& Monteleone, G. (2013). Appropriate nutrient supplementation in celiac disease. Ann Med, 45(8), 522-531. doi:10.3109/07853890.2013.849383

Casella, S., Zanini, B., Lanzarotto, F., Villanacci, V., Ricci, C., \& Lanzini, A. (2012). Celiac disease in elderly adults: clinical, serological, and histological characteristics and the effect of a gluten-free diet. Journal of the American Geriatrics Society, 60(6), 1064-1069.

Casellas, F., Rodrigo, L., Lucendo, A. J., Fernández-Bañares, F., Molina-Infante, J., Vivas, S., . . López-Vivancos, J. (2015). Benefit on health-related quality of life of adherence to gluten-free diet in adult patients with celiac disease. Revista Espanola de Enfermedades Digestivas, 107(4), 196-201.

CeliacFoundation. (2017). CELIAC DISEASE TREATMENT AND FOLLOW UP. Retrieved from https://celiac.org/celiac-disease/understanding-celiac-disease2/treating-celiac-disease/

Ciacci, C., Cirillo, M., Cavallaro, R., \& Mazzacca, G. (2002). Long-term follow-up of celiac adults on gluten-free diet: prevalence and correlates of intestinal damage. Digestion, 66(3), 178-185.

Ciacci, C., D'Agate, C., De Rosa, A., Franzese, C., Errichiello, S., Gasperi, V., . . Greco, L. (2003). Self-rated quality of life in celiac disease. Digestive Diseases \& Sciences, 48(11), 2216-2220.

Ciacci, C., Iavarone, A., Siniscalchi, M., Romano, R., \& Rosa, A. D. (2002). Psychological dimensions of celiac disease: Toward an integrated approach. Digestive Diseases and Sciences, 47(9), 2082-2087.

Ciccocioppo, R., Di Sabatino, A., \& Corazza, G. R. (2005). The immune recognition of gluten in coeliac disease. Clin Exp Immunol, 140(3), 408-416. doi:10.1111/j.1365-2249.2005.02783.x

Dowd, A., Jung, M., Chen, M., \& Beauchamp, M. (2016). Prediction of adherence to a gluten-free diet using protection motivation theory among adults with coeliac disease. Journal of Human Nutrition and Dietetics, 29(3), 391-398.

Dowd, A., \& Jung, M. E. (2017). Self-compassion directly and indirectly predicts dietary adherence and quality of life among adults with celiac disease. Appetite, 113, 293300.

Dowd, A., Tamminen, K., Jung, M., Case, S., McEwan, D., \& Beauchamp, M. (2014). Motives for adherence to a gluten-free diet: A qualitative investigation involving adults with coeliac disease. Journal of Human Nutrition and Dietetics, 27(6), 542549.

Fagerli, R. A., Lien, M. E., \& Wandel, M. (2005). Experience of dietary advice among Pakistani-born persons with type 2 diabetes in Oslo. Appetite, 45(3), 295-304. doi:10.1016/j.appet.2005.07.003

Fedorak, R. N., Switzer, C. M., \& Bridges, R. J. (2012). Canadian Digestive Health Foundation Public Impact Series 4: celiac disease in Canada. Incidence, prevalence, and direct and indirect economic impact. Can J Gastroenterol, 26(6), 350-352. 
Ferster, M., Obuchowicz, A., Jarecka, B., Pietrzak, J., \& Karczewska, K. (2015). Difficulties related to compliance with gluten-free diet by patients with coeliac disease living in Upper Silesia

Trudnosci zwia;zane z przestrzeganiem diety bezglutenowej przez chorych na celiakie mieszkaja;cych na Gornym Sla;sku. Pediatria i Medycyna Rodzinna, 11(4), 410418.

Foley, E., \& BeLue, R. (2017). Identifying Barriers and Enablers in the Dietary Management of Type 2 Diabetes in M'Bour, Senegal. J Transcult Nurs, 28(4), 348-352. doi:10.1177/1043659616649028

Ford, S., Howard, R., \& Oyebode, J. (2012). Psychosocial aspects of coeliac disease: a cross-sectional survey of a UK population. British Journal of Health Psychology, 17(4), 743-757.

Freeman, H. J. (2004). Lymphoproliferative and intestinal malignancies in 214 patients with biopsy-defined celiac disease. J Clin Gastroenterol, 38(5), 429-434.

Freeman, H. J. (2017). Dietary compliance in celiac disease. World J Gastroenterol, 23(15), 2635-2639. doi:10.3748/wjg.v23.i15.2635

Gendel, S. M. (2012). Comparison of international food allergen labeling regulations. Regul Toxicol Pharmacol, 63(2), 279-285. doi:10.1016/j.yrtph.2012.04.007

Green, P. H., Fleischauer, A. T., Bhagat, G., Goyal, R., Jabri, B., \& Neugut, A. I. (2003). Risk of malignancy in patients with celiac disease. Am J Med, 115(3), 191-195.

Gujral, N., Freeman, H. J., \& Thomson, A. B. (2012). Celiac disease: prevalence, diagnosis, pathogenesis and treatment. World J Gastroenterol, 18(42), 6036-6059. doi:10.3748/wjg.v18.i42.6036

Ha, J. F., \& Longnecker, N. (2010). Doctor-patient communication: a review. Ochsner J, 10(1), 38-43.

Hall, N. J., Rubin, G., \& Charnock, A. (2009). Systematic review: adherence to a glutenfree diet in adult patients with coeliac disease. Aliment Pharmacol Ther, 30(4), 315-330. doi:10.1111/j.1365-2036.2009.04053.x

Hall, N. J., Rubin, G. P., \& Charnock, A. (2013). Intentional and inadvertent nonadherence in adult coeliac disease. A cross-sectional survey. Appetite, 68, 56-62.

Hankey, G. L., \& Holmes, G. K. (1994). Coeliac disease in the elderly. Gut, 35(1), 65-67.

Hauser, W., Stallmach, A., Caspary, W. F., \& Stein, J. (2007). Predictors of reduced health-related quality of life in adults with coeliac disease. Alimentary Pharmacology \& Therapeutics, 25(5), 569-578.

Hodeib, M., Chang, J., Liu, F., Ziogas, A., Dilley, S., Randall, L. M., . . Bristow, R. E. (2015). Socioeconomic status as a predictor of adherence to treatment guidelines for early-stage ovarian cancer. Gynecol Oncol, 138(1), 121-127. doi:10.1016/j.ygyno.2015.04.011

Hogberg, L., Grodzinsky, E., \& Stenhammar, L. (2003). Better dietary compliance in patients with coeliac disease diagnosed in early childhood. Scandinavian Journal of Gastroenterology, 38(7), 751-754.

Hopman, E. G. D., Koopman, H. M., Wit, J. M., \& Mearin, M. L. (2009). Dietary compliance and health-related quality of life in patients with coeliac disease. European Journal of Gastroenterology and Hepatology, 21(9), 1056-1061.

Hughey, J. J., Ray, B. K., Lee, A. R., Kelly, C. P., Schuppan, D., \& Voorhees, K. N. (2017). Self-reported dietary adherence, disease-specific symptoms, and quality 
of life are associated with healthcare provider follow-up in celiac disease. Gastroenterology, 152 (5 Supplement 1), S266.

Institute, J. B. (2013). New JBI Levels of Evidence. University of AdelaideSchool of Translational Health Science.

Karaeren, H., Yokusoglu, M., Uzun, S., Baysan, O., Koz, C., Kara, B., . . . Uzun, M. (2009). The effect of the content of the knowledge on adherence to medication in hypertensive patients. Anadolu Kardiyol Derg, 9(3), 183-188.

Kerse, N., Buetow, S., Mainous, A. G., 3rd, Young, G., Coster, G., \& Arroll, B. (2004). Physician-patient relationship and medication compliance: a primary care investigation. Ann Fam Med, 2(5), 455-461.

Kothe, E. J., Sainsbury, K., Smith, L., \& Mullan, B. A. (2015). Explaining the intentionbehaviour gap in gluten-free diet adherence: The moderating roles of habit and perceived behavioural control. Journal of Health Psychology, 20(5), 580-591. doi:10.1177/1359105315576606

Krug, E. G., Mercy, J. A., Dahlberg, L. L., \& Zwi, A. B. (2002). The world report on violence and health. Lancet, 360(9339), 1083-1088. doi:10.1016/S01406736(02)11133-0

Kurien, M., White, W. L., Trott, N., \& Sanders, D. S. (2016). Does restriction of glutenfree prescription foods affect people with coeliac disease? Gut, 65, A166.

Kurppa, K., Lauronen, O., Collin, P., Ukkola, A., Laurila, K., Huhtala, H., . . . Kaukinen, K. (2012). Factors associated with dietary adherence in celiac disease: a nationwide study. Digestion, 86(4), 309-314.

Lamontagne, P., West, G. E., \& Galibois, I. (2001). Quebecers with celiac disease: analysis of dietary problems. Can J Diet Pract Res, 62(4), 175-181.

Lappalainen, R., Koikkalainen, M., Julkunen, J., Saarinen, T., \& Mykkanen, H. (1998). Association of sociodemographic factors with barriers reported by patients receiving nutrition counseling as part of cardiac rehabilitation. $J$ Am Diet Assoc, 98(9), 1026-1029. doi:10.1016/S0002-8223(98)00235-1

Lee, A. R., Ng, D. L., Diamond, B., Ciaccio, E. J., \& Green, P. H. R. (2012). Living with coeliac disease: survey results from the USA. Journal of Human Nutrition \& Dietetics, 25(3), 233-238. doi:10.1111/j.1365-277X.2012.01236.x

Lee, A. R., Ng, D. L., Zivin, J., \& Green, P. H. (2007). Economic burden of a gluten-free diet. J Hum Nutr Diet, 20(5), 423-430. doi:10.1111/j.1365-277X.2007.00763.x

Leffler, D. A., Edwards-George, J., Dennis, M., Schuppan, D., Cook, F., Franko, D. L., . . . Kelly, C. P. (2008). Factors that influence adherence to a gluten-free diet in adults with celiac disease. Dig Dis Sci, 53(6), 1573-1581. doi:10.1007/s10620007-0055-3

MacCulloch, K., \& Rashid, M. (2014). Factors affecting adherence to a gluten-free diet in children with celiac disease. Paediatr Child Health, 19(6), 305-309.

Mahadev, S., Simpson, S., Lebwohl, B., Lewis, S. K., Tennyson, C. A., \& Green, P. H. (2013). Is dietitian use associated with celiac disease outcomes? Nutrients, 5(5), 1585-1594.

Marchisotto, M. J., Harada, L., Kamdar, O., Smith, B. M., Waserman, S., Sicherer, S., . . . Gupta, R. S. (2017). Food Allergen Labeling and Purchasing Habits in the United States and Canada. J Allergy Clin Immunol Pract, 5(2), 345-351 e342.

doi:10.1016/j.jaip.2016.09.020 
Marshall, J. K. (2013). The burden of celiac disease in Canada: more work needed to lighten the load. Can J Gastroenterol, 27(8), 448.

Martin, S. (2010). Celiac disease and the gluten-free diet. Pediatric Health, 4(3), 321328.

Martos-Mendez; Jose, M. (2016). Self-efficacy and adherence to treatment: the mediating effects of social support. Jounral of Behavior, Health \& SOcial Issues, 7(2), 1929.

McLeroy, K. R., Bibeau, D., Steckler, A., \& Glanz, K. (1988). An ecological perspective on health promotion programs. Health Educ Q, 15(4), 351-377.

Miller, T. A., \& Dimatteo, M. R. (2013). Importance of family/social support and impact on adherence to diabetic therapy. Diabetes Metab Syndr Obes, 6, 421-426. doi:10.2147/DMSO.S36368

Moher, D., Liberati, A., Tetzlaff, J., Altman, D. G., \& Group, P. (2009). Preferred reporting items for systematic reviews and meta-analyses: the PRISMA statement. J Clin Epidemiol, 62(10), 1006-1012. doi:10.1016/j.jclinepi.2009.06.005

Moher, D., Shamseer, L., Clarke, M., Ghersi, D., Liberati, A., Petticrew, M., . . Group, P.-P. (2015). Preferred reporting items for systematic review and meta-analysis protocols (PRISMA-P) 2015 statement. Syst Rev, 4, 1. doi:10.1186/2046-4053-41

Moher, D., Tsertsvadze, A., Tricco, A. C., Eccles, M., Grimshaw, J., Sampson, M., \& Barrowman, N. (2008). When and how to update systematic reviews. Cochrane Database Syst Rev(1), MR000023. doi:10.1002/14651858.MR000023.pub3

Moussaid, M., Kammer, J. E., Analytis, P. P., \& Neth, H. (2013). Social influence and the collective dynamics of opinion formation. PLoS ONE, 8(11), e78433. doi:10.1371/journal.pone.0078433

Muhammad, H., Reeves, S., Ishaq, S., Mayberry, J., \& Jeanes, Y. M. (2017). Adherence to a Gluten Free Diet Is Associated with Receiving Gluten Free Foods on Prescription and Understanding Food Labelling. Nutrients, 9(7), 06.

Munt, A. E., Partridge, S. R., \& Allman-Farinelli, M. (2017). The barriers and enablers of healthy eating among young adults: a missing piece of the obesity puzzle: A scoping review. Obes Rev, 18(1), 1-17. doi:10.1111/obr.12472

Murray, J. A., Watson, T., Clearman, B., \& Mitros, F. (2004). Effect of a gluten-free diet on gastrointestinal symptoms in celiac disease. Am J Clin Nutr, 79(4), 669-673.

Myleus, A. R., N.R.; Green, P. (2016). Tu1393 Celiac Disease and Adherence to the Gluten-Free Diet - A Systematic Review and Meta-Analyses. Gastroenterology, 150(4), s893.

Nicklas, T. A., Jahns, L., Bogle, M. L., Chester, D. N., Giovanni, M., Klurfeld, D. M., . . . Tucker, K. L. (2013). Barriers and facilitators for consumer adherence to the dietary guidelines for Americans: the HEALTH study. J Acad Nutr Diet, 113(10), 1317-1331. doi:10.1016/j.jand.2013.05.004

Pinto-Sanchez, M. I., Verdu, E. F., Gordillo, M. C., Bai, J. C., Birch, S., Moayyedi, P., \& Bercik, P. (2015). Tax-deductible provisions for gluten-free diet in Canada compared with systems for gluten-free diet coverage available in various countries. Canadian Journal of Gastroenterology \& Hepatology, 29(2), 104-110. 
Popay, J., Roberts, H., Sowden, A., Petticrew, M., \& Arai, L. (2006). Guidance on the Conduct of Narrative Synthesis in Systematic Reviews: A Product from the ESRC Methods Programme. ESRC, 1.

Prince, H. E. (2006). Evaluation of the INOVA diagnostics enzyme-linked immunosorbent assay kits for measuring serum immunoglobulin $\mathrm{G}$ (IgG) and IgA to deamidated gliadin peptides. Clin Vaccine Immunol, 13(1), 150-151. doi:10.1128/CVI.13.1.150-151.2006

Programme, C. A. S. (2018). CASP Checklist. Retrieved from https://casp-uk.net/

Rajpoot, P., Sharma, A., Harikrishnan, S., Baruah, B. J., Ahuja, V., \& Makharia, G. K. (2015). Adherence to gluten-free diet and barriers to adherence in patients with celiac disease. Indian Journal of Gastroenterology, 34(5), 380-386.

Ramirez-Cervantes, K. L., Romero-Lopez, A. V., Nunez-Alvarez, C. A., \& UscangaDominguez, L. F. (2016). Adherence to a Gluten-Free Diet in Mexican Subjects with Gluten-Related Disorders: A High Prevalence of Inadvertent Gluten Intake. Revista de Investigacion Clinica, 68(5), 229-234.

Rampertab, S. D., \& Mullin, G. E. (2014). Celiac disease.

Rose, C., \& Howard, R. (2014). Living with coeliac disease: a grounded theory study. Journal of Human Nutrition \& Dietetics, 27(1), 30-40.

Rostom, A., Murray, J. A., \& Kagnoff, M. F. (2006). American Gastroenterological Association (AGA) Institute Technical Review on the Diagnosis and Management of Celiac Disease. Gastroenterology, 131(6), 1981-2002.

Roy, A., Pallai, M., Lebwohl, B., Taylor, A. K., \& Green, P. H. (2016). Attitudes Toward Genetic Testing for Celiac Disease. J Genet Couns, 25(2), 270-278. doi:10.1007/s10897-015-9867-z

Sainsbury, K., \& Mullan, B. (2011). Measuring beliefs about gluten free diet adherence in adult coeliac disease using the theory of planned behaviour. Appetite, 56(2), 476-483.

Sainsbury, K., Mullan, B., \& Sharpe, L. (2013a). Gluten free diet adherence in coeliac disease. The role of psychological symptoms in bridging the intention-behaviour gap. Appetite, 61(1), 52-58.

Sainsbury, K., Mullan, B., \& Sharpe, L. (2013b). A randomized controlled trial of an online intervention to improve gluten-free diet adherence in celiac disease. American Journal of Gastroenterology, 108(5), 811-817.

Sainsbury, K., Mullan, B., \& Sharpe, L. (2013c). Reduced quality of life in coeliac disease is more strongly associated with depression than gastrointestinal symptoms. J Psychosom Res, 75(2), 135-141. doi:10.1016/j.jpsychores.2013.05.011

Sainsbury, K., Mullan, B., \& Sharpe, L. (2015). Dissemination of an online theory-based intervention to improve gluten-free diet adherence in coeliac disease: the relationship between acceptability, effectiveness, and attrition. International Journal of Behavioral Medicine, 22(3), 356-364.

Shah, S., Akbari, M., Vanga, R., Kelly, C. P., Hansen, J., Theethira, T., . . . Leffler, D. A. (2014). Patient perception of treatment burden is high in celiac disease compared with other common conditions. American Journal of Gastroenterology, 109(9), 1304-1311. 
Sharp, P. B., \& Salyer, J. (2012). Self-efficacy and barriers to healthy diet in cardiac rehabilitation participants and nonparticipants. J Cardiovasc Nurs, 27(3), 253262. doi:10.1097/JCN.0b013e31821 efdc2

Silvester, J., \& Duerksen, D. (2013). Five things to know about...celiac disease. Cmaj, 185(1), 60. doi:10.1503/cmaj.111646

Silvester, J. A., \& Rashid, M. (2010). Long-term management of patients with celiac disease: current practices of gastroenterologists in Canada. Can J Gastroenterol, 24(8), 499-509.

Silvester, J. A., Weiten, D., Graff, L. A., Walker, J. R., \& Duerksen, D. R. (2016a). Is it gluten-free? Relationship between self-reported gluten-free diet adherence and knowledge of gluten content of foods. Nutrition, 32(7-8), 777-783.

Silvester, J. A., Weiten, D., Graff, L. A., Walker, J. R., \& Duerksen, D. R. (2016b). Living gluten-free: adherence, knowledge, lifestyle adaptations and feelings towards a gluten-free diet. Journal of Human Nutrition \& Dietetics, 29(3), 374382.

Smith, M. M. (2009). What is the relationship between quality of life and coping strategies of adults with celiac disease adhering to a gluten free diet? (Ph.D.), Duquesne University. Retrieved from http://search.ebscohost.com/login.aspx?direct=true \&db=cin20\&AN=109851473\& site $=$ ehost-live Available from EBSCOhost cin20 database.

Sohal, T., Sohal, P., King-Shier, K. M., \& Khan, N. A. (2015). Barriers and Facilitators for Type-2 Diabetes Management in South Asians: A Systematic Review. PLoS ONE, 10(9), e0136202. doi:10.1371/journal.pone.0136202

Treloar, C., Champness, S., Simpson, P. L., \& Higginbotham, N. (2000). Critical appraisal checklist for qualitative research studies. Indian J Pediatr, 67(5), 347351.

Twist, S. R., \& Hackett, A. F. (1992). An investigation of some implications of coeliac disease. Journal of Human Nutrition and Dietetics, 5(6), 343-350.

Ukkola, A., Maki, M., Kurppa, K., Collin, P., Huhtala, H., Kekkonen, L., \& Kaukinen, K. (2012). Patients' experiences and perceptions of living with coeliac disease implications for optimizing care. Journal of Gastrointestinal \& Liver Diseases, 21(1), 17-22.

Verrill, L., Zhang, Y., \& Kane, R. (2013). Food label usage and reported difficulty with following a gluten-free diet among individuals in the USA with coeliac disease and those with noncoeliac gluten sensitivity. Journal of Human Nutrition \& Dietetics, 26(5), 479-487. doi:10.1111/jhn.12032

Viljamaa, M., Collin, P., Huhtala, H., Sievanen, H., Maki, M., \& Kaukinen, K. (2005). Is coeliac disease screening in risk groups justified? A fourteen-year follow-up with special focus on compliance and quality of life. Aliment Pharmacol Ther, 22(4), 317-324. doi:10.1111/j.1365-2036.2005.02574.x

Villafuerte-Galvez, J., Vanga, R. R., Dennis, M., Hansen, J., Leffler, D. A., Kelly, C. P., \& Mukherjee, R. (2015). Factors governing long-term adherence to a gluten-free diet in adult patients with coeliac disease. Alimentary Pharmacology \& Therapeutics, 42(6), 753-760.

Zarkadas, M., Cranney, A., Case, S., Molloy, M., Switzer, C., Graham, I. D., . . . Burrows, V. (2006). The impact of a gluten-free diet on adults with coeliac 
disease: Results of a national survey. Journal of Human Nutrition and Dietetics, 19(1), 41-49.

Zarkadas, M., Dubois, S., MacIsaac, K., Cantin, I., Rashid, M., Roberts, K. C., . . . Pulido, O. M. (2013). Living with coeliac disease and a gluten-free diet: a Canadian perspective. Journal of Human Nutrition \& Dietetics, 26(1), 10-23.

Zolnierek, K. B., \& Dimatteo, M. R. (2009). Physician communication and patient adherence to treatment: a meta-analysis. Med Care, 47(8), 826-834. doi:10.1097/MLR.0b013e31819a5acc 